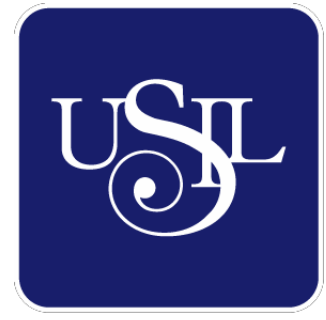

UNIVERSIDAD

SAN IGNACIO

DE LOYOLA

FACULTAD DE CIENCIAS EMPRESARIALES

Carrera de Economía

\title{
ANÁLISIS DE LA EFICIENCIA TÉCNICA EN LOS SERVICIOS DE SANEAMIENTO EN EL PERÚ URBANO, 2008-2016
}

Tesis para optar el Título Profesional de Licenciado en Economía

\section{ANDREA PAOLA BENAVENTE ORUÉ}

Asesor:

Dr. José Fernando Larios Meoño

Lima - Perú

2019 
"Análisis de la eficiencia técnica en los servicios de saneamiento en el Perú urbano, 2008-2016"

Fecha de Sustentación y Aprobación: Jueves 28 de marzo del 2019

Presidente de Jurado:

Dr. Torres Zorrilla, Jorge

Jurados:

Dr. Mougenot, Benoit Pierre Henri Noel

Mg. Castañeda Limas, Oliver 


\section{Contenido}

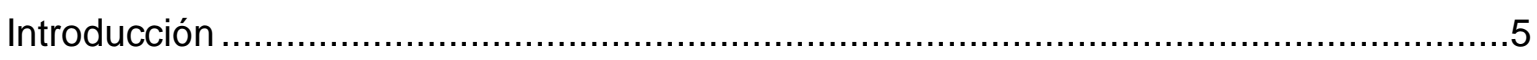

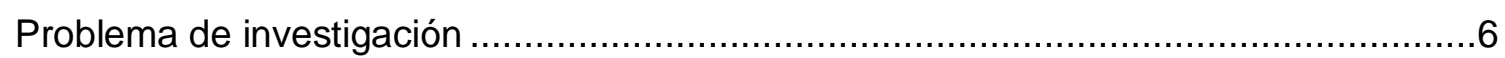

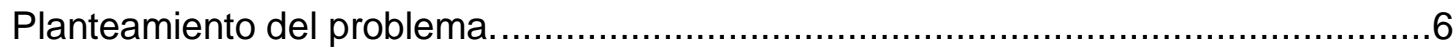

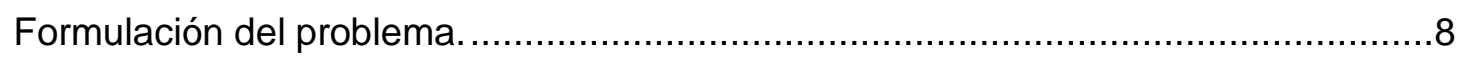

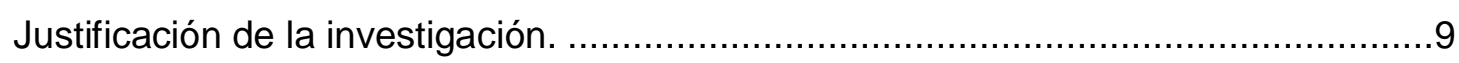

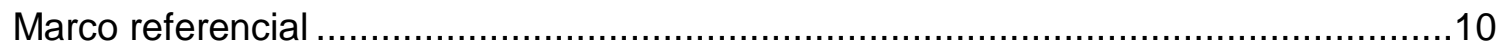

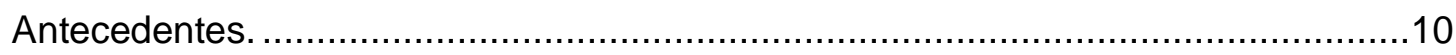

Hechos Estilizados: Limitada gestión administrativa-financiera ...............................13

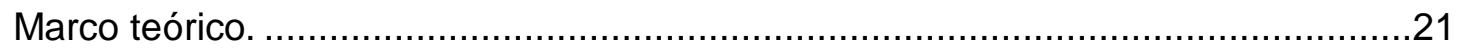

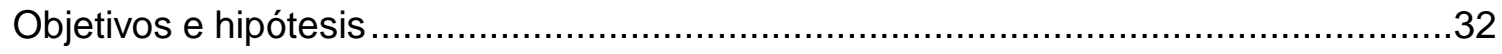

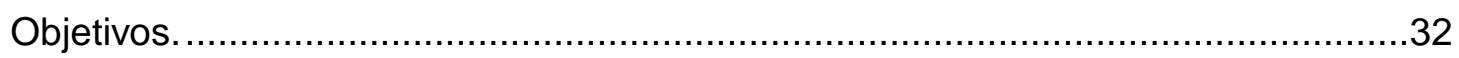

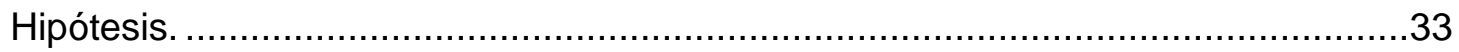

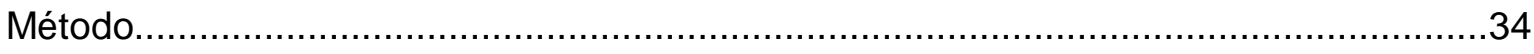

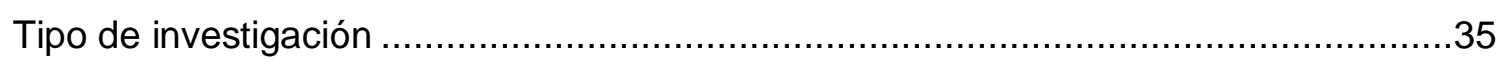

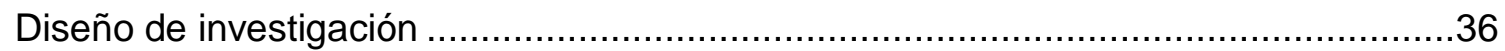

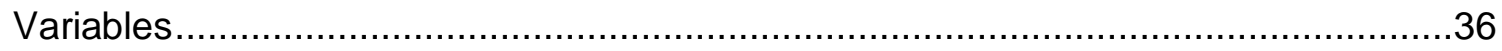

Muestra

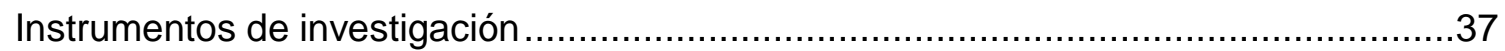

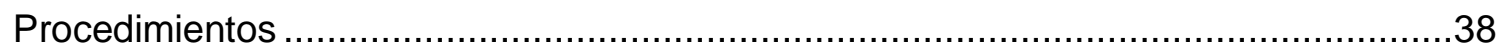

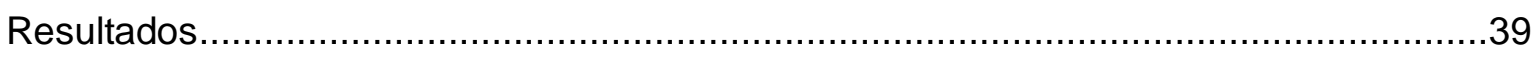

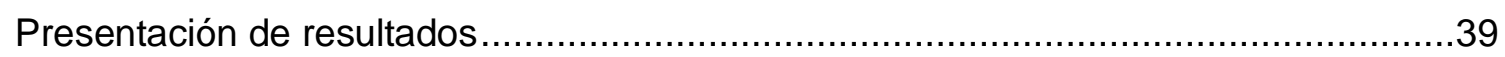

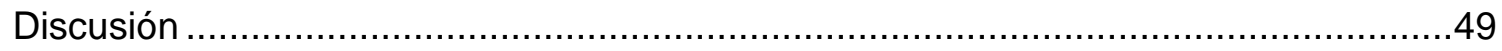

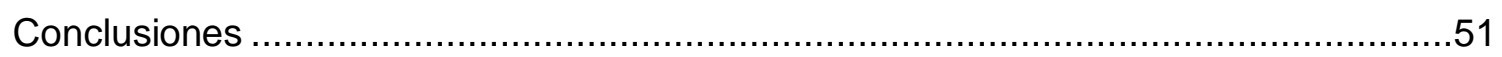

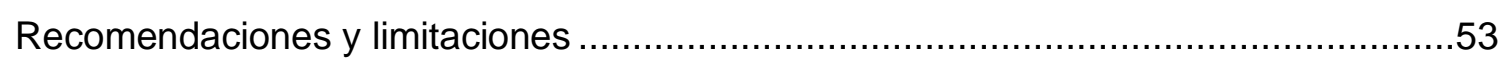

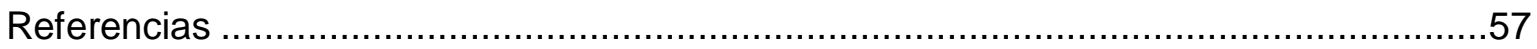

Anexos

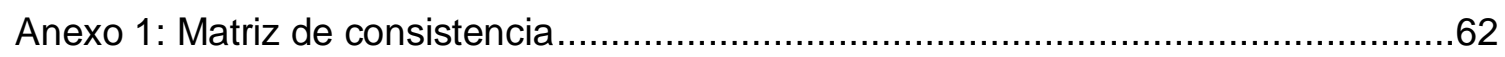

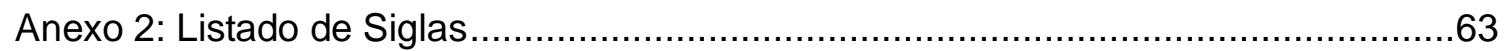

Anexo 3: Ejecución de Ingresos por Fuente de Financiamiento - EPS..........................63

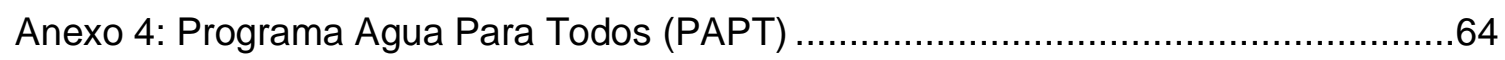

Anexo 5: Indicadores históricos de los Programa Presupuestales del Sector ...............65

Anexo 6: Ejecución de inversiones de los gobiernos locales en PPR 2015 ..................65

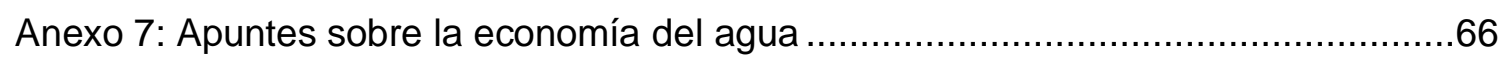

Anexo 8: Escala Mínima Eficiente del Monopolio ......................................................67

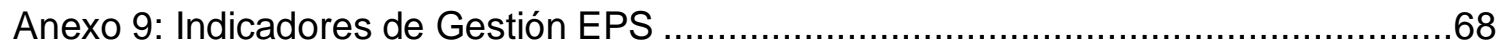

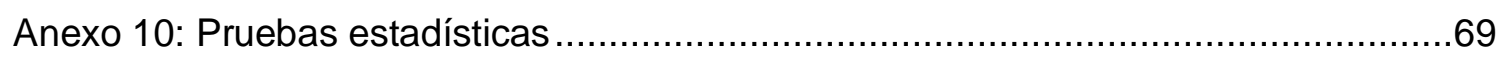

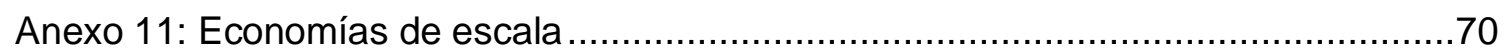




\section{Resumen}

La presente investigación estudia la eficiencia técnica en la prestación de servicios de agua potable y saneamiento en el Perú, desde un enfoque de la función costos, durante el periodo 2008-2016, particularmente, pretende identificar características asociadas a la gestión de 44 Empresas Prestadores de Servicios de Saneamiento (EPS) que capten la heterogeneidad de la muestra y expliquen la ineficiencia. Se diferenciaron dos etapas metodológicas aplicando un modelo panel de efectos fijos verdaderos para estimación de una frontera estocástica y un modelo de regresión lineal múltiple para identificar los determinantes directos de la ineficiencia en sí misma. Entre los principales hallazgos, se encontró que el nivel de ineficiencia en costos de las EPS en el Perú está determinado por la cobertura de agua (positivamente) y por índice de precipitaciones estandarizado (negativamente), así como se encontraría correlacionada negativamente con la pérdida de agua, el porcentaje de tratamiento de aguas residuales, la cobertura de alcantarillado y la altitud geográfica de estos proveedores; asimismo, se encontró que esta industria (EPS municipales) se encontraría en una etapa de deseconomías de escala para el periodo estudiado.

Palabras clave: Agua Potable, Saneamiento, Perú, EPS, Análisis de eficiencia, Heterogeneidad, Fronteras Estocásticas, Variables Ambientales

\section{Abstract}

The current research studies technical efficiency from a cost function approach in the Peruvian Water Sector during the period 2008-2016, in particular, it aims to identify management characteristics of 44 Peruvian water utilities (EPS), as per its initials in Spanish, to capture heterogeneity inside the sample. Methodologically, there are two steps, first applying a frontier stochastic model through a panel with true fixed effects and second a lineal regression model for identifying direct factors that explain inefficiency itself. The main findings show that cost inefficiency degree of the EPS is determined by water coverage (positively) and by the standardized precipitation index (negatively), also, that it is negatively correlated with the water losses, percentage of wastewater treatment, sewerage coverage and geographical altitude of this providers, furthermore, the results shows that this industry (municipal EPS) is located in a diseconomies of scale stage for the studied period.

Key words: Water, Peru, EPS, Efficiency Analysis, Heterogeneity, Stochastic Frontier Model, Environmental Variables 


\section{Introducción}

Las cifras de cobertura de agua potable y saneamiento son preocupantes en el contexto peruano; durante el año 2017, por ejemplo, en la zona urbana la cobertura de agua potable ascendía al $74 \%$, mientras que la cobertura de alcantarillado a $68 \%$ (Ministerio de Vivienda Construcción y Saneamiento, 2017a), siendo más alarmante aún la limitada provisión de estos servicios en la zona rural; enmarcando al sector en una problemática latente por resolver y peor aún en un contexto de déficit hídrico ambiental (Decretos Supremos Nos 086 y 089-2016-PCM, 2016), en el que solamente a finales del año 2016 se declararon en emergencia 18 regiones a causa del déficit hídrico provocado por la escasez de lluvias.

Por su parte, las Entidades Prestadoras de Servicios de Saneamiento (EPS) cuentan con una débil situación financiera y operativa, lo que, junto al contexto de bajos resultados en indicadores de cobertura, nos lleva a preguntarnos sobre el desempeño del sector. Con el fin de poder comprender cómo las características particulares de cada proveedor afectan el desempeño eficiente de la industria, la presente investigación tiene como objetivo general identificar cuáles son los determinantes de la ineficiencia técnica de las EPS en el Perú urbano en el periodo 2008-2016.

En ese sentido, se estudia la eficiencia técnica, desde un enfoque de la función costos, en el sector agua potable y saneamiento en el Perú, pretendiendo identificar características asociadas a la gestión de las EPS que capten la heterogeneidad de la muestra y expliquen la ineficiencia. Se diferenciaron dos etapas metodológicas, la primera etapa: un modelo panel aplicando la metodología de fronteras estocásticas incluye variables ambientales que afectan la función de costos directamente y en la segunda etapa: un modelo de regresión lineal que incluye variables ambientales que afectarían la ineficiencia de manera directa.

Asimismo, siendo la tesis uno de los requisitos para obtener la "Licenciatura" como grado académico, el desarrollo de la presente investigación tuvo como uno de sus objetivos intrínsecos aplicar los conocimientos adquiridos durante los estudios de pregrado de la autora, en particular en la carrera profesional de Economía en la Universidad San Ignacio de Loyola, para poder culminar con éxito la etapa universitaria y obtener el grado en mención.

La presente investigación consta de tres capítulos. El primero explica el problema, justificación y objetivos de la investigación, así como, los antecedentes peruanos e 
internacionales, la situación actual, y el marco teórico en el cual se enmarca. El segundo capítulo, explica la metodología usada y las variables por cada etapa. Finalmente, el capítulo tercero, presenta los resultados, discusiones, conclusiones, recomendaciones y limitaciones.

\section{Problema de investigación}

\section{Planteamiento del problema.}

Acceder a los servicios de agua potable y saneamiento básico en cantidad y calidad apropiadas garantiza la salud, vida y dignidad de las personas, es clave para el desarrollo nacional y está respaldado por los derechos humanitarios fundamentales a nivel internacional (Eid, 2015; World Health Organization - WHO, 2015).

En el Perú, la cadena de valor de la prestación de servicios de agua potable y saneamiento básico relaciona a los proveedores del servicio (actores más visibles), Gobiernos Locales, Gobiernos Regionales ${ }^{1}$, la Superintendencia Nacional de Agua y Saneamiento (SUNASS), como regulador del sector, el Organismo Técnico de la Administración de los Servicios de Saneamiento (OTASS) ${ }^{2}$, y a la Autoridad Nacional del Agua (ANA), como rector de los recursos hídricos ${ }^{3}$ (Decreto Legislativo № 1280, 2016). En la actualidad, existen en el Perú 50 proveedores del servicio que son reguladas por la SUNASS, de las cuales 48 son municipales, denominadas Empresas Prestadoras de Servicios de Saneamiento (EPS) ${ }^{4}$, una se encuentra en concesión privada (Aguas de Tumbes S.A) y SEDAPAL, administrada por el Gobierno Central, a través del Fondo Nacional de Financiamiento de la Actividad Empresarial del Estado - FONAFE (OTASS, 2017) ${ }^{5}$.

La SUNASS, dada su función fiscalizadora y sancionadora, podría sancionar a estos proveedores de los servicios de agua potable, de contar con información suficiente para iniciar un proceso administrativo sancionador, para lo cual puede realizar visitas inopinadas de supervisión; en efecto, durante el reciente problema de aniego en el distrito limeño de San Juan de Lurigancho, en el cual 1,584 personas, 284 viviendas, dos colegios y 22

\footnotetext{
1 Según la Ley Marco de la gestión y prestación de los Servicios de Saneamiento (DL N 1280), los gobiernos regionales tienen la función de asumir la ejecución de los programas de saneamiento, realizar un apoyo técnico, entre otros, y los Gobiernos Locales deben asignar recursos para el financiamiento de inversiones en materia de infraestructura de saneamiento (...) y financiar y cofinanciar la reposición y mantenimiento de la infraestructura de saneamiento en el ámbito rural.

${ }^{2}$ Adscrito al Ministerio de Vivienda Construcción y Saneamiento.

${ }^{3} \mathrm{Si}$ bien es cierto el agua como recurso es demandada por diferentes agentes, esta tesis se enfoca en la gestión del recurso hídrico para consumo humano es decir de uso doméstico / residencial o industrial.

${ }^{4}$ Conforme a lo dispuesto en Ley $N^{\circ}$ 26338, Ley General de Servicios de Saneamiento, Ias Entidades Prestadoras de Servicios de Saneamiento (EPS) son entidades constituidas con el exclusivo propósito de prestar servicios de saneamiento: servicios de agua potable, alcantarillado sanitario y pluvial, y disposición sanitaria de excretas, limitándose su ámbito al urbano en el marco del DL N 1240 que modifica la citada Ley general.

${ }^{5}$ La definición de las siglas se encuentra expuesta en el Anexo 2.
} 
comercios fueron afectados por el colapso de las redes de alcantarillado iniciándose así una emergencia sanitaria en la zona, cabe mencionar que aun cuando las irregularidades que causaron el problema puedan no ser directamente atribuibles al proveedor, sí existieron responsabilidades atribuibles a SEDAPAL ex ante el suceso, sin embargo SUNASS, intervino ex post, para llevar a cabo un proceso de supervisión, y posteriormente impuso una medida correctiva a SEDAPAL, con el fin de restablecer el servicio de agua potable según cronograma establecido, reflejándose aquí un problema de calidad del servicio, por el desmedro de la continuidad de la provisión, a los actuales clientes, ello sin tomar en cuenta el grave problema ambiental que ha generado el aniego, lo que demostraría que ningún proveedor de agua potable y saneamiento en el Perú, se encuentra en capacidad de manejar una situación como esta.

Las EPS se crearon con el fin de descentralizar la prestación del servicio ${ }^{6}$, vinculándolos a los gobiernos locales, con el fin de promover una mejora en la gestión de los recursos; sin embargo, no se habrían sentado las bases adecuadas (Oblitas, 2010) para que se garantice la adecuada provisión de estos servicios junto a los demás agentes de la cadena de valor. Una adecuada provisión incluiría una provisión continua y medidas inmediatas a problemas como el aniego; sin embargo, también debiera apuntar a garantizar un abastecimiento de agua potable a aquellas familias que no cuentan con una fuente segura y saludable de agua potable, y es en ese sentido que la presente investigación toma en cuenta la cobertura de agua y saneamiento.

La zona urbana del Perú comprende 23.9 millones de habitantes, aproximadamente, de los cuales solo 17.7 millones poseen cobertura de agua y 16.3 millones cobertura de alcantarillado; la brecha es más amplia en la provisión de estos servicios en la zona rural, donde solo el $62 \%$ de la población rural cuenta con cobertura de agua y $29 \%$ con cobertura de alcantarillado (Ministerio de Vivienda Construcción y Saneamiento, 2017a).

No se conoce si esta reducida cobertura del servicio podría deberse a los bajos niveles de inversión ejecutada en materia de ampliación de redes, o a la presencia significativa de pérdidas de agua en el procesamiento de agua potable que evidenciarían ineficiencias en los proveedores del servicio. Según SUNASS (2016), solo en el 2016 el volumen de agua no facturado ascendió a 35\% del total producido y distribuido; si se excluye a SEDAPAL, la cifra es más alarmante aun, llegando dicho volumen de pérdidas al 44\%.

\footnotetext{
${ }^{6}$ Si bien no fue hasta el 24 de julio de 1994, cuando la "Ley General de Servicio de Saneamiento" fue promulgada, que se organizan las EPS como tal, desde los 80 s se dieron las luces de descentralización con la creación del Servicio Nacional de Abastecimiento de Agua Potable y Alcantarillado - SENAPA y sus empresas filiales y unidades operativas.
} 
Asimismo, la precaria situación financiera de los proveedores municipales del servicio; con un margen operativo negativo, caso de varias EPS, durante el periodo 2013-2015 (OTASS, 2017); sumada a la poca capacidad de los ingresos tarifarios para financiar ${ }^{7}$ los costos totales asociados; inicia interrogantes respecto a si la tarifa no refleja enteramente los costos, o si los problemas recaen en la gestión más que en disponibilidad de recursos. En esta investigación abordamos el segundo debate, en el que los problemas de gestión recurrentes podrían estar afectando un progresivo incremento, en condiciones normales (sin problemas financieros), de la cobertura de los servicios de saneamiento.

La expuesta débil situación financiera y operativa de las EPS en la prestación de servicios de agua potable y saneamiento amerita su estudio a fin de comprender mejor sus deficiencias y adoptar soluciones óptimas para su desarrollo, considerando su estado de monopolio natural que desincentiva la eficiencia de las operaciones (Le Blanc, 2008; Laffont y Tirole, 1986), la minimización de costos de las EPS se ve desestimada como objetivo institucional. Es por ello que, partiendo de una mirada a la gestión de las EPS, la presente investigación plantea analizar la curva de costos de estas entidades, para medir la ineficiencia técnica de la provisión del servicio de agua potable, resolviendo de esta manera la siguiente interrogante:

¿Cuáles son los determinantes de la ineficiencia técnica de las Entidades Prestadoras de Servicios de Saneamiento (EPS) en el Perú urbano entre 2008 y $2016 ?$

\section{Formulación del problema.}

\section{Problema central.}

¿Cuáles son los determinantes de la ineficiencia técnica de las Entidades Prestadoras de Servicios de Saneamiento (EPS) en el Perú urbano entre 2008 y 2016 ?

\section{Problemas específicos.}

1. ¿Cuáles son los determinantes de la frontera de costos de la provisión de agua potable y saneamiento para las Entidades Prestadoras de Servicios de Saneamiento (EPS) en el Perú entre 2008 y $2016 ?$

\footnotetext{
${ }^{7}$ En el sector saneamiento, los recursos financieros provenientes de la recaudación tarifaria representaron alrededor de $66 \%$ del total de ingresos de las EPS en el año 2016 (ver Anexo 3); estos recursos serían usados para cubrir el costo de la operatividad de la entidad; sin embargo, un $9 \%$ de los ingresos se financiaron con "Donaciones y Transferencias" y otro $9 \%$ con "Endeudamiento"
} 
2. ¿Cuáles son las variables ambientales que afectan la función de costos de las Entidades Prestadoras de Servicios de Saneamiento (EPS) en el Perú entre 2008 y $2016 ?$

3. ¿La ineficiencia en costos está relacionada a variables ambientales observables de las Entidades Prestadoras de Servicios de Saneamiento (EPS) en el Perú entre 2008 y $2016 ?$

4. ¿En qué etapa de las economías de escala se encuentra la curva de costos de las Entidades Prestadoras de Servicios de Saneamiento (EPS) en el Perú entre 2008 y $2016 ?$

\section{Justificación de la investigación.}

La precaria situación financiera y operativa de las EPS (OTASS, 2017), no es nada más que la punta del iceberg de una problemática que engloba la gestión de uno de los recursos naturales más escasos del planeta, solamente a finales del año 2016 se declararon en emergencia 18 regiones a causa del déficit hídrico provocado por la escasez de lluvias ${ }^{8}$. En este contexto, y con la creciente demanda será necesario acudir a fuentes de agua alternas y tratamientos de descontaminación nuevos los cuales podrían ser muy costosos para el consumidor, pero de no ser asumidos en las tarifas podrían acelerar la quiebra de las EPS; esta investigación visibilizará la problemática, llamando a las EPS a tomar consciencia de su rol como gestor del recurso.

Asimismo, en el sector público no hay un mandato de maximización de beneficios o de minimización de costos propiamente dicho (o evaluado) que podrían "incentivar" a un comportamiento eficiente; sin embargo, existen restricciones presupuestarias y competencia por estos recursos al interior del Estado, que puede generar que cada institución pública tienda a ciertos objetivos como el de minimización de costos (austeridad), redistribución de ingresos, entre otros. De la misma forma las EPS, de mostrar ciertos niveles de eficiencia técnica y salud financiera, podrían tener acceso a recursos presupuestarios, o a posibilidades de emitir capital o deuda en los mercados financieros; por el cual el uso de medidas de eficiencia comparativa es de relevante importancia en este sector (Ferro, Lentini y Romero, 2011).

\footnotetext{
${ }^{8}$ Mediante los Decretos Supremos Ns 086 y 089-2016-PCM, la Presidencia del Consejo de Ministros, declaró el Estado de Emergencia por déficit hídrico en los departamentos de Moquegua, y Apurímac, Ancash, Ayacucho, Cajamarca, Cusco, Huancavelica, Ica, Junín, Lambayeque, La Libertad, Pasco, Piura, Puno, Tacna y Tumbes, así como en siete (07) provincias del departamento de Lima, y en cuatro (04) provincias del departamento de Arequipa respectivamente.
} 
Es así que, considerando que la gestión operativa del servicio permite a las EPS manejar sus costos en un sentido más amplio que la producción en sí misma ${ }^{9}$; la presente investigación realiza una evaluación paramétrica de la eficiencia de costos para de esta manera medir el rendimiento de cada entidad a través de un criterio estándar basado en un frontera de posibilidades de producción costo-eficiente relativa, porque dichas ineficiencias podrían poner (en algunas ya la están poniendo) en riesgo la estabilidad financiera y la sostenibilidad de la prestación del servicio de agua potable y saneamiento, el acceso universal a los servicios de saneamiento ${ }^{10}$ desde una perspectiva gestora y no solo asistencial (transferencia de recursos).

La presente investigación será un insumo primordial de los hacedores de política del sector saneamiento, de las EPS que podrán evaluar su rendimiento y su impacto en la política sectorial, de los académicos que tendrán otro punto de partida para un análisis global del sector desde un marco de eficiencias del uso recursos, sobre todo porque incluye variables ambientales en su análisis bajos dos enfoques ampliamente debatidos en la academia (influencia a la frontera o a la ineficiencia directamente); y finalmente, de la ciudadanía en general, que podrá valorar los costos asociados a la provisión del servicio recibido.

Por otro lado, esta investigación proporcionará un análisis claro sobre los costos que se enfrentan en la cadena productiva del servicio y de su potencial para atraer inversionistas bajo esquemas de provisión de servicios eficientes distintos a los que actualmente se generan con contratos de concesión de únicos prestadores de servicios de agua y saneamiento que, aunque bajo un régimen privado son fuentes de ineficiencia.

\section{Marco referencial}

\section{Antecedentes.}

Los trabajos empíricos que estudian los modelos de fronteras estocásticas usualmente parten de la misma definición de Aigner, Lovell y Schmidt (1977) ${ }^{11}$, sobre la eficiencia; sin embargo, se diferencian en la forma de incluir en el modelo diferentes condiciones ambientales que influenciarían los niveles de eficiencia, particularmente existen dos enfoques, 1 ) considerar que las condiciones ambientales afectan la tecnología productiva (a través de la función de producción o de costos) y 2) considerar que estas afectan directamente la eficiencia técnica de las empresas. Entre los autores que abordan

\footnotetext{
${ }^{9}$ La producción de agua se encuentra supeditada a la cobertura del servicio, así como a otros aspectos más complejos como los de infraestructura, ámbito geográfico, entre otros, fuera del alcance de las EPS.

${ }^{10}$ Objetivo de la Política Nacional de Saneamiento, aprobada mediante DS N 007-2017-VIVIENDA el 29 de marzo del 2017.

${ }^{11}$ Ver "Marco teórico" en el apartado "Análisis de Fronteras estocásticas" de la definición de "Eficiencia"
} 
la eficiencia en el sector saneamiento peruano bajo el primer enfoque, se encuentran Corton (2003) y Lin (2005). En el segundo enfoque, que es el que se utiliza en esta investigación, se han revisado autores que abordan el contexto peruano: Urrunaga y Jara (2013), e internacional: Faust y Baranzini (2014), y Bonifaz e Itakura (2014).

Corton (2003) con el objetivo de aportar en la implementación de un esquema de "benchmarking" y guiar acciones regulatorias en el sector agua y saneamiento, realiza una estimación de una frontera de eficiencia de costos determinística, para 44 EPS entre los años 1996-1998, como variables ambientales incluyó el número de distritos administrados para cada compañía y dummys para cada región natural (costa, sierra y selva), como resultado se encontró que la cultura organizacional y la interferencia política fueron detectados como los problemas que impactan el sector agua potable y saneamiento; asimismo, no existiría correlación entre la eficiencia y el rendimiento (margen operativo) lo que ocasiona desincentivos hacia la eficiencia. Cabe mencionar que su modelo no incluye los precios de los insumos ni indicadores de calidad del servicio.

Lin (2005) estimó una frontera estocástica de eficiencia de costos para 36 EPS, entre los años 1996-2001, para abordar la importancia de las variables de calidad del agua en el análisis de eficiencia, es así que, descubre que es necesario incorporar en el análisis, las variables que representan la calidad del servicio (medición de conexiones activas de agua, cobertura del servicio, continuidad del servicio y tasa de cloro residual) como variables pertenecientes al producto, y no solo como variables de control, así como que existiría una alta correlación los rankings de eficiencia alta entre los modelos que con o sin variables de calidad de agua. Este modelo sí incluye precios de insumos e indicadores de calidad del servicio.

Corton (2011) cambio de enfoqué metodológico, planteando una frontera estocástica de eficiencia de costos regional, mediante una forma funcional trans-logarítimica, para un panel de 43 EPS en el periodo 1996-2005. Entre sus resultados se encuentra que el incremento de $0.1 \%$ del costo se traduce en $1 \%$ de incremento de la producción, además los incremento en costos están sustentados básicamente en conexiones informales que no facturan, beneficio sobre el cual se "garantizan" mayores probabilidades de reelección electoral, así como, se realizó un ranking de eficiencia en función a la desviación del promedio, no se encontró relación entre la eficiencia y el margen operativo. 
Por su parte, el segundo enfoque fue adaptado por Urrunaga y Jara (2013) para un análisis de 37 EPS peruanas entre 1996 y 2010, estima una frontera estocástica de costos con una forma funcional de Cobb Douglas, incluye como variables ambientales la tendencia del tiempo y la estructura de mercado; sin embargo, al 5\% de significancia ninguna de estas dos sería significativa para la función de costos; sin embargo, las variables de calidad (\% pérdida de agua y \% cloro residual) explicarían la ineficiencia, otro hallazgo interesante es que indica la presencia de economías de escala. Cabe mencionar que estos autores utilizan también un enfoque no paramétrico (envolvente de datos) para descomponer los resultados de eficiencia de acuerdo al cambio tecnológico, encontrando que las EPS no se encontrarían operando en la escala óptima.

Del mismo modo, bajo el segundo enfoque, Bonifaz e Itakura (2014), analizan la ineficiencia de las firmas de la industria de agua entre 1999-2010, usando un panel desbalanceado de doce empresas de Latinoamérica, las cuales describen, como las más representativas para hallar una frontera estocástica de la forma funcional trans-logarítimica; concluye que, las compañías del sector privado tienen un mejor desempeño que la del público, asimismo, descubre que no existirían economías de escala o densidad, considerando el tamaño promedio actual del sector; finalmente encuentra una correlación positiva de la eficiencia con el tamaño de la firma y el tamaño de la red.

Finalmente, Faust y Baranzini (2014) estudian 141 proveedoras de agua potable en Suiza, durante el periodo 2002-2009, y compara la inclusión de variables de control (ambientales) bajo ambos enfoques, mediante una estimación de frontera estocástica con forma funcional trans-logarítmica, y con las variables en cuestión definidas como: el porcentaje de distribución sobre extracción de agua, la densidad de consumo, variables de altitud y meteorológicas, concluye que todas las variables exógenas afectan al costo y no a la eficiencia, especialmente el porcentaje de distribución de agua extraída, densidad poblacional, altitud y factores meteorológicos, resultaron ser muy significativos al explicar el costo.

En ese sentido, diversos autores abordan la metodología de fronteras estocásticas de costo desde un enfoque diferente aun considerando las mismas variables. Sin embargo, tomando en cuenta que, de los antecedentes presentados, solamente Urrunaga y Jara (2013) estudian los determinantes de la ineficiencia (segundo enfoque) para una muestra grande ${ }^{12}$

\footnotetext{
12 Bonifaz e Itakura (2014) también utilizan este enfoque e incluye Perú en su análisis; sin embargo, solo estudia dos empresas prestadoras de servicios de saneamiento SEDAPAL y Aguas Andinas.
} 
de los proveedores de agua potable y saneamiento peruano, esta investigación utilizará el segundo enfoque, asimismo para diferenciarnos de Urrunaga y Jara (2013) la forma funcional que se utiliza es la trans-logarítmica para un panel de datos de más de 30 EPS peruanas durante un periodo más actual: 2008-2016.

\section{Hechos Estilizados: Limitada gestión administrativa-financiera}

El Perú es considerado uno de los 20 países con mayor disponibilidad de agua, sus recursos se encuentran distribuidos en tres vertientes hidrográficas conformando grandes sistemas hídricos (Apaéstegui y Peña, 2017). Entre los componentes de la riqueza hídrica del país, se encuentra el agua atmosférica, en forma de precitaciones pluviales, la disponibilidad de agua proveniente de este componente es medida para cada vertiente hidrográfica siendo de $16.42 \mathrm{~mm}$ en el Pacífico, 2,696.56 mm en el Atlántico y de 129.85 mm en el Titicaca (Apaéstegui y Peña, 2017). Sin embargo, a pesar de la disponibilidad abundante de este recurso a nivel nacional, la distribución demográfica de nuestro país ha generado brechas importantes en la provisión, dado que gran proncentaje de la población se concentra en zonas con menos disponibilidad de agua. En esta investigación se usa un indicador de precipitaciones que nos permite tener una aproximación respecto a la disponibilidad de agua con la que cada proveedor de agua potable (EPS) estaría contando para realizar sus operaciones ${ }^{13}$.

La industria de agua potable y saneamiento en el Perú se encuentra en desarrollo, si bien el sector urbano se encuentra más adelantado que el rural, por los hechos que a continuación se describen se puede decir que en general aún no ha llegado a su madurez.

Según el Informe Final de Resultados de Evaluación de EPS de la Dirección de Evaluación del OTASS - (OTASS, 2017), durante el periodo 2013-2015 (casi 20 años después de su creación), el $50 \%$ de las EPS se encontraba con una capacidad financiera baja o muy baja, y con un indicador de liquidez corriente ajustado menor al $2 \%$; además el informe declara que el margen operativo de las EPS (48) era negativo en su mayoría, y de haber resultados positivos estos eran cercanos a cero ${ }^{14}$.

Por su parte, los diferentes niveles de gobierno realizan inversión pública en el sector, el gobierno central, por ejemplo, financia gasto de capital a través de transferencias de recursos para ejecución de proyectos de inversión en el sector, solamente entre 2011 y

\footnotetext{
${ }^{13}$ Esta disponibilidad de agua tan diversa para cada EPS, justifica la inclusión de variables como la altitud y las precipitaciones para identificar la influencia de variables ambientales sobre la ineficiencia en costos de los proveedores, dado que cada departamento enfrenta condiciones diversas no solo sociales, sino también climáticas.

${ }^{14}$ Cabe mencionar que, estos resultados corresponden solo a las 36 EPS que presentaron información a OTASS.
} 
2016 en el marco del Programa Nacional de Saneamiento Urbano y del Programa Nacional de Saneamiento Rural el monto ascendió a S/ 11604 millones; sin embargo, solo se lograron ejecutar S/ 6562 millones de estos recursos (Ministerio de Vivienda Construcción y Saneamiento, 2017b). Ello demuestra la carencia de capacidad de gestión en la ejecución de obras que muchas de las EPS y Gobiernos Locales poseen.

Para Oblitas (2010) existen tres etapas históricas marcadas que diferencian el proceso de desarrollo del sector y que han delineado la forma en la cual actualmente se maneja la provisión de agua potable y alcantarillado.

La primera etapa entre 1980 - 1990, en sus inicios todavía los servicios de agua potable y saneamiento eran administrados por el Gobierno Central, la responsabilidad recaía en el Ministerio de Fomento y Obras Públicas (MFOP), actualmente disuelto, a través de la Dirección Nacional de Obras Sanitarias y sus diferentes zonales, bajo un concepto de que el servicio público debe ser financiado y aun subsidiado por el Estado, con la meta de cobertura universal por encima de la eficiencia empresarial. Sin embargo, en 1981 se crea el Servicio Nacional de Abastecimiento de Agua Potable y Alcantarillado (SENAPA), constituyéndose como una sociedad de quince empresas filiales, entre las cuales se encontraba SEDAPAL y las demás ubicadas en departamentos de tamaño considerable; en los departamentos de menor tamaño se crearon unidades operativas; sin embargo, la creación de algunas de estas "empresas" no consideraban los criterios del tamaño de escala óptima como prioritarios, poniendo en riesgo su sostenibilidad.

Durante esta primera etapa, la creación del SENAPA dio un giro al sector al orientar el servicio con dirección al usuario y no solamente al desarrollo de obras, aquí se inicia un enfoque más empresarial del sector, aun cuando requerían de financiamiento público. El gran giro en esta etapa se dio en el año 1990 con el DL $N^{\circ} 574$, en el que se dispuso la transferencia de las empresas filiales y las unidades operativas, a excepción de SEDAPAL, a los gobiernos locales; sin embargo, esta transferencia se hizo de forma poco planificada, SENAPA se limitó a dar asistencia técnica a los gobiernos locales.

La segunda etapa entre 1990 - 2000, en 1993 con la aprobación de la nueva constitución del Perú, se ratificó la responsabilidad de los gobiernos municipales en la prestación del servicio de agua potable y saneamiento, además que el rol rector, regulador y supervisor del sector sería asumido por el Estado, por tanto, el Estado al dejar de ser el ente financiador principal, buscó que las EPS puedan sostenerse por sí solas a través de su recaudación, y finalmente se involucraría al sector privado (Oblitas, 2010). 
Asimismo, en el año 1992 se crea la Superintendencia Nacional de Servicios de Saneamiento - SUNASS, para cumplir el rol regulador del Estado y se desactiva el SENAPA. En 1994, se promulga la "Ley general de Servicios de Saneamiento", primer marco normativo del sector que organiza 45 EPS a nivel nacional, 44 municipales con accionariado propio del Gobierno Local adjunto y SEDAPAL que se mantuvo como empresa pública de propiedad del Gobierno Central, con esta Ley se definen también la escala mínima de una EPS, correspondiendo al ámbito provincial, criterios netamente geográficos y no de sostenibilidad ni eficiencia a escala óptima.

Durante esta segunda etapa, a pesar que la inversión superó los niveles de la década anterior, gran parte del financiamiento provino de tesoro público y el Fondo Nacional de Vivienda (FONAVI) en calidad de deuda que no hizo más que causar, en parte, la actual crisis financiera en muchas de las EPS. La regulación se centró en establecer un sistema tarifario para las empresas, así como definir indicadores de gestión que guiaran progresivamente a los proveedores de agua en el uso eficiente de sus recursos. En esta etapa se constituyó el Programa Nacional de Agua Potable y Alcantarillado con categoría de Proyecto Especial y autonomía técnica y administrativa otorgada mediante Decreto Supremo N 018-93-PRES del 10 de agosto de 1993, este sería el origen de los futuros programas del gobierno para atender la problemática del sector.

La tercera etapa se llevó a cabo entre los años 2000 y $2011^{15}$, periodo en el cual se debía institucionalizar ciertas estrategias y funciones, es así que, entre otros, se consolida la institucionalidad del órgano rector a través de la creación del Ministerio de Vivienda, Construcción y Saneamiento (MVCS); reorganización del directorio de SUNASS; entre los cambios operativos, se simplifica el sistema tarifario, se estipula la transparencia de la información regulatoria, y se da una inclusión de representantes de la población y del nivel de gobierno regional en los directorios de las EPS, que puedan aligerar la carga política local. En esta etapa se incrementa el número de EPS a 50, debido a la modificación del TUO de la Ley General de Servicios de Saneamiento con Decreto Supremo Nº31-2008VIVIENDA (aprobado el 30 de noviembre de 2008) que permite la creación de Pequeñas EPS, denominadas "PES" para la provisión a poblaciones entre 15 y 40 mil habitantes.

${ }^{15}$ Si bien es cierto Oblitas (2010) define la tercera etapa al periodo comprendido entre los años 2000 y 2008 , los años posteriores hasta el 2011 mantuvieron la misma política de gestión, razón por la cual se incluyeron en esta tercera etapa. 
En paralelo a este desarrollo, América Latina enfrentaba una situación similar, la Figura 1, presenta el porcentaje de viviendas con acceso a agua potable por tuberías en América Latina, poniendo al Perú en una situación desfavorable, con cifras debajo del promedio de la región. Esto demuestra pocos resultados de las reformas o cambios que se dieron hasta el $2009^{16}$.

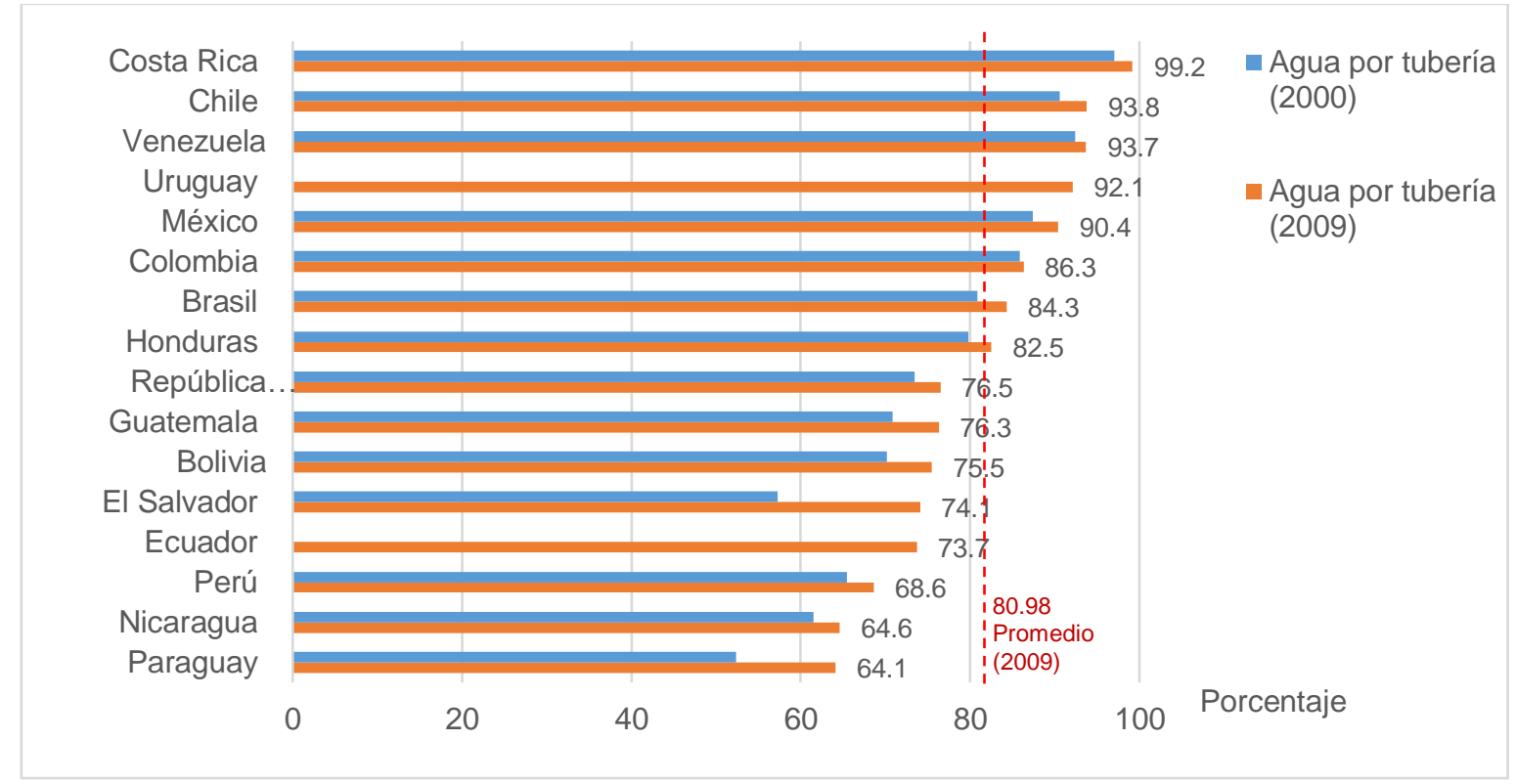

Figura 1. Viviendas con disponibilidad de agua por tuberías (ámbito nacional). Adaptado de CEPAL - Anuario Estadístico de América Latina y el Caribe, 2010 (UN y CEPAL, 2011)

Durante esta tercera etapa, se constituye Programa de Apoyo a la Reforma del Sector Saneamiento (PARSSA), mediante Decreto Supremo № 004-2002-VIVIENDA, sobre el cual no se tiene mucha información en números; sin embargo, toma relevancia al convertirse en la base del conocido Programa Agua para Todos (PAPT), programa abanderado del gobierno peruano durante los años 2006-2010. El Anexo 4, señala mayores alcances al respecto, así como a los resultados de su inversión descentralizada.

Podría plantearse una cuarta etapa posterior a lo expuesto por Oblitas (2010), la cual estaría comprendida entre 2011 - 2016, durante esta etapa los cambios se centraron en una reforma estructural y de estrategias sectoriales que sentaron ciertas bases para el desarrollo del sector, aunque estas aún se están implementando en la actualidad, fue un buen inicio de reestructuración.

\footnotetext{
${ }^{16}$ Lamentablemente las reformas no nos permitieron avanzar en la tabla y las deficiencias persisten en la actualidad, donde según el Banco Mundial (2019), el Perú se encuentra en el último lugar de Sudamérica en materia dee cobertura de agua básica, inclusive por debajo de países como Bolivia y Ecuador, que podrían presentar los mismos problemas estructurales que nosotros.
} 
EI PAPT tuvo una serie de cuestionamientos a partir del nuevo periodo de gobierno (2011 2016), reconocidas las falencias del PAPT en la atención del sector rural, en el año 2012, el gobierno entrante decidió modificar la denominación del PAPT por el de Programa Nacional de Saneamiento Urbano (PNSU) teniendo como ámbito de intervención las áreas urbanas a nivel nacional, y para atención del sector rural se crea el Programa Nacional de Saneamiento Rural (PNSR) mediante Decreto Supremo № 002-2012-VIVIENDA del 06 de enero de 2012, además el mismo Decreto Supremo, faculta al MVCS, a dictar las normas que resulten pertinentes para mejorar la gestión de los programas, esta disposición complementaria final, permite al gobierno establecer medidas legales que enmarquen la modernización y reforma del sector, a partir de ello se inició un proceso de modificaciones al marco normativo y legal que al parecer acabaron con la aprobación del Plan Nacional de Saneamiento en el 2017.

Publicada la Ley № 30045 (2013), Ley de Modernización de los Servicios de Saneamiento, con importantes aportes como: la aclaración de competencia entre los diferentes niveles de gobierno, el regulador (SUNASS), las EPS, entre otros; la limitación del ámbito de las EPS al sector urbano ${ }^{17}$; la creación del OTASS como encargado de cautelar la ejecución de la política del ente rector en materia de administración para la prestación de servicios de saneamiento a cargo de las EPS del ámbito nacional y con este la puesta en marcha del Régimen de Apoyo Transitorio (RAT) ${ }^{18}$ que busca apoyar en el equilibrio financiero de las EPS, a través de asistencia técnica - financiera y de evaluaciones constantes, a manera de promoción a la integración de las EPS, se deja sin efecto cualquier procedimiento orientado a la conformación de las denominadas "PES"19 y se prohíbe cualquier fragmentación de las actuales EPS.

Asimismo, en materia de promoción de la inversión pública en el sector, se establece que el Gobierno Nacional destinaría al menos 3\% de los recursos asignados a gastos de inversión para obras de agua potable y saneamiento a aquellos gobiernos regionales y locales que no reciban canon, sobre canon o regalías minera para destinarlos al financiamiento o cofinanciamiento de proyectos de inversión en agua potable y saneamiento ${ }^{20}$.

\footnotetext{
17 Según el art. 2 de la Ley $N^{\circ} 30045$.

${ }^{18}$ Según el art. 22 de la Ley $N^{\circ}$ 300045. Para conocer más sobre las causales de aplicación del régimen, la duración máxima, las acciones que comprende entre otros relacionados se recomienda revisar el Capítulo III de la mencionada Ley. ${ }^{19}$ Como fue mencionada anteriormente, su creación fue autorizada mediante Decreto Supremo N 031-2008-VIVIENDA, aprobado el 30 de noviembre de 2008.

${ }^{20}$ Según el art. 32 de la Ley $N^{\circ} 30045$.
} 
Mediante Decreto Legislativo № 1240 (2015) se aprueban modificaciones normativas para la implementación de Ley de Modernización de los Servicios de Saneamiento, Ley № 30045 (2013), las cuales incluyeron modificaciones a la Ley General de Servicios de Saneamiento, Ley $N^{\circ} 26338$ (1994), para una mayor congruencia de las competencias de las entidades recientemente creadas y el sistema actual.

Entre las principales incorporaciones a la Ley $N^{\circ} 30045$ (2013), se encuentra la inclusión de la potestad sancionadora del OTASS, la aclaración del proceso de evaluación de las EPS por parte de OTASS y transformación societaria de las EPS hacia Sociedades Anónimas Ordinarias, sobre sus modificaciones, es relevante mencionar la precisión sobre las transferencias para el fortalecimiento de la administración de servicios. Sobre las modificaciones e incorporaciones a la Ley № 26338 (1994), éstas se realizan de tal manera que la Ley de Modernización quede normada y rija en todas las entidades competentes que enmarcan sus funciones en la Ley General, es así que aspectos como el ámbito urbano de las EPS, las funciones de los diferentes agentes del sector (gobiernos locales y regionales, EPS, OTASS, SUNASS), son establecidas en concordancia a la Ley $\mathrm{N}^{\circ} 30045$ (2013), Ley de Modernización de los Servicios de Saneamiento, y sus modificatorias.

A partir de estas modificaciones legales, surgió una nueva necesidad, la de establecer el marco normativo que regule la prestación de los servicios de saneamiento a nivel nacional, que establezca medidas orientadas a la gestión eficiente de los prestadores de servicios de saneamiento, es así que se aprueba la Ley Marco de la Gestión y Prestación de los Servicios de Saneamiento mediante Decreto Legislativo № 1280 (2016).

Finalmente, para culminar todos estos cambios normativos, el 30 de marzo del 2017 se aprueba la Política Nacional de Saneamiento, mediante Decreto Supremo № 007-2017VIVIENDA (2017), que establece las medidas para enfrentar la situación del sector. La presente investigación pretende estudiar el periodo 2008-2016 por lo que no ahondaremos demasiado en esta Política Nacional aprobada dado que su implementación está siendo progresiva desde el 2018 y no influiría en los indicadores de gestión estudiados.

Estos cambios normativos, se vienen implementando progresivamente y aunque sus resultados no podrían ser evaluados en el corto plazo, las incertidumbres que causaron entre los agentes involucrados del sector podrían haber influido en la cadena de valor de la provisión del servicio de agua potable y saneamiento. Particularmente, entre los años 2013 y 2016, las estadísticas del Instituto Nacional de Estadística e Informática - INEI (INEI, 2017) muestran que existe un peligroso 9.5\% de la población urbana que no cuenta 
con servicio de alcantarillado y alrededor de $6.8 \%$ de esta misma población cuenta con un abastecimiento de agua de formas poco salubres e inseguras (ver Figuras 2 y 3 ).

A lo largo del desarrollo de esta etapa surgieron varias iniciativas para resolver la situación, como la implementación de los programas presupuestales orientados a resultados: PNSU y PNSR, el Anexo 5 resume los indicadores históricos de dichos programas para el periodo 2010-2016; sin embargo, a pesar de ello, el indicador "Cobertura de hogares con agua segura" del presupuesto por resultados, se habría reducido entre el 2013 y 2015.

Estos programas presupuestales siguen siendo ejecutados por los tres niveles de gobierno (nacional, regional y local), y su objetivo es reducir la brecha de infraestructura a nivel nacional en el sector saneamiento. De un análisis al presupuesto asignado y ejecutado en los programas presupuestales antes mencionados de los gobiernos locales ${ }^{21}$, se evidencia una pobre ejecución de recursos, lo que podría explicar la situación crítica de cobertura, entre otros indicadores de resultado de los programas; el Anexo 5, muestra la ejecución de inversiones de los gobiernos locales dentro de estos programas presupuestales en el año 2015, a nivel nacional.

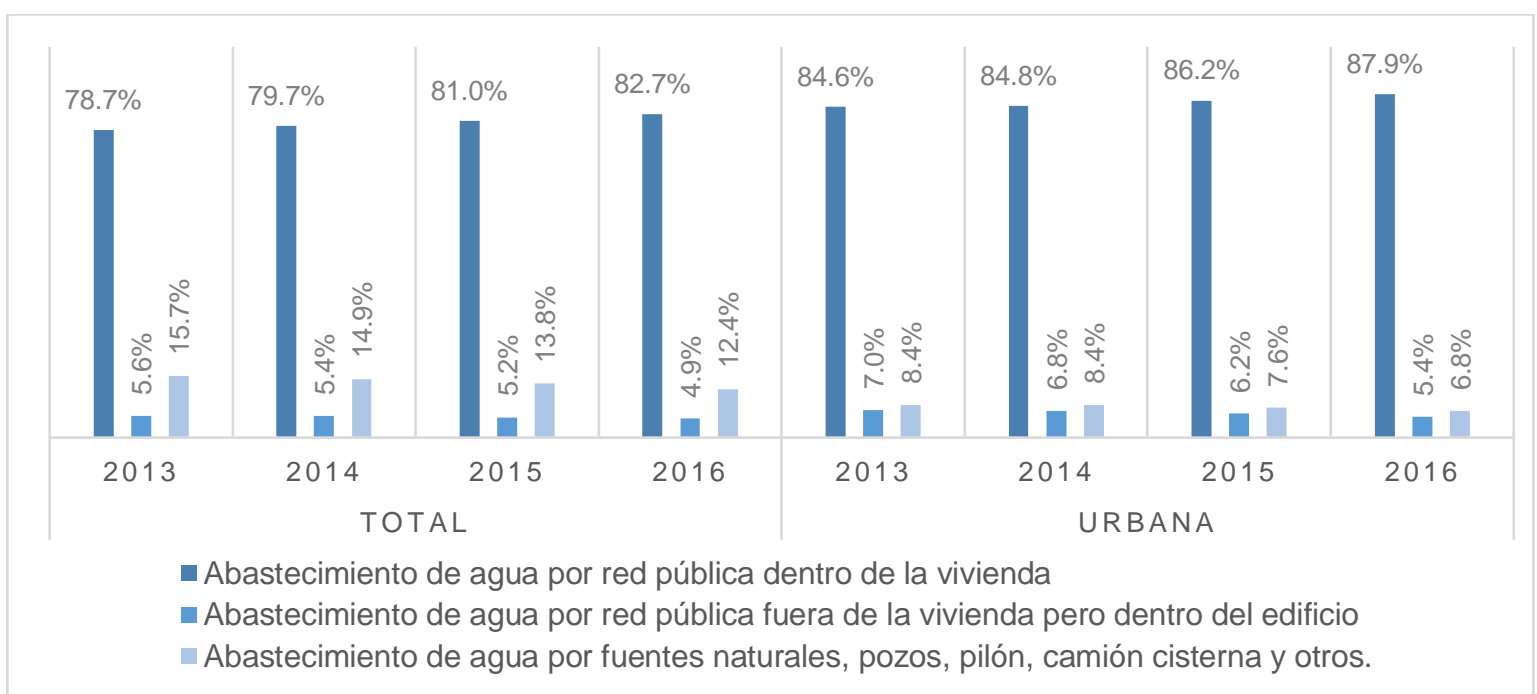

Figura 2. Porcentaje de población con acceso a agua según forma de abastecimiento (2013-2016). Adaptado de ENAHO y Encuesta Nacional de Programas Presupuestales (INEI, 2017)

\footnotetext{
${ }^{21}$ Los gobiernos locales son responsables de monitorear y mejorar la cobertura, según la nueva normativa vigente.
} 


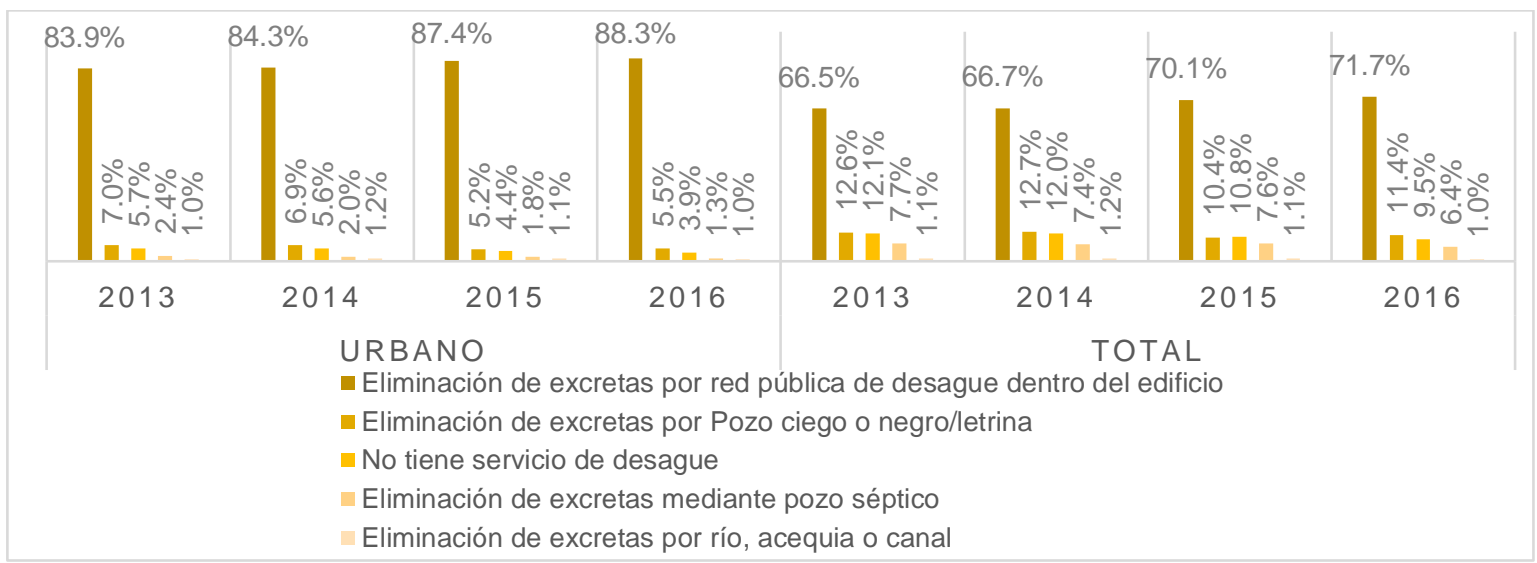

Figura 3. Porcentaje de población con conexión a desagüe según forma de eliminación (2013-2016). Adaptado de ENAHO y Encuesta Nacional de Programas Presupuestales (INEI, 2017)

Por otro lado, el MVCS realiza transferencias de recursos generalmente a gobiernos locales para el financiamiento de proyectos de inversión, solamente durante el periodo 2011 - 2016 se transfirieron recursos a diferentes regiones para financiar 2,790 proyectos de inversión en ejecución (por S/11,654 mil millones), 576 proyectos del PNSU (por S/6,064 mil millones) y 2,222 proyectos del PNSR (por S/ 5540 mil millones); sin embargo, solo se logró una ejecución parcial de dichos recursos, alcanzando un nivel de ejecución del $65 \%$ para el PNSU y 48\% para el PNSR, aproximadamente, situación realmente preocupante ante el poco crecimiento de la cobertura que evidencian la falta de infraestructura (Ministerio de Vivienda Construcción y Saneamiento, 2017b).

Por su parte, tenemos a los principales involucrados en el mejoramiento de la cobertura de agua potable y alcantarillado, los proveedores, las EPS cuya cobertura, dentro del ámbito de intervención, es muy reducida, la Figura 4 muestra la situación de cobertura por las empresas distribuidora por grupo de EPS (grande, mediana, pequeña ${ }^{22}$ ), $\operatorname{SEDAPAL}^{23}$ y ATUSA para el año 2016.

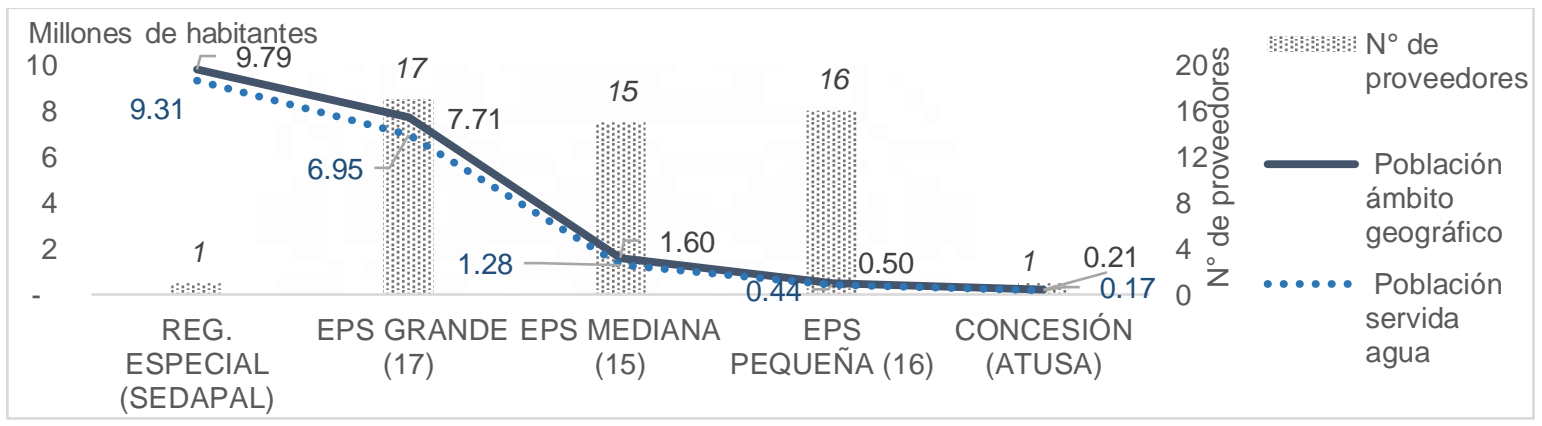

Figura 4. Cobertura de agua potable por tipo de EPS (2016). Adaptado de SUNASS (2017).

\footnotetext{
${ }^{22}$ Según clasificación SUNASS (2007). Según el número de conexiones una EPS es pequeña si cuenta con hasta 15 mil conexiones y mediana si alcanza un rango de 15 mil a 40 mil conexiones.

${ }^{23}$ Se excluye SEDAPAL para distinguir valores atípicos.
} 
Durante los últimos años la cobertura de alcantarillado por red tuvo un crecimiento más acelerado que el del agua potable, la Figura 5 muestra el crecimiento de la cobertura de agua potable y alcantarillado dentro de la red; SEDAPAL muestra un mayor índice; sin embargo, preocupa la situación de las medianas o grandes; en general si bien el crecimiento del agua potable ha sido regularmente sostenido la EPS pequeñas han tenido un particular comportamiento durante los años 1998 y 2002, sin embargo, para el 2016 llega a superar, respecto al nivel de cobertura a las EPS medianas, esto no hace más que decirnos que una fusión entre EPS medianas y pequeñas podría ayudar a un crecimiento más acelerado.
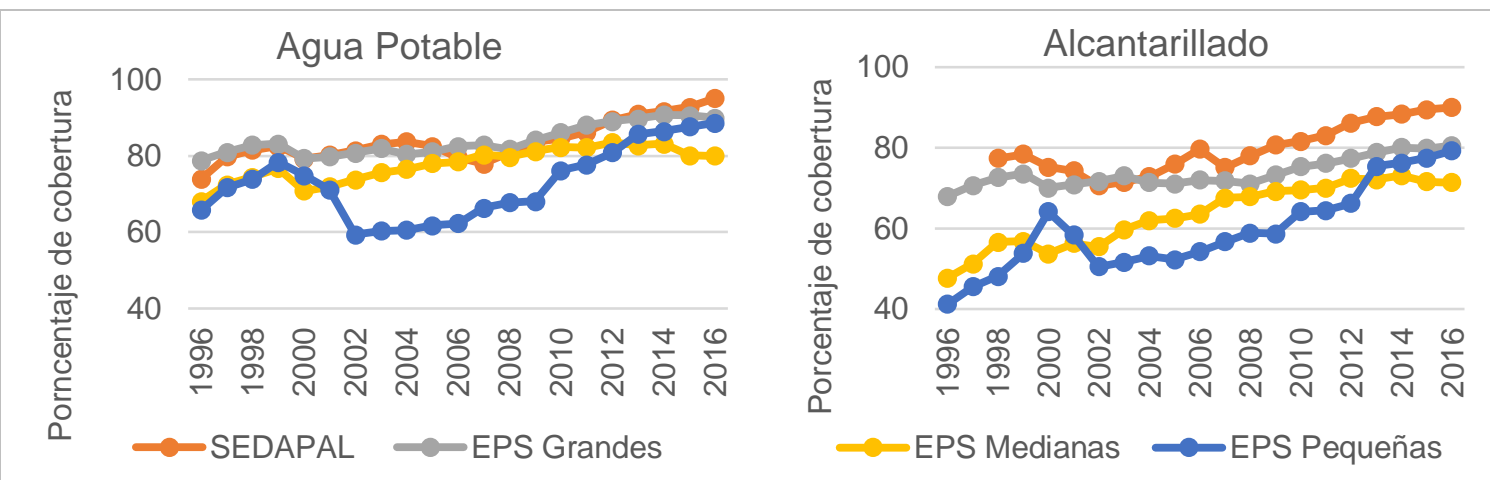

Figura 5. Cobertura histórica de agua potable y alcantarillado por tipo de EPS. Adaptado de SUNASS (2017).

Esta es la situación en la que se encuentra la actual provisión de servicios del sector agua potable y saneamiento, con resultados limitados e insuficientes en el incremento de cobertura y calidad del agua potable y una carencia de capacidades de gestión y uso de los recursos asignados por las entidades involucradas en su desarrollo.

\section{Marco teórico.}

\section{Monopolio Natural.}

La industria del agua es considerada como un "Monopolio natural" (Dalhuisen, De Groot y Nikjamp, 1999), toda vez que la inversión inicial necesaria para la red de distribución es tan grande que no sería posible que dos firmas operaran rentablemente en el mismo mercado, en este sentido, Dalhuisen et al. (1999) justifica la distribución pública; sin embargo, argumenta que la cadena de producción podría ser separada de tal manera que los "procesos" que no requieran de tales inversiones (no procedan como monopolio) sean organizados de diferente manera, entre una mezcla privada y pública.

Partiendo de la definición de una industria monopolística, ésta se trata de mercados donde existe una sola empresa oferente, característica que le otorga poder de mercado para influir 
sobre el precio y producción de tal manera que maximice sus beneficios, sin la restricción del precio dado por el mercado como el caso de la competencia perfecta (Varian, 2010), como se puede observar en la Figura $6\left(\mathrm{CP}^{*}\right)$ que compara una maximización en monopolio y competencia perfecta para una curva de demanda lineal.

Los monopolistas maximizan sus beneficios haciendo que el ingreso marginal iguale al costo marginal de sus operaciones, los monopolistas tienen el poder de influir en el precio y como su curva de demanda no es perfectamente elástica, el precio será mayor al costo marginal generando así beneficios positivos (véase Figura 6, zona "Beneficios" sombreada de gris).

La función de costes de las empresas debería definirse sobre el coste mínimo necesario para producir cierta cantidad, la libertad de ajuste de factores para la minimización de puede variar en función a la disponibilidad de estos. En el corto plazo, algunos factores no podrán ser modificados por su excesivo precio y tiempo de inversión, mientras que en el largo plazo la empresa podría modificar todos los factores. En ese sentido, la función de costos de corto plazo representa el costo mínimo para producir cierta cantidad ajustando solamente costos variables, mientras que en el largo plazo representa el costo mínimo para producir cierta cantidad ajustando todos los factores que lo lleven a su decisión óptima de factores (Varian, 2010).

Para fines de esta investigación, se estimará la función costo considerando que los factores productivos pueden ajustarse; sin embargo, no se descarta la idea de que las EPS podrían operar en exceso de capacidad, dado que como se explicó en el capítulo anterior, el mercado de agua potable y saneamiento en el Perú está lejos de llegar a su óptimo, principalmente debido a que los costos en infraestructura (capital) son excesivamente altos, el tamaño de planta está determinado principalmente por la jurisdicción (ámbito de competencia normativo) y dependen en gran medida de los cambios de estación (Faust y Baranzini, 2014).

En la determinación del precio el monopolista tendrá siempre en cuenta la elasticidad de la demanda, elegir el tramo de demanda inelásticos implicaría un ingreso marginal negativo que lo desviaría de su condición de optimización (ingreso marginal igual a costo marginal) por tanto en este tramo el monopolista no estaría maximizando sus beneficios. El monopolista solo podrá maximizar sus beneficios en el tramo en el cual la elasticidad es igual o mayor que uno (en valor absoluto), es decir elástica o unitaria (Varian, 2010). Para comprender esta maximización de beneficios del monopolista, que depende del poder de 
mercado de la empresa de acuerdo a su eficiencia, representada por el costo marginal (Dammert, Molinelli y Carbajal, 2013), y a la demanda de la industria, se presenta la siguiente Figura que representa el monopolio con una curva de demanda lineal.

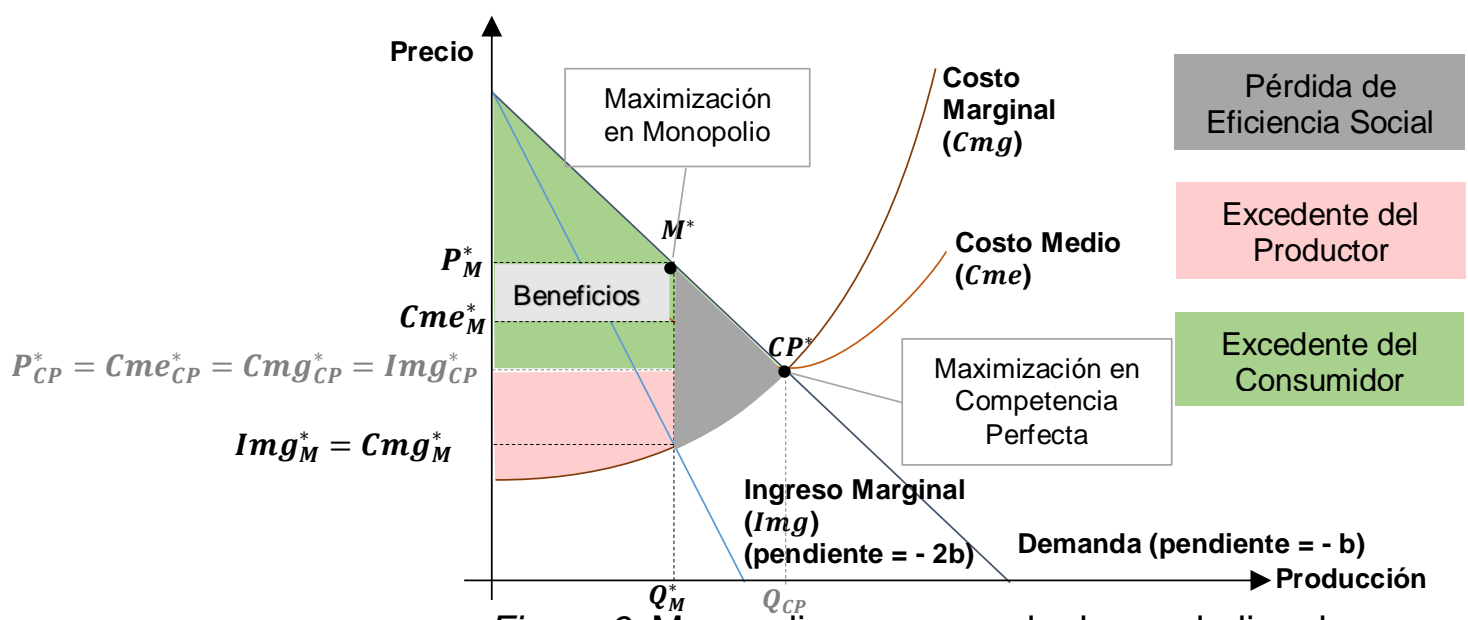

Figura 6. Monopolio con curva de demanda lineal.

Adaptado de Varian (2010)

Este comportamiento monopolista, que aumenta el precio y reduce la cantidad producida (véase la Figura 6, pasar del punto $C P^{*}$ a $M^{*}$ ), resulta siendo ineficiente en sentido de Pareto (Varian, 2010), ya que a pesar de incrementar el bienestar de los productores a costa del de los consumidores, se genera una pérdida irrecuperable de eficiencia o comúnmente llamada Pérdida de Eficiencia Social (PES) que ninguno de los dos agentes logra absorber, véase zona "PES" sombreada de gris en la Figura 6.

Frente a esta situación es necesaria la actuación del Estado mediante la regulación de precios, impuestos, entre otros, de manera que se pueda controlar el accionar monopolista y se reduzca la pérdida de bienestar; sin embargo, existen escenarios en los cuales el Estado no puede incidir directamente en el precio, por ejemplo, puesto que, de presionar a la baja, podría generar el cierre del "negocio" y la nula provisión del producto o servicio reduciría aún más el bienestar de la sociedad. Este es el caso de los monopolios naturales, situación a la que frecuentemente se enfrentan los servicios públicos (Varian, 2010) como el que se está estudiando en esta investigación.

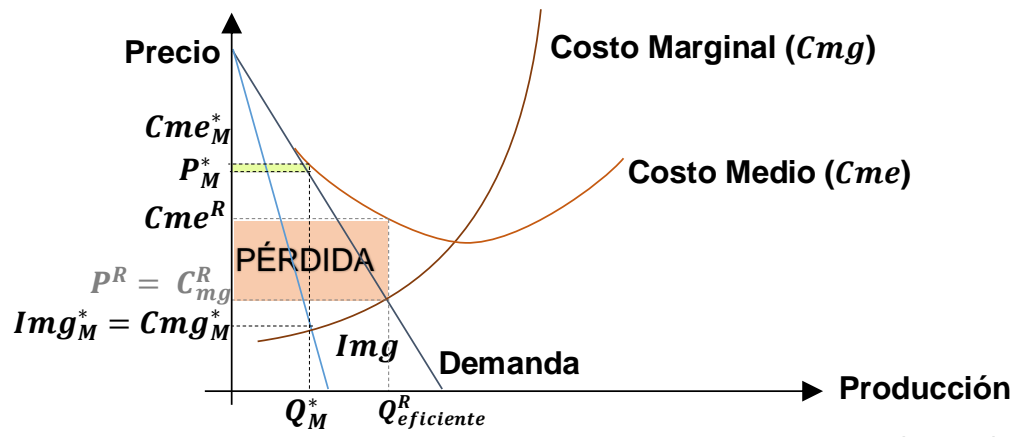

Figura 7. El Monopolio Natural. Adaptado de Varian (2010) 
Los monopolios naturales se caracterizan por presentar sub-aditividad en su función de costos (Dammert et al., 2013) definida como la situación en la que el costo de producir cierta cantidad es menor si esta es producida por una empresa en comparación al costo de producir la misma cantidad por más de una empresa, por lo que sería más eficiente que solamente una empresa produzca.

La Figura 7, representa un Monopolio Natural, en el cual, si el regulador fija el precio al nivel del costo marginal, produce una cantidad eficiente $Q_{e f i c i e n t e}^{R}$; sin embargo, el Costo total de ese nivel de producción ( $\left.\boldsymbol{C} \boldsymbol{m} \boldsymbol{e}^{R} \boldsymbol{x} \boldsymbol{Q}_{\text {eficiente }}^{R}\right)$ supera el Ingreso total $\left(\boldsymbol{P}^{R} \boldsymbol{x} \boldsymbol{Q}_{\text {eficiente }}^{R}\right)$, generando pérdidas para el productor, en esta situación el oferente preferirá cerrar antes de producir. Para Varian (2010) esto podría suceder en empresas con costes fijos grandes y costes marginales pequeños, particularmente en esta investigación la industria de agua potable y saneamiento presenta esta característica, toda vez que para iniciar con su distribución se requiere una gran inversión en la construcción de infraestructura de redes, almacenamiento, transporte y tratamiento (Dalhuisen et al., 1999).

La Figura 7 también expone el caso particular en el cual, a pesar de actuar ineficientemente como monopolista, generando pérdidas económicas (véase zona sombreada de amarillo), causado principalmente por los grandes costes incurridos que hace que la curva de Costo medio se encuentre por encima de la demanda, en estos casos con el fin de promover la provisión del servicio, el Estado podría subvencionar parte de los costos incurridos. Recordemos que el punto de cierre de la empresa es aquel momento en el cual el precio cae por debajo de la curva de costo variable medio, dado que el ingreso total sería insuficiente para cubrir costos variables necesarios para la operatividad de la entidad en el corto plazo.

Entonces, habrían tres casos en este tipo de mercados 1) Comportamiento monopolista con beneficios, 2) Se fija un precio igual al Costo Marginal, 3) Comportamiento monopolista con pérdidas, ninguno de los tres casos es viable, el primero es ineficiente en sentido de Pareto, y el segundo y tercero generan pérdidas, si se tratase de un bien o servicio imprescindible para el bienestar de la sociedad, como el agua potable y saneamiento ${ }^{24}$, el Estado tendría que intervenir a fin de promover su provisión, es por ello que la mayoría de monopolios naturales son regulados o gestionados por el estado.

${ }^{24}$ La cobertura universal de agua potable y saneamiento se encuentra como objetivo de desarrollo sostenible al 2030. 
En la regulación, para asegurar beneficios no negativos el Estado puede permitir al monopolista actuar en el punto tal que el precio sea igual al Costo medio, sin embargo, el nivel de producción se reduce considerablemente de aquel considerado eficiente en sentido de Pareto ${ }^{25}$. Por el lado de gestión estatal se pretende fijar un precio igual al coste marginal, similar justificación a las regulaciones, por tanto, el estado subvencionaría parte del costo. Sin embargo, en ambas "soluciones" la problemática se centra en la medición de costos fijos y variables de los servicios, averiguar los verdaderos costos de las empresas es complicado; para Varian (2010) inclusive las subvenciones pueden seguir siendo ineficientes, en ese sentido cabe la duda si la cura es peor que la enfermedad.

Laffont y Tirole (1986) en su modelo básico de regulación diseña un mecanismo de transferencias gubernamentales a monopolios naturales para financiarlas (con el supuesto que estas empresas no cobran a los consumidores) usando un modelo que explica el costo de manera endógena, y de esta manera intenta resolver el problema del "principal agente" y maximizar el excedente social. Si bien su modelo se centra en el cálculo de la "transferencia gubernamental" óptima señala que el costo de producción dependería del tipo de curva de costos que enfrente la firma (cuánto menor será el costo más eficiente será la empresa) y el esfuerzo del manager para reducir el costo, para que este esfuerzo tenga incentivos los autores presuponen un mecanismo de transferencias para combatir el riego moral y la asimetría de información.

Es por ello que, con el fin de abordar problemas como ineficiencia asignativa, ineficiencia productiva (o técnica), ineficiencia distributiva, disparidad de rentas, ineficiencias dinámicas y distorsión de la calidad (Dammert et al., 2013), el Estado tiene el deber que regular los monopolios naturales. En esta investigación se pretende explicar e identificar el problema relacionado a la ineficiencia productiva (o técnica).

\section{Problema de Minimización de Costos.}

La función de costos de producción de una empresa representa el gasto que debe efectuar para adquirir los factores necesarios para producir bienes, antes de ellos la empresa debería decidir su plan de producción a ejecutar, en afán de minimizar beneficios la firma elegirá el plan de producción menos costoso para cada posible nivel de producción, dentro de esta cadena de decisiones se define una demanda de factores (aquella combinación que minimice el costo) condicionada al nivel de producción, y asumiendo los

\footnotetext{
${ }^{25}$ Una mayor explicación sobre la escala mínima eficiente se explica en el Anexo № 6
} 
precios de factores, de esta manera la firma resolverá el problema de minimización de costos para formar su función de costos $c(\mathbf{w}, q)$ que es el valor mínimo posible de gasto que incurrirá la empresa para alcanzar el nivel de producción $q$ dado el vector de precios de factores $\mathbf{w}>>0$ y el nivel de producción $q>0$.

Cuando la función de producción es continua y estrictamente creciente, las propiedades que la función de $\operatorname{costos} c(\mathbf{w}, q)$ son las siguientes (Keat y Young, 2004):

- Homogénea de grado uno en los precios de los factores.

- Es continua en $\mathbf{w}$ y en $q$

- Es creciente en $q$

- Es estrictamente creciente y no acotada en $q$

- Es cóncava en $\mathbf{w}$

Los costos de toda empresa están relacionados a la cantidad de factores de producción requeridos y a los precios de estos, tradicionalmente estos factores de producción se agrupan en trabajo $(L)$ y capital $(K)$, de tal manera que el costo $(C)$ esté en función de dichos estos factores y de sus precios. Sin embargo, en mercados no homogéneos como el del saneamiento en el Perú (ver apartado "Hechos Estilizados)", la función de costos incluye otros factores adicionales que influyen en la producción, como aquellos relacionados al efecto de la escala de la red (Antonioli y Filippini, 2001), en sección "Antecedentes" se revisaron variables que han sido catalogadas de este tipo por diversos autores. Es por ello que a partir de la disponibilidad de las variables se definen aquellas a ser incluidas en esta investigación.

\section{Eficiencia.}

Se define la eficiencia como aquella representada por un proceso productivo que no solamente llega al objetivo (eficacia) sino que también lo hace al mínimo costo posible, eficientemente (Ferro et al., 2011), o como aquella distancia entre la cantidad de insumos y producto de la empresa y la mejor frontera posible de su industria (Daraio, C y Simar L., 2007). Es esta la "eficiencia" que se quiere abordar en esta tesis, con un enfoque aplicado al sector agua potable y saneamiento, en particular, a la provisión del servicio prestado por las EPS.

Por otro lado, la "eficiencia asignativa" tendría que ver con consideraciones económicas, decisiones de costos y precios (Ferro et al., 2011), es decir considera aquella combinación 
tomando en cuenta el costo marginal relativo de los insumos, pues una asignación (de recursos) eficiente para cada insumo generará mejores resultados del producto, aun cuando no todos los procesos productivos tienen el mismo grado de flexibilidad para reemplazar insumos, se trata de asignar los recursos a aquellos insumos menos costosos considerando el nivel de reemplazo posible entre estos. Para Dammert et al. (2013) desde una perspectiva más aplicativa, la eficiencia asignativa sería el resultado donde los precios reflejan los costos marginales de producción del bien, el cual hace que el excedente total en el mercado sea el máximo posible ver Figura 6.

Farrell (1957) definió la "eficiencia técnica" como aquella que permite maximizar la producción, a partir de un conjunto dado de insumos; establecida la relación entre la cantidad producida y los insumos requeridos, se crean diversas combinaciones (técnicas productivas) de insumos para la meta de producción, estas combinaciones suelen ser representadas por una función de producción económica; con el uso de Capital $(\mathrm{K})$ y Trabajo (L) como los factores de producción por naturaleza para representar un conjunto de insumos; la combinación más eficiente será aquella que pueda usar menos insumos para obtener el mismo nivel de producción, a esta combinación se le denominará técnicoeficiente, pues implica relaciones puramente físicas o ingenieriles (Ferro et al., 2011). Esta eficiencia también llamada técnica, se da cuando se produce al menor costo posible para la sociedad como consecuencia de alcanzar el coste medio mínimo posible para cada nivel de producción $\left(\boldsymbol{C m e}_{\text {MIN }}\right)$. Como lo muestra la siguiente Figura:

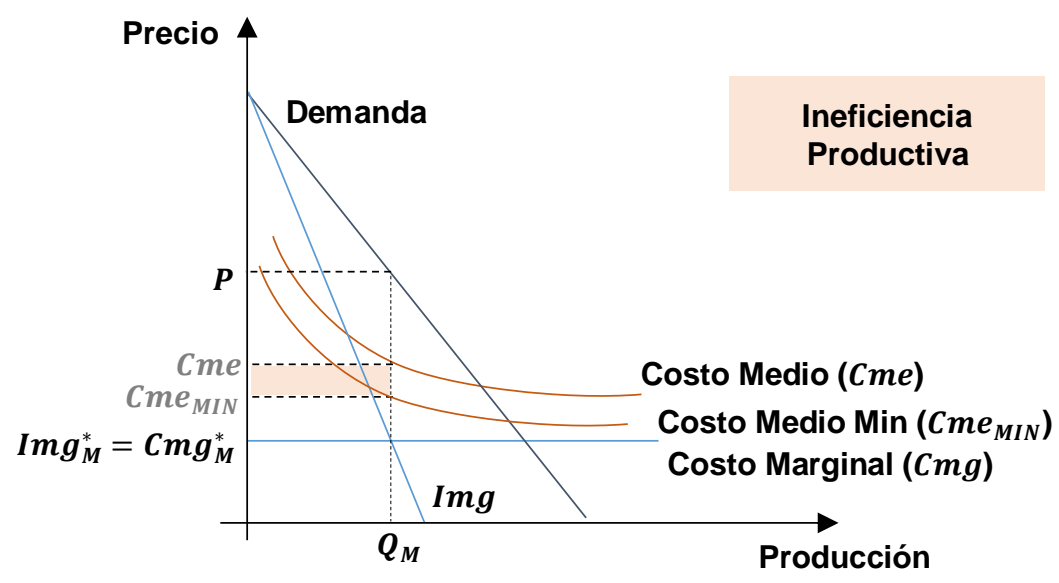

Figura 8. Ineficiencia productiva. Adaptado de Dammert, Molinelli y Carbajal (2013)

La eficiencia económica o total, engloba la eficiencia asignativa y técnica, es decir, se buscará a aquellas combinaciones de producción que minimicen el costo considerando los precios relativos de los factores y la intensidad de capital en la industria, y el precio/tarifa establecida. Esta investigación, se centrará en estudiar la eficiencia técnica 
a través de un análisis de costos, teniendo en cuenta que un análisis de tarifas y de bienestar para la eficiencia asignativa está fuera del alcance por la limitada disponibilidad de la información estadística y por la presencia de factores externos (políticos) que la influyen.

Si bien esta investigación utiliza un enfoque referido a costos, es necesario señalar las ventajas y desventajas de los dos enfoques (producción vs costos) estudiadas por Romero y Ferro (2007):

a) Función de producción (permite medir eficiencia técnica), que relaciona Producto contra insumos (como capital y trabajo), se usa normalmente cuando está en manos de la firma decidir el nivel de producción o de los insumos, entre sus ventajas se encuentra que puede medirse sin necesidad de imponer un supuesto de comportamiento sobre las empresas (como maximización de beneficios 0 minimización de costos), sólo requieren datos físicos, favorece las comparaciones internacionales y en el tiempo por la homogeneidad de las medidas.

b) Función de costos (permite medir eficiencia total, técnica más asignativa) relaciona costos contra producto y precios de los insumos (como renta del capital y salario del trabajo) se usa normalmente cuando no está en manos de la firma decidir el nivel de producción entre las ventajas se encuentra que requiere suponer un objetivo para los productores (en general, maximización de beneficios o minimización de costos)

En la práctica las mediciones de eficiencia han estado basadas en desempeños reales, intentando obtener las mejores prácticas de un conjunto de competidores para usarlas como referencia, dicho valor de referencia se le conoce comúnmente como Benchmarking y debería ser usado normalmente como comparador o incentivo. En este sentido, mediante una experiencia empírica, Berg (2010) logró clasificar los enfoques de medición de desempeño en: indicadores parciales (razones o porcentajes), indicadores totales 0 agregados (practicas muestrales relativas), comparación con un ideal teórico, métrica de procesos, y comparación de desempeño percibido (Ferro et al., 2011).

Este estudio, pretende comparar prácticas muestrales de las EPS durante el periodo 20082016, por tanto, utiliza indicadores totales o agregados. En esta clasificación, (Ferro et al., 2011), da a conocer distintas técnicas de medición comparativa de eficiencia, entre las cuales las fronteras paramétricas, econométricas estocásticas o determinísticas, y no 
paramétricas, por medio de programación matemática, son las más usadas. Esta investigación utilizará la metodología paramétrica, con el fin de utilizar los conocimientos econométricos aprendidos.

En el enfoque no paramétrico, el método más usado es el análisis de envolvente de datos (DEA), el cual fue introducido por primera vez por Charnes A., Cooper W. y Rhodes E. (1978) para la toma de decisiones en eficiencia con énfasis en la evaluación de programas públicos planteando una nueva interpretación de eficiencia no solamente ingenieril sino de control del comportamiento gestor de los programas. Es así que introdujeron un modelo de programación matemática no lineal en función de las unidades de decisión (DMU); en el que se calcula la tasa máxima de combinación entre la producción ponderada y los factores de producción ponderados, que definiría la medida de eficiencia de cada DMU. Posteriormente, se define una frontera de eficiencia a partir de la comparación relativa de los indicadores de eficiencia de las empresas del clúster, esta metodología define a la ineficiencia como toda perturbación aleatoria de la estimación.

El método paramétrico pudiera ser estocástico o determinístico, donde la primera considera que las desviaciones de la Frontera se descomponen de dos componentes independientes: uno aleatorio y otro de ineficiencia; mientras que el determinístico consideran como ineficiencia cualquier desviación de la frontera de producción. En esta investigación se utilizará el análisis de frontera de costos estocástica debido a que mediante esta se puede separar la heterogeneidad no observada y la eficiencia del término de error distinguiendo así la heterogeneidad observada y no observada atribuible o no a la eficiencia, asimismo, la medición del error y los shocks aleatorios se acomodan en frontera estocástica haciendo que la técnica sea menos sensible a los valores extremos (Faust y Baranzini, 2014).

\section{Análisis de fronteras de eficiencia estocástica.}

El análisis de la eficiencia a través de una frontera estocástica fue introducido por Aigner, Lovell y Schmidt (1977) en su formulación y estimación de modelos de fronteras estocásticas de funciones de producción con la particularidad de separar el componente de error en una perturbación simétrica (error de modelamiento) y la ineficiencia técnica; para estos autores, el proceso productivo está sujeto a dos perturbaciones aleatorias económicamente distinguibles $\left[\varepsilon_{i t}=u_{i t}+v_{i t}\right]$, la primera $\left(u_{i t}\right)$ es negativa para reflejar el hecho que cada firma producirá sobre o por debajo de la frontera, cualquier desviación de la producción de la frontera $\left[f\left(x_{i} ; \beta\right)+v_{i}\right]$, sería el resultado de factores bajo el control de la firma como la ineficiencia económica y técnica, el esfuerzo de los productores y 
empleados entre otros; en ese sentido, los autores definen una frontera que es aleatoria y que sería el resultado de eventos externos inclusive. En ese sentido, el término de ineficiencia de $u_{i t}$ es estimado indirectamente a partir de la esperanza condicional de $u_{i t}$ (Jondrow, Lovell, Materov y Schmidt, 1982) dados los valores observados de $\varepsilon_{i t}=u_{i t}+$ $v_{i t}, E\left[u_{i t} \mid \varepsilon_{i t}\right]$, en esta investigación se usará este estimador para hallar el indicador de ineficiencia en costos.

Posteriormente, Coelli, Perelman y Romano (1999) introdujeron al análisis de eficiencia técnica, definida en el párrafo anterior, las variables ambientales como influencia en los modelos de fronteras estocásticas. Los autores definieron dos enfoques, el primero asume que las variables ambientales afectan la forma de la tecnología (la frontera de producción en sí misma) y el segundo asume que estas variables afectan el grado de ineficiencia técnica directamente.

Metodológicamente, lo propuesto por Coelli, Perelman y Romano (1999) inició una serie de investigaciones empíricas para incluir variables ambientales que capten la heterogeneidad de la data en los modelos de estimación de ineficiencia. Entre ellas, Greene (2005) propuso un modelo de efectos fijos verdaderos para data panel ${ }^{26}$ que incluye un término de error adicional (one-sided) cuyo promedio ayudaría en la estimación de los efectos de ineficiencia mediante una simulación de Monte Carlo para llegar a la convergencia ; de esta manera, se trata de resolver el problema de los parámetros para distinguir la heterogeneidad no observada $\left(v_{i t}\right)$ que otros modelos (como tobit, probit, etc.) no terminaron de resolver (Greene, 2005) y así superar las limitaciones que se encontraría al utilizar un modelo de efectos fijos tradicional, en el cual el término de error comprende la ineficiencia y la heterogeneidad no observada. En la presente investigación se usa este modelo para estimar un término de error diferenciado que identifique la ineficiencia $\left(u_{i t}\right)$ y la heterogeneidad no observada $\left(v_{i t}\right)$.

Si bien estas definiciones de eficiencia técnica - productiva, fueron realizadas a partir de estimaciones sobre la función de producción, es posible adaptarla para estudiar la ineficiencia técnica desde problema de minimización de costos que enfrentan los monopolios, en este sentido, Antonioli y Filippini (2001), Faust y Baranzini (2014) entre otros realizaron esta adaptación. En ese sentido, en esta investigación, el costo mínimo estaría en función del vector de los precios de los factores $\mathbf{p}$ y de la producción $\mathbf{Y}$, a lo cual se añaden variables relacionadas a los factores de producción I y otras variables

\footnotetext{
${ }^{26}$ Si bien la heterogeneidad expuesta por Greene (2005) identifica la heterogeneidad mediante variables dummy, en esta
} investigación se identificará la heterogeneidad mediante variables nominales. 
ambientales Z, (Bonifaz e Itakura, 2014), puedo ser expresada como: $C=f(\mathbf{Y}, \mathbf{I}, \mathbf{p}, \mathbf{Z})+$ $u_{i t}+v_{i t}$.

El término del error tiene dos componentes $v_{i t}$ que se asume tiene una distribución normal y representaría el ruido blanco de la estimación, y $u_{i t}$ una variable aleatoria no negativa interpretada como la medida de ineficiencia de costos, no negativa debido a que las empresas no podrían operar debajo de la frontera de costo variable estocástica $f(\ldots)$ (Faust y Baranzini, 2014); esta separación del término del error $\left(\varepsilon_{i t}=u_{i t}+v_{i t}\right)$ es necesaria dado que se quiere distinguir entre la heterogeneidad no observable $\left(v_{i t}\right)$ y las desviaciones de la frontera atribuibles a la eficiencia $\left(u_{i t}\right)$.

Los dos enfoques, de inclusión de variables ambientales, definidos por Coelli et al. (1999), son considerados en esta investigación, por tanto, la variable $u_{i t}$ que mide la ineficiencia estaría explicada por variables específicas de las empresas representadas en el vector $\mathbf{E}$ y $e_{i t}$ como una variable random: $u_{i t}=\alpha \mathbf{E}_{i t}+e_{i t}$. En ese sentido, la ineficiencia de costos de la empresa i-ésima para el periodo $t$ (Bonifaz e Itakura, 2014) se mide mediante: $\exp \left(\alpha \mathbf{E}_{i t}+e_{i t}\right)$.

Cabe mencionar, para estimar una frontera de costos estocástica es necesaria la especificación de la forma funcional de la frontera de costos (Faust y Baranzini, 2014); para la especificación de la función de costos, existen diferentes formas funcionales en su modelamiento. Como se sabe, las funciones como CES y Cobb Douglas son muy populares por las características que posee pero son muy restrictivas, la primera requiere que la elasticidad de sustitución sea la misma entre cualquier par de factores y la segunda restringe las posibilidades de sustituir los insumos haciendo que $\sigma=1$ (Nicholson y Snyder, 2012); sin embargo, el desarrollo empírico ha logrado demostrar formas funcionales más flexibles que mantiene las propiedades de dominio, monotonicidad, continuidad, concavidad, homogeneidad y diferenciabilidad (Fuss, McFadden, y Mundlak, 1978), como la "Translog"; asimismo, entre los antecedentes se han identificado dos formas funcionales recurrentes, la trans-logarítimica y la Cobb Douglas.

Empíricamente, se trabajan con formas funcionales linealizadas, lineales en los parámetros, para estimar los modelos usando técnicas de regresión lineal; el método más común para linealizar es la aplicación de logaritmo a las formas funcionales originales, la siguiente tabla muestra esta operación para las dos formas funcionales recurrentes. 
Tabla 1

Formas Funcionales linealizadas

\begin{tabular}{lcc}
\hline Tipo & Forma Funcional Original & Forma Logarítmica \\
\hline Cobb & $y=\beta \prod_{n=1}^{N} X_{n}^{\beta_{n}}$ & $\ln y=\ln \beta_{0}+\sum_{n=1}^{N} \beta_{0} \ln x_{n}$ \\
\hline Translog & $y=\exp \left(\beta_{0}+\sum_{n=1}^{N} \beta_{0} \ln x_{n}\right.$ & $\ln y=\beta_{0}+\sum_{n=1}^{N} \beta_{n} \ln x_{n}$ \\
& & $\left.+\frac{1}{2} \sum_{n=1}^{N} \sum_{m=1}^{N} \beta_{n m} \ln x_{n} \ln x_{m}\right)$ \\
& & $+\frac{1}{2} \sum_{n=1}^{N} \sum_{m=1}^{N} \beta_{n m} \ln x_{n} \ln x_{m}$
\end{tabular}

Nota: Donde $\mathrm{y}=$ Variable Dependiente $\mathrm{x}=$ Variables Explicativas. Elaboración propia, adaptado de Coelli, Rao, O'Donnel y Battese (2005)

En esta investigación se utiliza el análisis de frontera estocástica con la forma funcional trans-logarítimica, por ser la más flexible cumpliendo con las propiedades mínimas para esta función, antes mencionadas, para especificar $C=f(\mathbf{Y}, \mathbf{I}, \mathbf{p}, \mathbf{Z})+u_{i t}+v_{i t}$, donde $C$ es la proxy de costo, $\mathbf{Y}$ el vector de producto, I el vector de insumo, $\mathbf{p}$, el vector de precios de los insumos, $\mathbf{Z}$ el vector de variables ambientales, $u_{i t}$ medida de ineficiencia, y $v_{i t}$ ruido blanco

Es importante señalar que entre los antecedentes existe discusión respecto a la inclusión de variables ambientales en el análisis según los enfoques de Coelli et al. (1999); para fines de esta investigación las primeras son aquellas variables ambientales del sector o contexto representadas en la matriz $\mathbf{Z}$, mientras que las segundas están bajo el control de la empresa pero que no afectan directamente la frontera de costos de la empresa. La operacionalización de estas variables se revisan en el siguiente capítulo.

\section{Objetivos e hipótesis}

\section{Objetivos.}

\section{Objetivo central.}

Analizar las variables que influyen en la ineficiencia de técnica de las Entidades Prestadoras del Servicios de Agua Potable y Saneamiento en el Perú urbano durante el periodo $2008-2016$.

\section{Objetivos específicos.}

1. Identificar las variables de producción y factores productivos que influyen en la frontera de costos de las Entidades Prestadoras de Servicios de Saneamiento (EPS) en el Perú entre 2008 y 2016. 
2. Identificar las variables ambientales que influyen en la función de costos de las Entidades Prestadoras de Servicios de Saneamiento (EPS) en el Perú entre 2008 y 2016.

3. Identificar las variables ambientales observables que se relacionan con la ineficiencia de costos de las Entidades Prestadoras de Servicios de Saneamiento (EPS) en el Perú entre 2008-2016

4. Determinar en qué etapa de las economías de escala se encuentra la curva de costos de las Entidades Prestadoras de Servicios de Saneamiento en el Perú entre 2008 y 2016

\section{Hipótesis.}

\section{Hipótesis central.}

La ineficiencia en costos de las Entidades Prestadoras de Servicios de Saneamiento (EPS) es explicada significativamente, por el porcentaje de medición de conexiones activas, la pérdida de agua, el porcentaje de tratamiento de aguas residuales, el porcentaje de cobertura de agua, el porcentaje de cobertura de alcantarillado, el índice de precipitación estandarizado y la altitud geográfica en el Perú urbano de manera significativa, durante el periodo 2008-2016.

\section{Hipótesis específicas.}

1. Los costos operativos de las Entidades Prestadoras de Servicios de Saneamiento (EPS) se encuentran explicados por el volumen producido de agua potable, el número de trabajadores, el número de conexiones de agua y el costo de la energía, en el Perú urbano entre 2008 y 2016.

2. Los costos operativos de las Entidades Prestadoras de Servicios de Saneamiento (EPS) se encuentran controlados por el consumo de agua potable, y el porcentaje de agua extraída de la fuente subterránea, en el Perú urbano entre 2008 y 2016.

3. La ineficiencia en costos se encuentra correlacionado con el porcentaje de medición de conexiones activas, el porcentaje de pérdida de agua, el porcentaje de tratamiento de aguas residuales, el porcentaje de cobertura de agua, el porcentaje de cobertura de alcantarillado, el índice de precipitación estandarizado y la altitud geográfica de las Entidades Prestadoras de Servicios de Saneamiento en el Perú (EPS) entre 2008 y 2016.

4. La curva de costos de las Entidades Prestadoras de Servicios de Saneamiento (EPS) en el Perú entre 2008 y 2016, se encuentra en una etapa de deseconomías de escala. 


\section{Método}

Para esta investigación se utilizó la metodología paramétrica estocástica mediante una función de costos tipo trans-logarítmica que es una forma más generalizada y flexible de la conocida función de producción de Cobb Douglas, y cumple las mismas propiedades. (Coelli et al., 2005). El modelo a seguir se explica en (i), donde $C$ es el costo, $Y$ es el vector de producto, I es el vector de insumo, $\mathbf{p}$ es el vector de precios de los insumos, $\mathbf{Z}$ el vector de variables ambientales, $u_{i t}$ medida de ineficiencia, y $v_{i t}$ ruido blanco ${ }^{27}$ (Bonifaz e Itakura, 2014).

$$
C=f(\mathbf{Y}, \mathbf{I}, \mathbf{p}, \mathbf{Z})+u_{i t}+v_{i t}
$$

Finalmente, el término de ineficiencia de $u_{i t}$ es estimado indirectamente usando el estimador planteado por Jondrow, Lovell, Materov y Schmidt (1982) a partir de la esperanza condicional de $u_{i t}$ dados los valores observados de $\varepsilon_{i t}=u_{i t}+v_{i t}, E\left[u_{i t} \mid \varepsilon_{i t}\right]$.

$$
\text { Ineficiencia en costos }=E\left[u_{i t} \mid \varepsilon_{i t}\right]
$$

En (i), $u_{i t}$ medida de ineficiencia estaría explicada por variables específicas de las EPS representadas en el vector $\boldsymbol{E}$ y $e_{i t}$ como una variable random ${ }^{28}$ :

$$
\begin{gathered}
\hat{u}_{i t}=\alpha \mathbf{E}_{i t} \\
u_{i t}=\hat{u}_{i t}+e_{i t} \\
u_{i t}=\alpha \mathbf{E}_{i t}+e_{i t}(\mathrm{iii})
\end{gathered}
$$

Esta medida de ineficiencia para cada firma es una variable aleatoria no negativa que depende de otras variables explicativas que controlan las características de la EPS.

El modelo aplicado con una forma funcional trans-logarítmica para la estimación de una frontera de costos estocástica, siguiendo a (i) y descomponiendo los vectores mencionados, tiene la siguiente especificación:

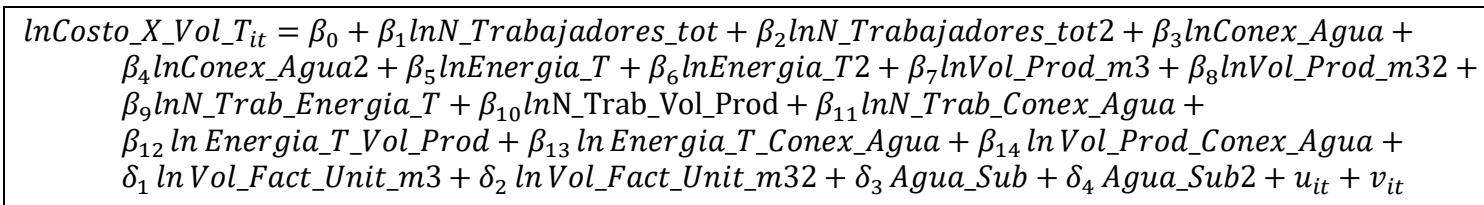

En la ecuación (iv) $u_{i t}$ representa la medida de ineficiencia y $v_{i t}$, el ruido blanco del modelo; asimismo, las variables explicativas y la explicada se definen en Tabla 2, estas variables tienen la transformación logarítmica, a su vez se elevó al cuadrado, y se multiplicó entre

\footnotetext{
${ }^{27}$ Los componentes de cada vector $(\mathbf{Y}, \mathbf{I}, \mathbf{p}, \mathbf{Z})$ serán detallados en la sección "Variables".

${ }^{28}$ Los componentes del vector E, serán detallados en la sección "Variables".
} 
las variables explicativas (efectos cruzados), siguiendo la forma funcional elegida, cabe mencionar que, la presente investigación se centra la interpretación de las variables logtransformadas y no de sus cuadrados y/o efectos cruzados.

La metodología de estimación elegida para la data panel de esta investigación es la denominada de efectos fijos verdaderos ("True Fixed Effects") mediante el método de Momentos Generalizados. Asimismo, la distinción del término del error entre ineficiencia y ruido blanco siguió lo propuesto por Greene $(2005)^{29}$.

Como segunda etapa de análisis se identifican los determinantes de la ineficiencia siguiendo (ii). El método de estimación de este modelo será mediante Mínimos Cuadrados Ordinarios, por ello se analizará el problema de la multicolinealidad, esto ocurre cuando las variables independientes del modelo están altamente correlacionadas entre sí, y la heterocedasticidad, esto se presenta cuando la varianza del error del modelo no es constante. Estos problemas se analizan con el fin de obtener estimadores insesgados y eficientes según Gauss-Markov. A continuación, se presenta la ecuación de segundo modelo planteado.

$$
\begin{aligned}
\text { Ineficiencia }_{\text {it }}= & \alpha_{1} \text { Conx }_{\text {Act }} \text { Micro } \\
& +\alpha_{2} \text { Agua }_{\text {no }_{\text {facturada }}}+\alpha_{3} \text { Trat }_{\text {AR }}+\alpha_{4} \text { Cobert }_{\text {Agua }}+\alpha_{5} \text { Cobert }_{\text {Alcan }}+ \\
& \alpha_{6} \text { SPI }_{\text {dic__ } 12 m}+ \\
& \alpha_{7} \text { Altitud }_{\text {provincial }}+e_{i t}(\mathrm{v})
\end{aligned}
$$

Donde Ineficiencia representa la ineficiencia en costos de la EPS y $e_{i t}$, el residuo del modelo planteado. Las demás variables explicativas serán presentadas en la Tabla 3.

Finalmente, en la tercera etapa de análisis se desarrolló un modelo de regresión lineal simple que explica el costo medio $(c)$, definido como el costo operativo por volumen producido, en función de la producción, definida como el volumen de producción total, siguiendo la siguiente especificación:

$$
c=f(\mathbf{Y})+w_{i t} \rightarrow \text { Costo_X_Vol } \boldsymbol{I}_{\boldsymbol{i t}}=\alpha_{1} \text { Vol_Prod_m } 3_{i t}+w_{i t}(\mathrm{vi})
$$

\section{Tipo de investigación}

El tipo de investigación es del tipo cuantitativa, ya que se analiza datos anuales de las 44 EPS en cada variable mencionada, y además es explicativa para encontrar la relación profunda entre las variables (Larios, González y Álvarez, 2016).

\footnotetext{
${ }^{29}$ Ver Marco Teórico (pág. 30)
} 


\section{Diseño de investigación}

El diseño de la investigación es no experimental, dado que la data y los resultados no se obtiene por experimentos sino más bien se utilizan fuentes secundarias (Larios, González y Álvarez, 2016).

\section{Variables}

El modelo a seguir en (i), (ii) y (iv) utiliza las siguientes variables para la estimación de frontera de costos y para explicar la ineficiencia en costos.

\section{Tabla 2}

Variables de la función de costos y frontera de costos

\begin{tabular}{|c|c|c|c|c|c|}
\hline Tipo & Vector & Variable & $\begin{array}{c}\text { Variable } \\
\text { Operacional } \\
\text { Stata }\end{array}$ & Descripción & $\begin{array}{c}\text { Autor } \\
\text { precedente }\end{array}$ \\
\hline Costo & $\begin{array}{c}\text { Variable } \\
\text { explicada }\end{array}$ & Costo total & Costo_X_Vol_T & Costo operativo total (S/) & $\begin{array}{c}\text { Faust y Baranzini } \\
(2014)\end{array}$ \\
\hline \multirow[t]{3}{*}{ Insumos } & Vector (I) & Trabajo & $\begin{array}{c}\text { N_trabajadores } \\
\text { tot }\end{array}$ & Número de trabajadores totales & $\begin{array}{c}\text { Faust y Baranzini } \\
(2014)\end{array}$ \\
\hline & Vector (I) & Capital & Conex_Agua & Número de conexiones totales de agua & $\begin{array}{c}\text { Urrunaga y Jara } \\
(2013)\end{array}$ \\
\hline & Vector $(p)$ & $\begin{array}{l}\text { Costo de la } \\
\text { energía }\end{array}$ & Energía_T & Costo en energía total (S/) & $\begin{array}{c}\text { Faust y Baranzini } \\
(2014)\end{array}$ \\
\hline Producto & $\begin{array}{l}\text { Vector } \\
\text { (Y) }\end{array}$ & $\begin{array}{c}\text { Volumen } \\
\text { Producido Total }\end{array}$ & Vol_Prod_m3 & Volumen producido total $\left(\mathrm{m}^{3}\right)$ & $\begin{array}{c}\text { Bonifaz e Itakura } \\
(2014)\end{array}$ \\
\hline \multirow[t]{2}{*}{$\begin{array}{l}\text { Ambientales } \\
\text { (de control) }\end{array}$} & $\begin{array}{l}\text { Vector } \\
(Z)\end{array}$ & Consumo 30 & $\begin{array}{l}\text { Vol_Fac_Unit_ } \\
\text { M3 }\end{array}$ & $\begin{array}{l}\text { Volumen facturado/365/Población } \\
\text { efectivamente servida promedio con } \\
\text { conexiones activas. Volumen facturado } \\
\text { unitario ( } \mathrm{m}^{3} \text { por habitante al día) }\end{array}$ & $\begin{array}{c}\text { Romero y Ferro } \\
(2007)\end{array}$ \\
\hline & $\begin{array}{l}\text { Vector } \\
(\mathrm{Z})\end{array}$ & $\begin{array}{c}\text { \% Agua } \\
\text { Subterránea }\end{array}$ & Agua_Subt_ & $\begin{array}{l}\text { (\%) Volumen extraído de fuentes } \\
\text { subterráneas / Volumen producido total }\end{array}$ & $\begin{array}{c}\text { Romero y Ferro } \\
(2007)\end{array}$ \\
\hline
\end{tabular}

Nota: Estimación de la frontera de costos y determinantes de la función costos (i). Elaboración propia

El modelo a seguir en (iii) y (v) utiliza las siguientes variables para la estimación de frontera de costos variables y para explicar la ineficiencia en costos.

\section{Tabla 3}

Variables explicativas de la ineficiencia

\begin{tabular}{ccccc}
\hline Tipo & Variable & $\begin{array}{c}\text { Variable } \\
\text { Operacional } \\
\text { Stata }\end{array}$ & Descripción & $\begin{array}{c}\text { Autores } \\
\text { precedentes }\end{array}$ \\
$\begin{array}{c}\text { Explicativa } \\
\text { (vector E) }\end{array}$ & $\begin{array}{c}\text { \% Conexiones } \\
\text { activas con } \\
\text { micromedición }\end{array}$ & $\begin{array}{c}\text { Conx_Act_ } \\
\text { Micro }\end{array}$ & $\begin{array}{c}\text { Conexiones activas con micromedición (\%) } \\
\text { (Conexiones activas con medidor }\end{array}$ & $\begin{array}{c}\text { Romero y Ferro } \\
(2007) ; \text { Bonifaz e } \\
\text { Itakura (2014) }\end{array}$ \\
\hline
\end{tabular}

\footnotetext{
${ }^{30}$ Estos autores incluyen como variables ambientales a la población residente, al volumen despachado ( $\left.\mathrm{m}^{3} / \mathrm{día}\right)$ y a la densidad de la red; sin embargo, esta última requiere contar con la longitud total de la red, información que no se encuentra disponible para Perú, es por ello que con la información disponible se calculó un indicador que mida el consumo en función al volumen facturado ( $\mathrm{m}^{3} /$ día) por habitante, que capture las tres variables propuestas por Romero y Ferro (2007), si bien SUNASS calcula un indicador de consumo unitario medido el subregistro por año y EPS es alto, por la cual en esta investigación se consideró el indicador "Volumen Facturado Unitario" de SUNASS con insumo para la variable ambiental "Consumo".
} 


\begin{tabular}{|c|c|c|c|c|}
\hline Tipo & Variable & $\begin{array}{l}\text { Variable } \\
\text { Operacional } \\
\text { Stata }\end{array}$ & Descripción & $\begin{array}{l}\text { Autores } \\
\text { precedentes }\end{array}$ \\
\hline & $\begin{array}{l}\% \text { de pérdida de } \\
\text { agua }\end{array}$ & Agua_no_fact & $\begin{array}{l}\text { Agua No Facturada (\%) (Volumen producido- } \\
\text { Volumen facturado)/Volumen producido) }\end{array}$ & \\
\hline & $\begin{array}{l}\text { \% Tratamiento de } \\
\text { agua residual }\end{array}$ & Trat_A_R & $\begin{array}{l}\text { Tratamiento de Aguas Residuales (\%) } \\
\text { (Volumen tratado/Volumen recolectado) }\end{array}$ & \multirow{3}{*}{$\begin{array}{l}\text { Bonifaz e Itakura } \\
(2014)\end{array}$} \\
\hline & $\begin{array}{c}\% \text { de cobertura de } \\
\text { agua }\end{array}$ & Cobert_Agua & $\begin{array}{l}\text { Población servida con conexión domiciliaria } \\
\text { de agua potable sobre Población residente. }\end{array}$ & \\
\hline & $\begin{array}{l}\text { \% de cobertura de } \\
\text { alcantarillado }\end{array}$ & Cobert_Alcan & $\begin{array}{c}\text { Población servida con alcantarillado sanitario } \\
\text { sobre Población residente. }\end{array}$ & \\
\hline & $\begin{array}{l}\text { Índice de } \\
\text { Precipitación } \\
\text { Estandarizado }^{31}\end{array}$ & SPI_12m_dec & $\begin{array}{c}\text { Índice de precipitación estandarizado } \\
\text { departamental para los } 12 \text { últimos meses } \\
\text { (calculado en diciembre) }\end{array}$ & $\begin{array}{c}\text { Faust y } \\
\text { Baranzini (2014) }\end{array}$ \\
\hline & Altitud & Altitud_prov & $\begin{array}{l}\text { Altitud de la capital de la provincia en que se } \\
\text { encuentra la EPS (m.s.n.m) }\end{array}$ & $\begin{array}{c}\text { Faust y } \\
\text { Baranzini (2014) }\end{array}$ \\
\hline
\end{tabular}

Nota: Estimación de la ineficiencia de costos y sus determinantes (ii). Elaboración propia

Finalmente, el modelo a seguir en (vi) para el estudio de las economías de escala utiliza como variable explicativa al costo medio $(c)$, definido como el costo operativo por volumen producido, y la producción (Y), definida como el volumen de producción total.

\section{Muestra}

El estudio analiza data panel para el periodo 2008-2016, de frecuencia anual para 44 $E S^{32}$, el alcance geográfico de estudio se limita al Perú y a la zona urbana. La elección de la muestra se basó en que estas comparten ciertas características que generan una posibilidad de comparación relativa en una misma frontera de eficiente, estas principalmente son: 1) el tipo de régimen estatal involucrado (municipal), 2) las restricciones presupuestarias y 3) el tamaño de las empresas. Los estudios anteriores demuestran que existen dos problemas al utilizar la metodología de frontera estocástica los cuales están relacionadas al número de variables usadas en el cálculo y la presencia de valores extremos. Por las razones descritas, para esta investigación no se incluyó en el análisis a las empresas proveedoras de agua SEDAPAL, por ser contar con el ámbito geográfico más grande del país provee valores atípicos que podrían distorsionar nuestro análisis, del mismo modo ATUSA, por haber tenido un régimen privado durante el periodo de estudio.

\section{Instrumentos de investigación}

Entre los instrumentos de investigación a usar se encuentran observaciones de series de tiempo de datos procesados por la SUNASS y el Ministerio de Vivienda Construcción y

\footnotetext{
${ }^{31}$ Es un índice para evaluar el estado de sequía o exceso de lluvia definido por la Organización Meteorológica Mundial (OMM). Valores altos del SPI están asociados con épocas muy húmedas mientras que valores bajos indican sequía. 3248 EPS son el universo de las EPS de administración pública municipal (no incluye SEDAPAL ni la Empresa de Agua Potable y Alcantarillado de Tumbes-ATUSA), aun cuando ATUSA en septiembre del 2018 terminó contrato de concesión no ha sido incluida en el análisis. ${ }^{32}$ Se excluyeron del total de EPS municipales las siguientes entidades: EMSA PUNO S.A., EMSAP CHANKA S.C.R.L., EMSAPA CALCA S.R.L. y AGUAS DEL ALTIPLANO S.R.L.
} 
Saneamiento relacionadas con el sector, así como, datos históricos de las precipitaciones del Servicio Nacional de Meteorología e Hidrología del Perú - SENAMHI (mediante su base de datos PISCO) y del Instituto Nacional de Estadística e Informática - INEI, del mismo modo, también se utilizaron los antecedentes anteriormente mencionados.

\section{Procedimientos}

Se utilizó información secundaria provista por la Superintendencia Nacional de Agua y Saneamiento - SUNASS, en el marco de la Ley de Transparencia de Información. En particular las variables relacionadas a la gestión de las EPS utilizadas en la metodología pertenecen a indicadores de gestión auto-reportados por las EPS al órgano regulador ${ }^{33}$. Por otro lado, como fuente de información también se encuentra el INEI (2014) para la segmentación de geográfica de las EPS que permitan identificar a estos proveedores según la altitud de la provincia y las lluvias presentadas en sus departamentos, de acuerdo al índice estandarizado del SENAMHI (2019) por departamento.

Para la estimación del modelo de datos panel planteado utilizaremos el programa estadístico STATA 14, porque este programa cuenta con diversos paquetes estadísticos para el análisis de datos y para la estructura de tipo datos de panel para fronteras de eficiencia estocásticas (Belotti, Daidone, llardi, \& Atella, 2013) ${ }^{34}$ definidas en el marco teórico. Para efectos prácticos se utilizó el mismo programa estadístico para las regresiones lineales de la segunda y tercera etapa metodológica.

\footnotetext{
${ }^{33}$ En el Anexo 9, se lista los indicadores de gestión solicitados por SUNASS a las EPS, lamentablemente existe un subregistro de información.

${ }^{34}$ La última versión del paquete "Stochastic frontier models for panel data" fue creado por Federico Belotti, Silvio Daidone, Giuseppe Ilardi y Vincenzo Atella, inició su distribución el 22 de mayo del 2015; asimismo, este paquete se adapta a modelos fijos o variantes en el tiempo.
} 


\section{Resultados}

\section{Presentación de resultados}

A continuación se presenta la estimación del modelo de datos de panel planteado mediante un modelo de efectos fijos usando el paquete "Stochastic frontier models for panel data" de Stata 14 antes mencionado.

\section{Tabla 4}

Estimación del modelo panel de efectos fijos de fronteras estocásticas

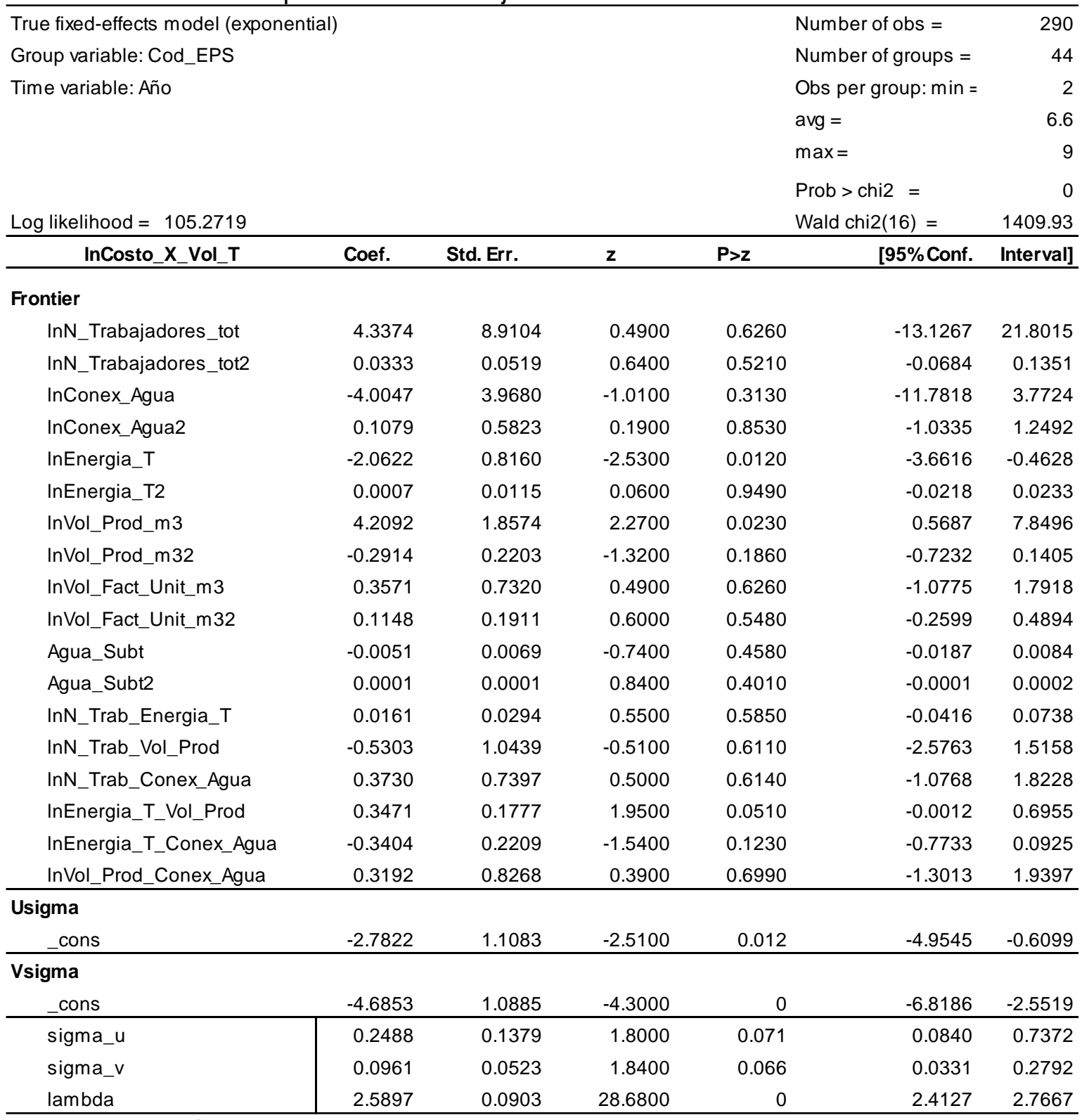

Nota: Elaboración Propia

La estimación realizada anteriormente nos permite cuantificar el impacto que tienen las variables explicativas y de control sobre la variable dependiente mediante ecuacion de forma trans-logaritmica, cuya especificacion es mejor que la Coob-Douglas debido a que 
presenta menor criterio de informacion de Akaike y ademas presenta un mayor $\mathrm{R}$ cuadrado $^{35}$. La estimación realizada anteriormente nos permite cuantificar el impacto que tienen las variables explicativas y de control sobre la variable dependiente. Estas variables independientes representan factores asociados a la función de costos de EPS, cabe mencionar que la variable dependiente hace referencia a los costos operativos totales (S/).

Respecto a la significancia global, se cumple la significancia conjunta o del modelo (ver sección Metodología) que explica los costos operativos totales, debido a que el valor de la probabilidad $\mathrm{Chi}^{2}(0.0000)$ es menor al valor de significancia (0.05). Este resultado nos permite rechazar la hipótesis nula, que nos indica que el vector de coeficientes es igual a cero, y aceptar la hipótesis alternativa en la cual este vector es diferente de cero.

Se cumple la significancia individual para las variables explicativas: "costo de la energía" y "volumen producido de agua potable", al $5 \%$ de nivel de significancia. Esto se cumple debido a que los estimadores analizados son diferentes de cero; esto se concluyó mediante el análisis de la prueba "z" debido a que los valores de estas probabilidades son menores al valor de significancia asumida (0.05) y, por ello, rechazamos las hipótesis nulas de que los estimadores, de las variables en mención, sean iguales a "0". Sin embargo, en el caso de las variables explicativas "número de trabajadores" y "conexiones de agua" no se cumple la significancia al $5 \%$, esto debido a que los valores de sus probabilidades son: 0.626 y 0.313 respectivamente, siendo estos mayores a 0.05 .

Por su parte, de la revisión a los resultados de los estimadores de las variables de control o ambientales que afectarían al costo operativo, se puede observar (Tabla 4) que el consumo de agua potable y el porcentaje de agua extraída de la fuente subterránea no cumplen la significancia individual para explicar los costos operativos totales de las EPS al $5 \%$ de nivel de significancia.

Asimismo, el modelo de panel de efectos fijos de frontera estocástica permitió estimar la ineficiencia en costos de las EPS, como componente externo de la función de costos mencionada, según las ecuaciones (ii) y (iii) de la sección metodología y Usigma de la Tabla 4; la Tabla 5 muestra en un listado de los valores promedios, mínimos y máximos de la ineficiencia en costos (como porcentaje de desviación de la frontera) según cada EPS.

\footnotetext{
${ }^{35}$ Ver Anexo 10 para la comparación de criterios de información de estas dos formas funcionales.
} 
Tabla 5

Estadísticos de la inficiencia en costos según las EPS

\begin{tabular}{|c|c|c|c|}
\hline EPS & Promedio & Mínimo & Máximo \\
\hline EMAPA Y S.R.L. & $33.00 \%$ & $6.29 \%$ & $72.88 \%$ \\
\hline EPS ILO S.A. & $28.62 \%$ & $5.64 \%$ & $109.41 \%$ \\
\hline SEMAPACH S.A. & $27.23 \%$ & $3.21 \%$ & $67.15 \%$ \\
\hline EMAPA PASCO S.A. & $26.97 \%$ & $5.93 \%$ & $89.97 \%$ \\
\hline SEMAPA BARRANCAS.A. & $26.94 \%$ & $5.84 \%$ & $65.72 \%$ \\
\hline EMPSSAPAL S.A. & $25.93 \%$ & $6.37 \%$ & $55.40 \%$ \\
\hline EMAPA HUACHO S.A. & $25.66 \%$ & $5.66 \%$ & $55.57 \%$ \\
\hline EPS MOQUEGUAS.A. & $25.58 \%$ & $5.14 \%$ & $70.29 \%$ \\
\hline EPS NOR PUNO S.A. & $25.29 \%$ & $5.25 \%$ & $84.13 \%$ \\
\hline EMAPAT S.R.L. & $25.25 \%$ & $6.85 \%$ & $48.05 \%$ \\
\hline EPS MANTARO S.A. & $23.07 \%$ & $6.46 \%$ & $56.70 \%$ \\
\hline EMAPACOP S.A. & $22.62 \%$ & $6.19 \%$ & $57.27 \%$ \\
\hline EMAPA MOYOBAMBA S.R.L. & $21.32 \%$ & $4.01 \%$ & $49.89 \%$ \\
\hline SEDAPAR S.R.L. (Rioja) & $20.88 \%$ & $8.52 \%$ & $44.47 \%$ \\
\hline EPSSMU S.R.L. & $20.41 \%$ & $6.70 \%$ & $74.25 \%$ \\
\hline EMUSAP S.R.L. & $19.33 \%$ & $4.65 \%$ & $47.64 \%$ \\
\hline EPS SELVA CENTRAL S.A. & $19.30 \%$ & $6.69 \%$ & $40.58 \%$ \\
\hline SEDALIB S.A. & $18.39 \%$ & $4.92 \%$ & $32.34 \%$ \\
\hline EMAPA HUANCAVELICA S.A.C & $18.18 \%$ & $5.59 \%$ & $32.33 \%$ \\
\hline EPS TACNAS.A. & $18.18 \%$ & $6.81 \%$ & $45.34 \%$ \\
\hline SEDACUSCO S.A. & $17.75 \%$ & $5.81 \%$ & $58.16 \%$ \\
\hline EPSEL S.A. & $17.45 \%$ & $5.79 \%$ & $37.77 \%$ \\
\hline EPS SEDALORETO S.A. & $17.37 \%$ & $5.48 \%$ & $32.28 \%$ \\
\hline SEDAHUANUCO S.A. & $17.34 \%$ & $5.45 \%$ & $28.29 \%$ \\
\hline EPS MARAÑON S.R.L. & $16.97 \%$ & $6.03 \%$ & $30.78 \%$ \\
\hline EPS SIERRA CENTRAL S.R.L. & $16.32 \%$ & $6.73 \%$ & $39.82 \%$ \\
\hline EMSAPA YAULI S.R.L & $15.75 \%$ & $6.12 \%$ & $35.53 \%$ \\
\hline SEDACAJ S.A. & $15.69 \%$ & $5.29 \%$ & $25.07 \%$ \\
\hline EPS GRAU S.A. & $15.55 \%$ & $5.80 \%$ & $39.43 \%$ \\
\hline EMAPA HUARAL S.A. & $15.16 \%$ & $7.78 \%$ & $28.17 \%$ \\
\hline EMAPISCO S.A. & $13.69 \%$ & $4.79 \%$ & $24.68 \%$ \\
\hline EMUSAP ABANCAY S.A.C. & $13.40 \%$ & $7.13 \%$ & $20.50 \%$ \\
\hline EMAQ S.R.L. & $13.27 \%$ & $6.82 \%$ & $23.28 \%$ \\
\hline EPS CHAVIN S.A. & $13.22 \%$ & $8.41 \%$ & $20.43 \%$ \\
\hline EMAPAB S.R.L. & $13.18 \%$ & $6.87 \%$ & $18.77 \%$ \\
\hline SEDAM HUANCAYO S.A.C & $13.17 \%$ & $8.36 \%$ & $18.20 \%$ \\
\hline SEDAPAR S.A. & $13.07 \%$ & $4.48 \%$ & $25.55 \%$ \\
\hline EMAPA SAN MARTIN S.A. & $12.95 \%$ & $11.68 \%$ & $14.22 \%$ \\
\hline EMAPICAS.A. & $12.46 \%$ & $6.32 \%$ & $20.94 \%$ \\
\hline SEDACHIMBOTE S.A. & $11.82 \%$ & $8.18 \%$ & $16.35 \%$ \\
\hline SEDA AYACUCHO S.A. & $11.53 \%$ & $7.23 \%$ & $14.58 \%$ \\
\hline SEDAJULIACA S.A. & $10.79 \%$ & $8.33 \%$ & $13.67 \%$ \\
\hline EMAPAVIGS S.A.C. & $10.75 \%$ & $9.04 \%$ & $12.45 \%$ \\
\hline EMAPA CAÑETE S.A. & $10.49 \%$ & $7.91 \%$ & $11.58 \%$ \\
\hline
\end{tabular}

Nota: Elaboración Propia

Según esta tabla podemos resaltar que existe una mayor ineficiencia en costos, en promedio, en EMAPA Yunguyo S.R.L., y como menor ineficiencia en la EPS EMAPA 
CAÑETE S.A. dentro del rango de años de análisis, cuyos grados de ineficiencia promedio fueron de $33 \%$ y $10.49 \%$, respectivamente. La siguiente figura representa de una manera más clara la situación de ineficiencia para las 44 empresas, definida a través de la ineficiencia promedio calculada.

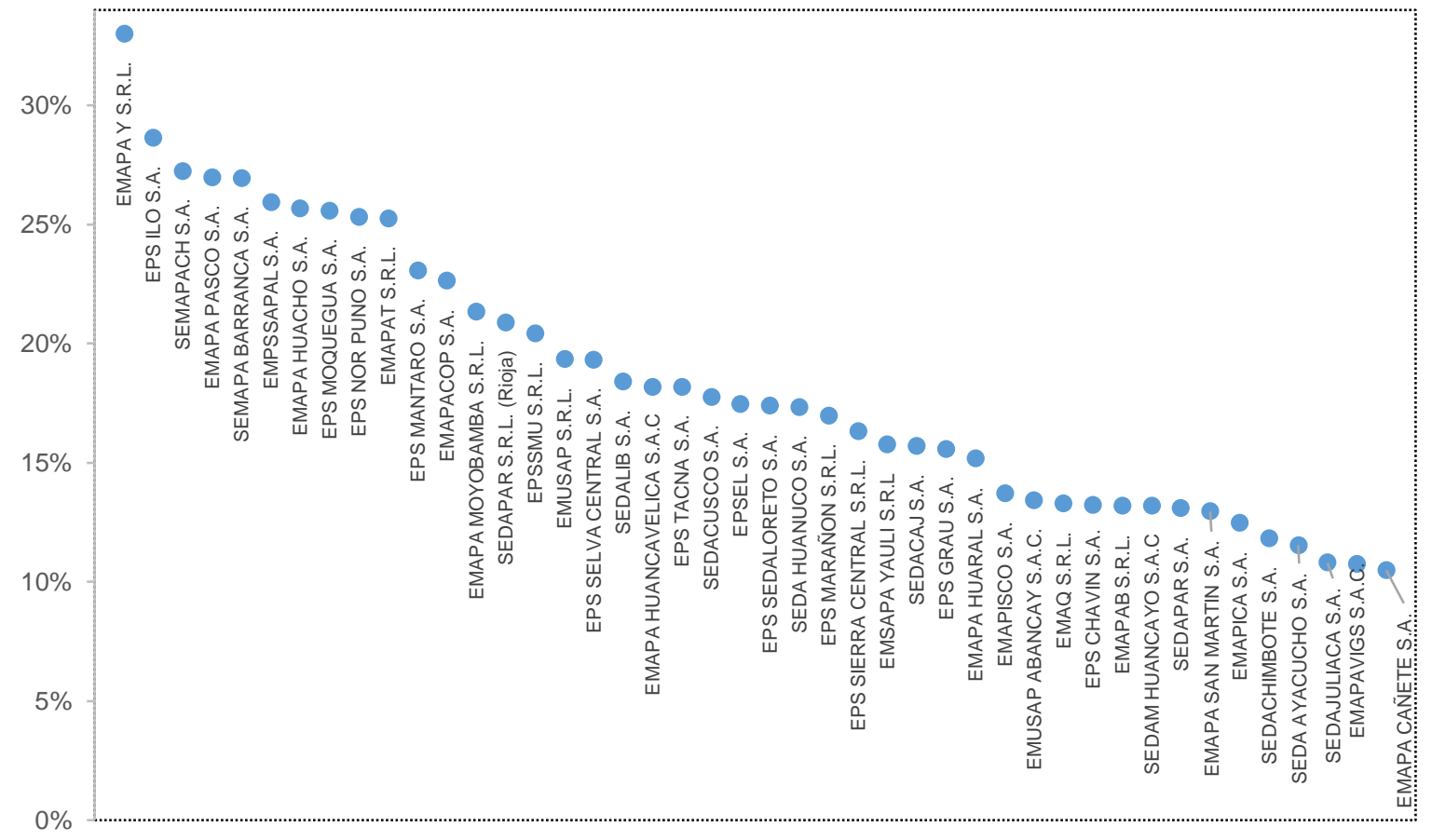

Figura 9. Ineficiencia promedio de costos de las EPS. Elaboración Propia

La siguiente Figura muestra la evolución del grado de ineficiencia en costos (en promedio), entendida como la desviación de la frontera eficiente calculada, de las EPS durante el periodo 2008 al 2016.

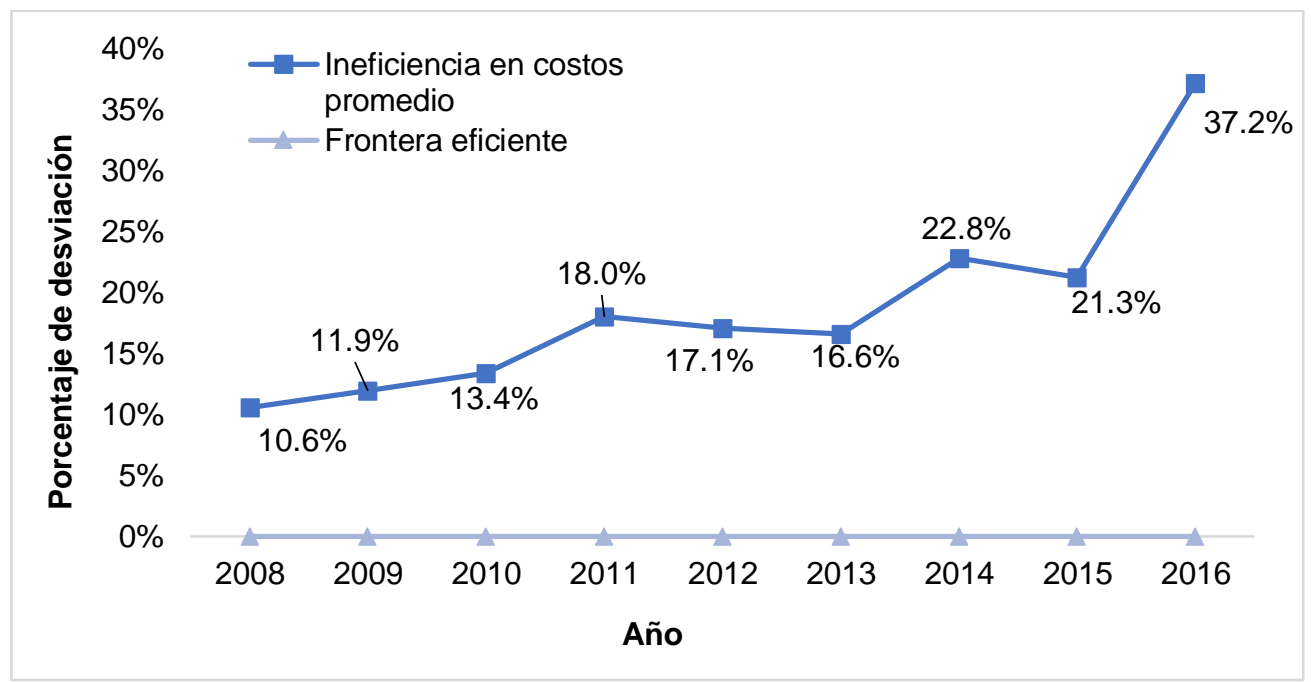

Figura 10. Ineficiencia promedio de costos de las EPS, 2008-2016. Elaboración Propia 
Como podemos observar del año 2008 al 2010 la ineficiencia promedio se incrementó en $3 \%$ aproximadamente, creciendo al mismo ritmo anualmente, para el año 2011, se incrementó en 5\% solamente en un año, para luego tener una caída poco significativa, consecutiva anual hasta el año 2013, alcanzando un nivel de $16.6 \%$. Posteriormente, en el 2014 se registró un significativo incremento hasta llegar a $22.8 \%$, el cual a pesar que durante el 2015 cayó 1.5 punto porcentuales, al 2016 habría llegado a su pico en 8 años con un nivel de $37.2 \%$ de ineficiencia de costos en promedio anual.

Asimismo, de un análisis de histogramas, paradójicamente la distribucion de la ineficiencia en costos de las EPS es asimétrica negativa (la media, valor promedio, es menor a la mediana de esta variable), por lo que menores grados de ineficiencia concentran mayor frecuencia o densidad de EPS.

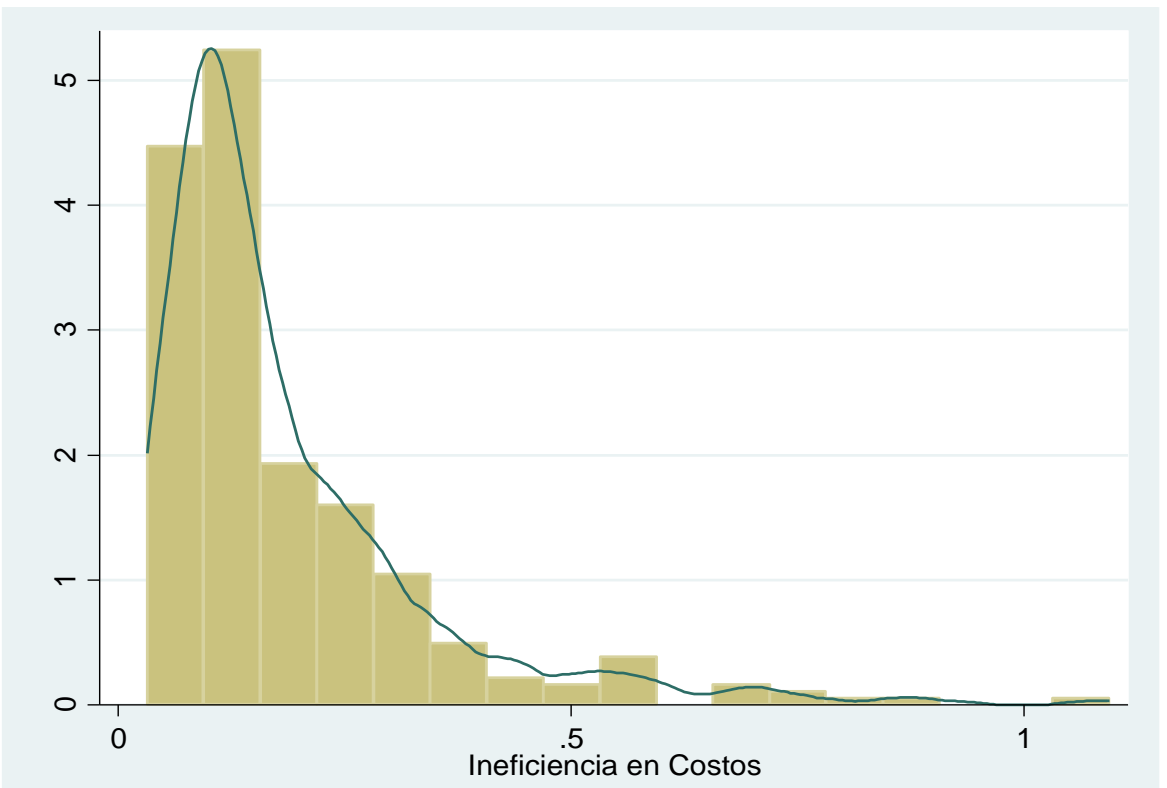

Figura 11. Histograma de la ineficiencia en costos de las EPS. Elaboración Propia

Por otro lado, siguiendo a la descripción metodológica expuesta en la anterior sección, durante una segunda etapa se realizó la estimación de Mínimos Cuadrados Ordinarios tomando en cuenta como variable dependiente la ineficiencia en costos de las EPS asociadas a potenciales factores determinantes (variables ambientales recogidas de los antecedentes previos). En primer lugar, se hizo un análisis de multicolinealidad, se encontró que los valores del VIF eran menores a 10, asimismo, se hizo un test para detectar heterocedasticidad mediante la prueba de White, la cual debido a que la probabilidad $\mathrm{Chi}^{2}$ resultante es mayor a 0.05 , con lo cual no se rechaza la hipotesis nula de homocedasticidad $^{36}$.

\footnotetext{
${ }^{36}$ Los resultados de estas pruebas, de multicolinealidad y heterocedasticidad, se encuentran en el Anexo 10.
} 
Tabla 6

Estimación del modelo lineal múltiple de Ineficiencia en Costos

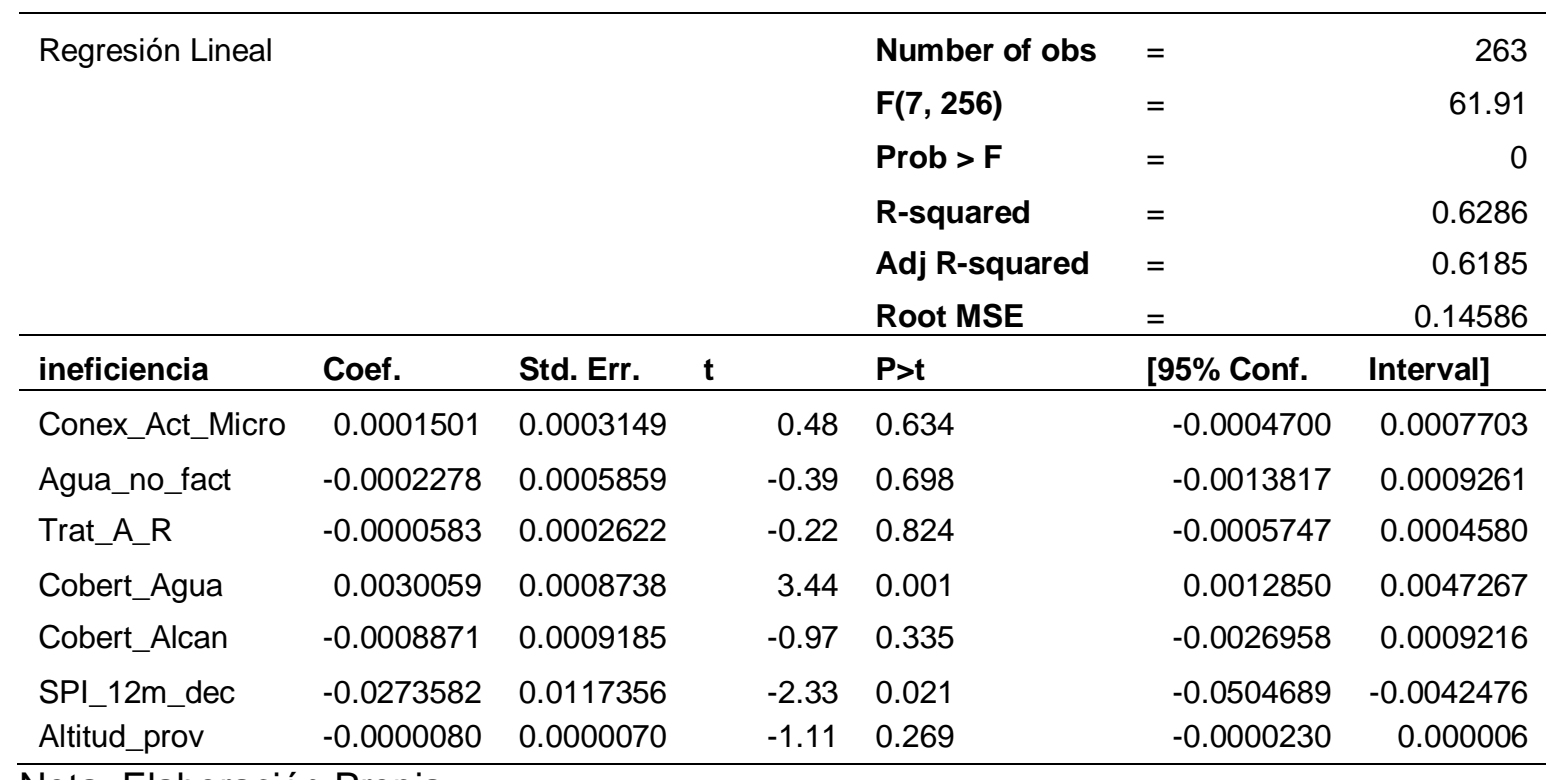

Nota: Elaboración Propia

Entre los resultados de las estimación de la ineficiencia en costos se encontró lo siguiente:

- Según el coeficiente de determinación, R cuadrado, las variables independientes en conjuntos explican en $62.86 \%$ la variabilidad de la variable dependiente.

- La significancia del modelo se cumple en este modelo estimado debido a que el valor de la probabilidad $F(0.0000)$ es menor al valor de significancia (0.05). Esto nos permite rechazar la hipótesis nula, vector de coeficientes igual a cero, y aceptar la hipótesis alterna.

- A un nivel de significancia del 5\%, las variable explicativas "Cobertura del agua potable" (Cobert_Agua) y “Índice estandarizado de precipitaciones" (SPI_12m_dec) son signficativos, debido a que los valores de la probabilidad t son menores al valor de significancia (0.05). En caso de las otras variables independientes, las variales explicativas "Conexiones activas con micromedición" (Conex_Act_Micro), "Agua No Facturada" (Agua_no_fact), "Tramiento de Aguas Residuales" (Trat_A_R), "Cobertura de alcantarillado" (Cobert_Alcan) y "Altitud" (Altitud_prov), no se cumple debido aque sus probabilidades t son mayores al nivel de significancia mencionado.

Para poder observar la relación de la ineficiencia en costos con las dos variables significativas (cobertura de agua y el índice estandarizado de precipitaciones) se muestra la dispersión de las 44 EPS comparativamente entre la ineficiencia en costos y las dos variables ambientales signficativas. De acuerdo a nuestros resultados, incrementos en cobertura podrían generar incrementos en la ineficiencia de costos, así como, incrementos 
en el índice de precipitación (ubicación geográfica más húmeda) estarían asociados a menores niveles de ineficiencia.

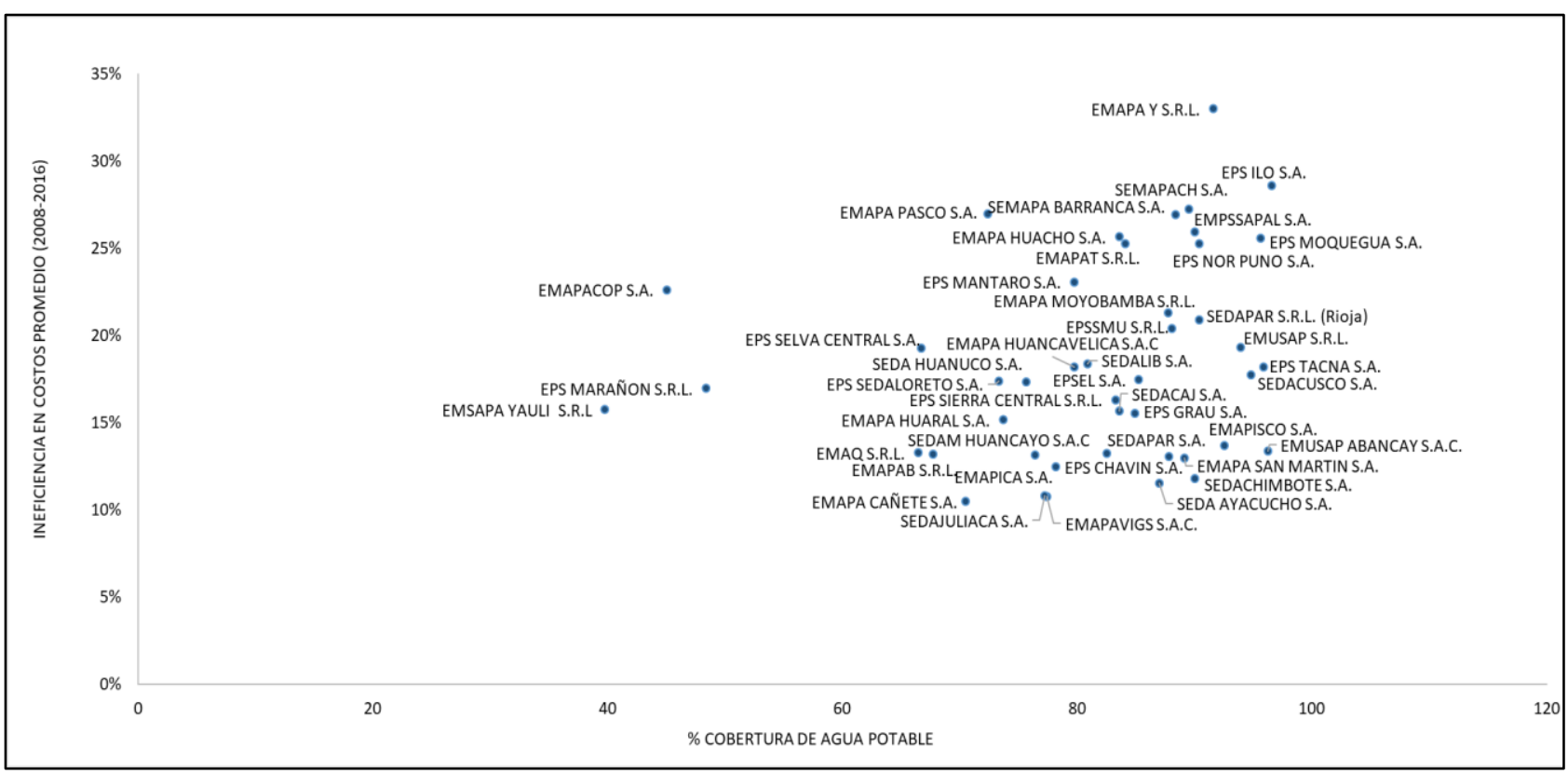

Figura 12. Gráfico de dispersión de la "Ineficiencia en costos" y la "Cobertura de agua". Elaboración Propia

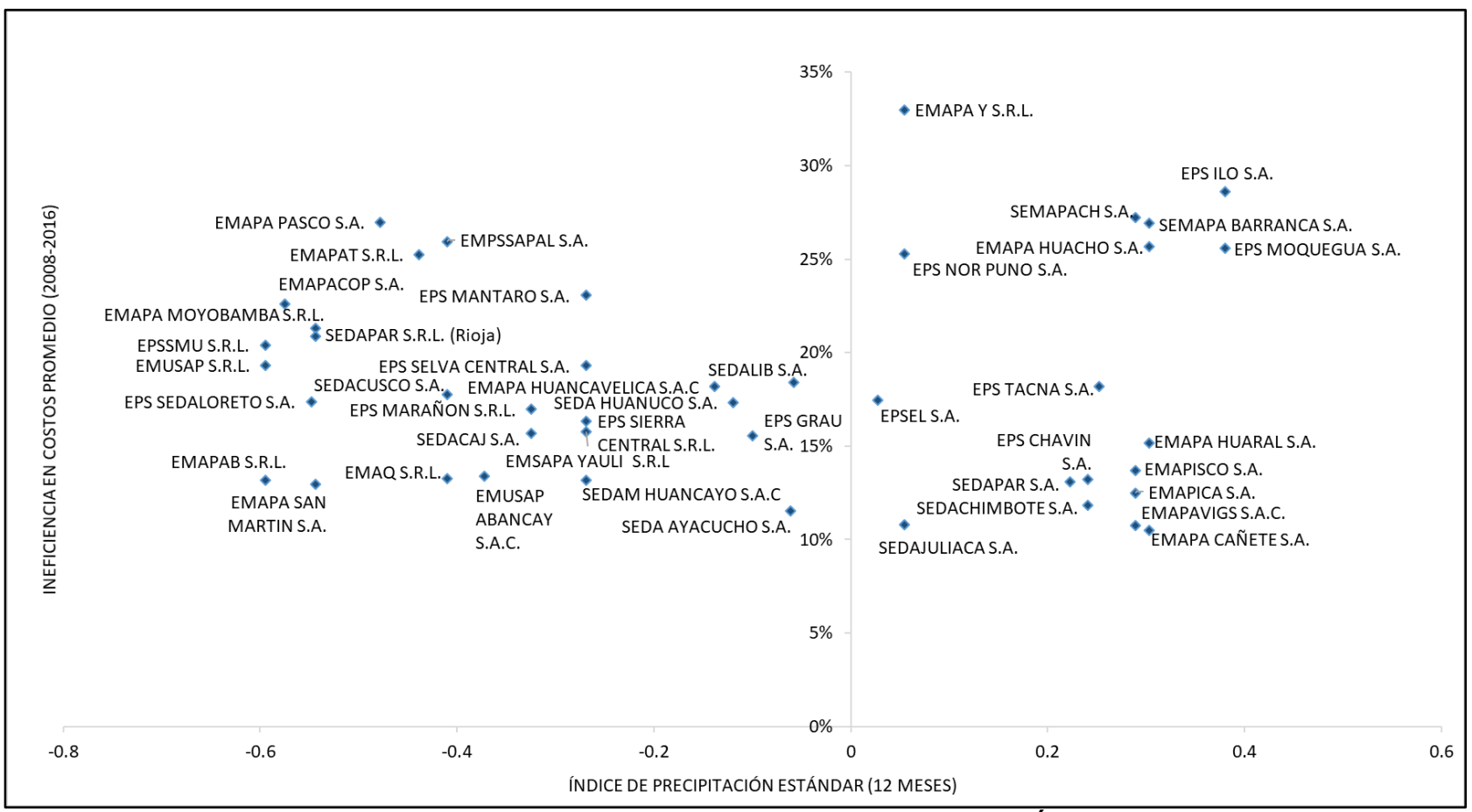

Figura 13. Gráfico de dispersión de la "Ineficiencia en costos" y el "Índice de precipitación estándar". Elaboración Propia

Asimismo, a pesar que la altitud geográfica no resultó ser significativapara explicar la ineficiencia en costos, en la siguiente figura se muestra la dispersión de las 44 EPS 
comparativamente entre estas dos variables, como podemos observar no existiría una relación clara entre la altitud geográfica en que se encuentra la EPS y la ineficiencia en costos que esta presenta.

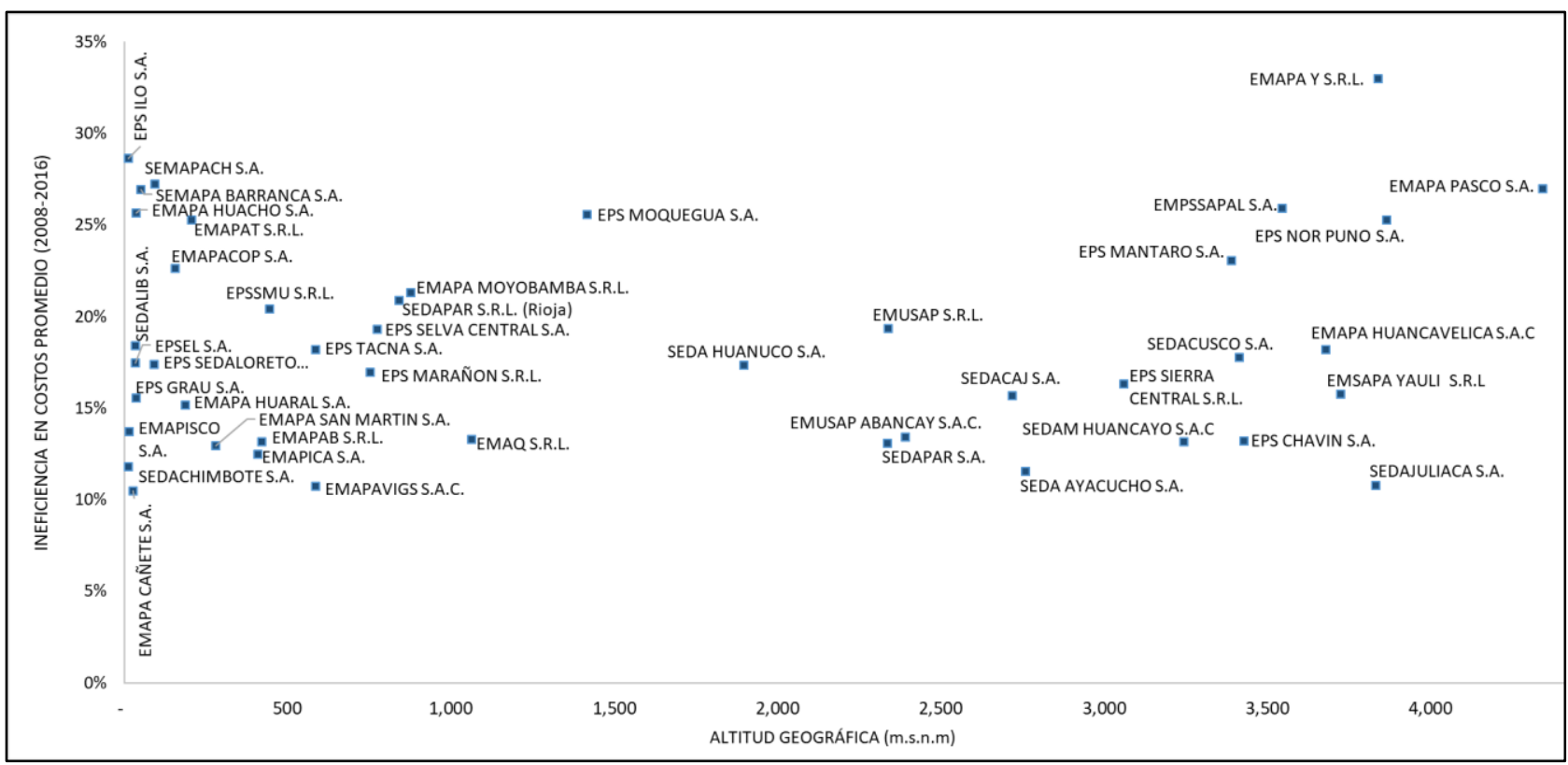

Figura 14. Gráfico de dispersión de la "Ineficiencia en costos" y la "Altitud geográfica". Elaboración Propia

A continuación se presenta la matriz de correlación de las variables que afectarían la ineficiencia en costos, conexiones activas con micromedición, agua no facturada, tratamiento de aguas residuales, cobertura de alcantarillado, índice de precipitación estandarizada y la altitud.

Tabla 7

Matriz de correlación de Pearson (factores de ineficiencia)

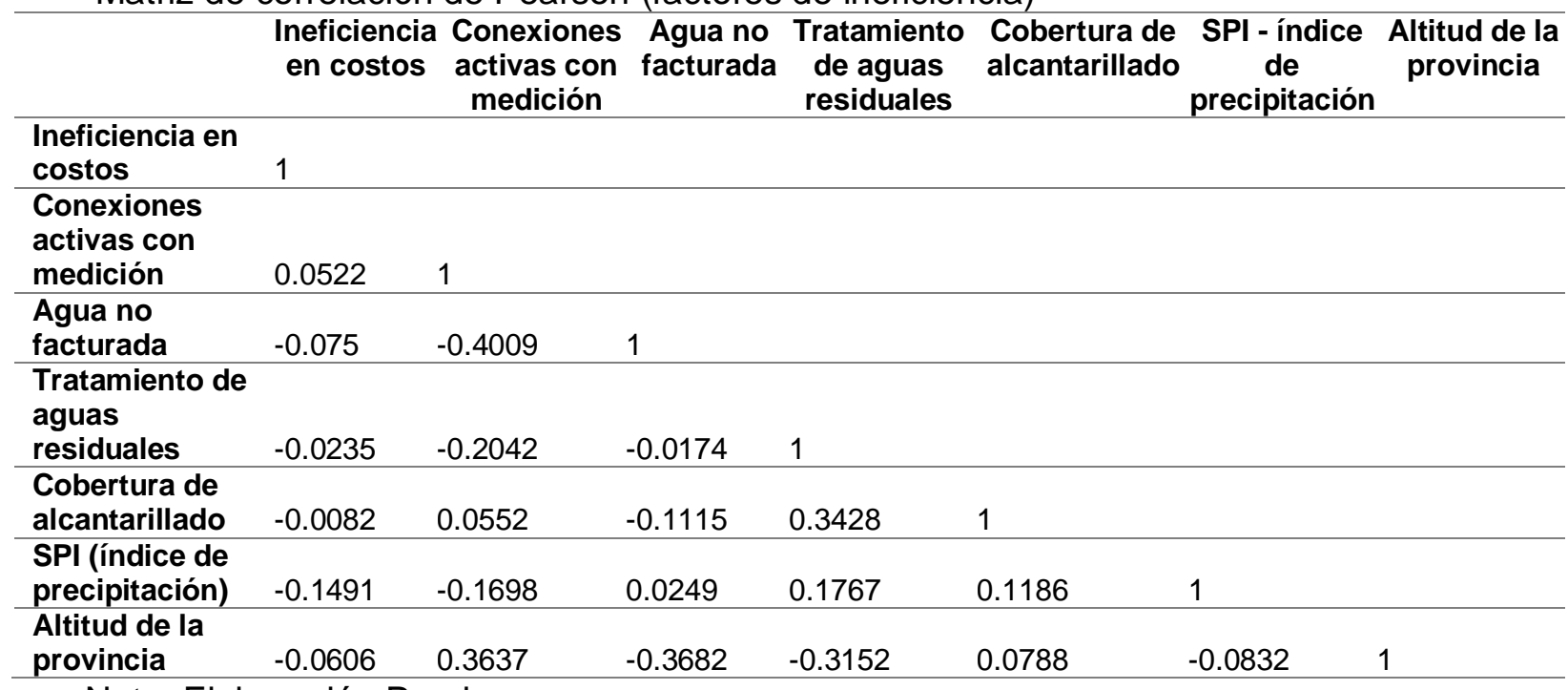

Nota: Elaboración Propia 
Como podemos observar en la matriz de correlación, la primera columna muestra cómo se correlacionan las conexiones activas con micromedición, agua no facturada, tratamiento de aguas residuales, cobertura de alcantarillado, el índice de precipitación estandarizado y la altitud geográfica respecto a la ineficiencia en costos, y que dicha correlación se da en $0.0522,-0.0750,-0.0235,-0.0082,-0.1491$ y -0.0606 , respectivamente. De estos resultados, se pueden inferir que existe correlación entre las variables debido a que esta correlación es distinta a cero.

Centrándonos en la relación signficativamente negativa de la variable ambiental "SPIÍndice de Precipitación Estándar" y la "ineficiencia en costos", los hallazgos indicarían que una reducción de las precipitaciones incrementaría la ineficiencia en costos de las proveedores de agua potable (EPS), esta influencia se explicaría en la disponibilidad de agua, cuánta más lluvia exista en una ciudad, la cuenca hidrográfica de la misma tendrá mayor disponibilidad de agua superficial que podría ser tratada por las EPS para luego ser distribuida como agua potable, la existencia de lluvias favorecería, entonces, a la gestión de las EPS toda vez que simplifica los procedimientos de extracción, dado que la extracción de agua subterránea o la extracción de una fuente lejana a la planta de tratamiento, sería mucho más costosa .

Si bien es cierto, precipitaciones extremas podrían asociarse a un deterioro de la calidad de agua, por el flujo de residuos contaminantes que serían arrastrados con las lluvias, que incrementaría el costo de tratamiento (Faust y Baranzini, 2014), consideramos que esto podría ser cierto para temporadas muy extremas; sin embargo, para el periodo estudiado (2008-2016) el índice de precipitación estandarizado nos señala que la presencia de lluvias y/o sequías (cada 12 meses) en el Perú no presenta niveles anormales sino por el contrario bastantes neutrales (rango +/-1), esto explicaría por qué según nuestros resultados, la presencia de lluvias no está asociada con incrementos a los costos de las EPS.

Por otro lado, se analizó la relación de la ineficiencia en costos y la cobertura de agua, particularmente, bajo dos enfoques: de dependencia y correlación. Para evaluar la depedendencia se utilizó la prueba de Spearman, como se puede ver en la Tabla 8 , podemos inferir que la ineficiencia y la cobertura del agua son dos variables dependientes entre sí. Es posible llegar a esta conclusión debido a que el valor de la probabilidad $t$ (0.0006) es menor al valor de significancia asumida (0.05), y esto nos permite rechazar la hipótesis nula de independencia. 


\section{Tabla 8}

Prueba de Spearman

Number of obs $=290$

Spearman's rho $=0.2009$

Test of Ho: Cobert_Agua and ineficiencia are independent

Prob $>\mathrm{t}=0.0006$

Nota: Elaboración Propia

Posteriormente, se calculó la magnitud de la relación entre la variable ineficiencia en costos y la cobertura de agua potable mediante una matriz de correlación, los resultados muestran que la magnitud de relación entre estas dos variables analizadas se da en 0.1219 , siendo esta relación positiva (directamente proporcional), como se puede ver en la Tabla 9.

\section{Tabla 9}

Matriz de correlación de Pearson Cobertura de agua e Ineficiencia

\begin{tabular}{lll}
\hline & Cobertura de agua & Ineficiencia en costos \\
\hline Cobertura de agua & 1 & 0.1219 \\
\hline Ineficiencia en costos & 0.1219 & 1
\end{tabular}

Nota: Elaboración Propia

Por otro lado, con el fin de analizar la posición de las economías de las EPS se realizó la estimación de un modelo de regresion lineal bivariado, donde la variable explicada es costo operativo por volumen producido (expresado en $\mathrm{S} / . / \mathrm{m}^{3}$ ), representando al costo medio, y la variable explicativa es el volumen producido total (expresado en $\mathrm{m}^{3}$ ). Asimismo, se verifica la homocedasticidad para obtener estimadores eficientes, según los resultados de los test (ver Anexo 10) se puede descartar heterocedasticidad debido a que la probabilidad $\mathrm{Chi}^{2}(0.3743)$ es mayor a la significancia de $5 \%$, y esto nos permite no rechazar la hipótesis nula de homoscedasticidad. El Anexo 11 describe teóricamente las economía de escala. La siguiente tabla muestra los resultados de esta estimación.

\section{Tabla 10}

Estimación del modelo lineal múltiple de Costo Operativo medio

\begin{tabular}{|c|c|c|c|c|c|c|}
\hline Regresión Lineal & & & & & $\begin{array}{l}\text { Number of obs } \\
\text { F(1, 503) } \\
\text { Prob > F } \\
\text { R-squared } \\
\text { Adj R-squared } \\
\text { Root MSE } \\
\end{array}$ & $\begin{array}{l}=505 \\
=27.84 \\
=0 \\
=0.0525 \\
=0.0506 \\
=0.50677\end{array}$ \\
\hline Costo_Op_x_Vol_Prod & Coef. & Std. Err. & $\mathbf{t}$ & $P>t$ & [95\% Conf. & Interval] \\
\hline Vol_Prod_m3 & 0.000000007 & 0.000000001 & 5.28 & 0.00 & 0.000000005 & 0.000000010 \\
\hline cons & 0.831699900 & 0.029070400 & 28.61 & 0.00 & 0.774585500 & 0.888814400 \\
\hline
\end{tabular}

Nota: Elaboración propia

Según los resultados mostrados podemos destacar que la variable explicativa impacta significativamente, probabilidad $t$ mayor a la significancia, y en una magnitud de 
0.00000000734 sobre dichos costos operativos unitarios. Asimismo, dicho impacto es mayor a cero, estimador positivo, y esto nos permite concluir que incrementos en el volumen de producción incrementa el costo medio (costos operativos por volumen producido) de la industria, por lo que no hay economías de escala en las EPS. Por lo tanto, se concluye que las EPS se encuentran en una etapa de deseconomías de escala, podría ser cuestionable el hecho de tener un estimador cercano a cero; sin embargo, teniendo en cuenta que nuestra explicada es un costo unitario se podría justificar su tamaño.

\section{Discusión}

De una revisión a los antecedentes y en comparación de estos con nuestros resultados, tenemos interesantes cuestiones que analizar. En primer lugar, Urrunaga y Jara (2013) concluyeron mediante la estimación de una frontera estocástica de costos con una forma funcional de Cobb Douglas para 37 EPS que las variables ambientales no aportan para explicar los costos, las variables explicativas asociadas a la calidad explican significativamente a la ineficiencia. Al respecto, esta investigación incrementaría el sustento empírico para incluir variables de calidad, como la cobertura de agua que resultó ser significativa al $5 \%$ para explicar la ineficiencia en la presente investigación. Asimismo, los autores resaltaron que hubo presencia de economías de escala en estas EPS durante el periodo 1996-2010; sin embargo, como se ha explicado en esta investigación se sugiere la presencia de deseconomías de escala, esta diferencia puede deberse al periodo de tiempo estudiado, toda vez que según la Figura 10 de ineficiencia promedio, la ineficiencia en costos se mantuvo en un nivel menos al 14\%, con un crecimiento lento entre 2008 y 2010 ; sin embargo, en el periodo posterior hasta el 2016, a excepción del periodo 2011-2013, el indicador de ineficiencia se incrementó considerablemente, lo que habría cambiado la figura de economías de escala.

Por su parte, Faust y Baranzini (2014) concluyeron mediante el análisis comparativo de las 141 proveedoras de agua potable en Suiza, a través de una estimación de frontera estocástica, que las variables exógenas (porcentaje de distribución sobre extracción de agua, la densidad de consumo, y variables de altitud y meteorológicas) impactan significativamente a los costos y no a la eficiencia. En la presente investigación para el ámbito peruano, se incluyó la variable consumo ${ }^{37}$ como variable ambiental que afectaría directamente los costos operativos; sin embargo, no se encontró significancia individual; asimismo, se encontró que el índice de precipitación estandarizado impacta directamente

\footnotetext{
${ }^{37}$ La diferencia entre densidad de consumo y consumo, es que la primera toma en cuenta la longitud de la red, y la segunda es el volumen facturado $\left(\mathrm{m}^{3}\right)$ diario por habitante.
} 
a la ineficiencia en costos, si bien no se estudió la significancia del porcentaje de facturación, el porcentaje de no facturación (pérdida de agua) no es significativo como variable explicativa de la ineficiencia directamente al igual que la altitud.

Regresando al contexto peruano, Corton (2011) señaló que, mediante la estimación de la frontera estocástica de eficiencia de costos regional, un aumento de la producción conjunta (agua producida y perdida) en $1 \%$ incrementa los costos en $0.1 \%$ respecto a las 43 EPS, además que el aumento de los costos está asociado a las conexiones informales que no facturan. Asimismo, este resultado se relaciona a un costo netamente político de la junta directiva por los votos obtenidos por la población más pobre de estos municipios. Según nuestros resultados, el agua no facturada no afecta significativa y positivamente sobre el indicador de ineficiencia en costos.

Finalmente, Lin (2005) concluyó a través de la estimación de una frontera estocástica de eficiencia de costos para 36 EPS, el modelo estimado debe incluir variables explicativas que representen la calidad del servicio como pertenecientes al producto debido a la importancia, y debe incluirse precios de insumos e indicadores de calidad. Esto debido a que los resultados hallados indicaron ello a través de una alta correlación de clasificación pese que a las estas entidades presentan calificaciones distintas según los modelos utilizados. Respecto lo mencionado, el modelo estimado en la presente investigación tomó en cuenta variables explicativas asociadas a los precios de los insumos e indicadores de calidad del servicio (micromedición y cobertura); sin embargo, aun cuando los insumos fueron incluidos como variables explicativas directas del costo, los indicadores de calidad fueron incluidos en la segunda etapa de esta investigación en la cual solo la cobertura obtuvo el nivel de significancia al $5 \%$ para explicar la ineficiencia de costos de manera directa.

Relacionado el tema de los insumos productivos, nuestros resultados indican que las variables número de trabajadores y número de conexiones totales no son significativas para el costo operativo de las EPS, el primero, asociado al trabajo, está relacionado a los costos variables que se incurren en las actividades; sin embargo, su no significancia podría estar relacionada a las restricciones normativas, toda vez que el personal de planta no puede ser reducido en función a la producción, por estar en condición permanente según régimen privado $\mathrm{DL} 728$, asimismo, de producirse un incremento en la producción, tampoco se puede incrementar personal según normativa presupuestaria, a menos que sea personal eventual, el cual que no debiera incrementar el costo en gran cuantía. 


\section{Conclusiones}

Los resultados de la presente investigación sobre 44 EPS en el Perú urbano durante el periodo 2008-2016 nos llevan a evaluar las hipótesis planteadas y concluir lo siguiente:

Se planteó como objetivo general analizar las variables que influyen en la ineficiencia técnica de las Entidades Prestadoras de Servicios de Saneamiento (EPS) en el Perú urbano durante el periodo 2008-2016. A partir de la estimación de la frontera de costos estocástica se identificó el indicador de ineficiencia en costos (o técnica según definición del primer capítulo), y del análisis de regresión lineal se encontró que:

- el porcentaje de cobertura de agua, y

- $\quad$ el índice de precipitación estandarizado, cumplen la significancia (al 5\%) para explicar la ineficiencia en costos de las EPS en el Perú urbano durante el periodo 2008-2016.

aun cuando las otras variables:

- el porcentaje de medición de conexiones activas

- la pérdida de agua (porcentaje de agua no facturada)

- el porcentaje de tratamiento de aguas residuales,

- la cobertura de alcantarillado, y

- la altitud, no son significativas (al 5\%) individualmente,

el modelo en general sí explica de manera global la ineficiencia en costos, por tanto, se procedió al no rechazo de la hipótesis general de la presente tesis. Sin embargo, es importante señalar que el coeficiente significativo el cercano a "0", un incremento de $1 \%$ del porcentaje de cobertura de agua, incrementaría el indicador de ineficiencia de costos en 0.003 puntos porcentuales.

El primer objetivo específico planteaba identificar las variables de producción y de factores productivos que influyen en la frontera de costos de las EPS en el periodo de estudio, particularmente se identificó que:

- el costo de la energía y

- el volumen producido de agua potable, cumplen dicha significancia individual para explicar los costos operativos totales de las EPS de Agua Potable y Saneamiento (presentan probabilidades menores a 0.05) en el Perú urbano entre 2008 y 2016 ; 
el modelo también incluyó proxys de los factores de producción capital y trabajo:

- número de conexiones y

- número de trabajadores, respectivamente; sin embargo, no resultaron ser significativas al $5 \%$ del nivel de significancia. Por tanto, se rechaza la hipótesis nula planteada.

Asimismo, se planteó como segundo objetivo específico identificar las variables ambientales que influyen en la frontera de costos de las Entidades Prestadoras de Servicios de Saneamiento en el Perú entre 2008 y 2016. Como resultado de la evaluación de significancia de las variables ambientales se encontró que:

- el consumo de agua potable (volumen facturado por habitante al día), y

- el porcentaje de agua extraída de la fuente subterránea, no cumplen con la significancia individual (al 5\%) para explicar los costos operativos totales de las EPS en el Perú urbano entre 2008 y 2016. Por tanto, se rechaza la hipótesis nula planteada.

Por su parte, se planteó como tercer objetivo específico el identificar las variables observables que se relacionan con la ineficiencia de costos de las Entidades Prestadoras de Servicios de Saneamiento en el Perú entre 2008 y 2016. Del análisis de correlación se encontró:

correlación positiva de la ineficiencia en costos y las variables:

- porcentaje de conexiones activas medidas y

- cobertura de agua; y

correlación negativa de la ineficiencia en costos y las variables:

- porcentaje de agua no facturada,

- porcentaje de tratamiento de aguas residuales,

- la cobertura de alcantarillado,

- $\quad$ el índice de precipitación estandarizado, y

- la altitud;

dicha correlación indicaría la existencia de una relación de las variables explicativas mencionadas y el indicador de ineficiencia calculado para las Entidades Prestadoras de Servicios de Saneamiento en el Perú entre 2008 y 2016; cabe mencionar que, el coeficiente 
de correlación de Pearson es cercano a "0"; sin embargo, nos da señales de la dirección de la relación positiva o negativa.

Finalmente, se planteó como cuarto objetivo específico identificar las características particulares de la curva de costos de las Entidades Prestadoras de Servicios de Saneamiento en el Perú entre 2008 y 2016 que la ubican en una etapa de las economías de escala, cuya hipótesis hace referencia a una etapa de deseconomías de escala. En la Tabla 10 se muestran resultados del análisis de resultados de la estimación de los Costos Operativos por volumen producido $\left(\mathrm{S} / / \mathrm{m}^{3}\right)$ se encontró que la variable Volumen Producido $\left(\mathrm{m}^{3}\right)$, es significativa individualmente, a un nivel de significancia de $5 \%$ y de signo positivo. Este estimador nos indica que el aumento del volumen de la producción incrementa los costos operativos; si nos situamos en la recta de costos a largo plazo y estimamos el grado de economía de escala de las EPS durante este periodo, el aumento del volumen de la producción incrementa los costos operativos por volumen producido $\left(\mathrm{S} / / \mathrm{m}^{3}\right)$; el aumento del Volumen Producido Total impacta positivamente y en una magnitud de 0.00000000734 sobre el costo operativo por volumen producido. Este resultado nos indica que la situación de las EPS, respecto a los costos productivos de este grupo de proveedores, se sitúa en deseconomías de escala, donde el aumento de la producción hace aumentar los costos medios (Tabla 4). Por tanto, no se rechaza la cuarta hipótesis específica. Aun cuando es posible que algunas EPS grandes individualmente no se encuentren en esta etapa, se precisa que los resultados son significativos para todo el grupo de proveedores incluidos en la muestra.

\section{Recomendaciones y limitaciones}

El hallazgo de deseconomías de escala inicia el cuestionamiento sobre el tamaño óptimo de las EPS y la normatividad vigente para una posible reorganización operativa y jurisdiccional, de tal manera que aquellas EPS que se encuentren compartiendo un ambiente geográfico cercano que no permite aprovechar las economías de escala por la atomización, puedan integrarse, el departamento de Junín, por ejemplo, sería un candidato a la reorganización junto a las cinco EPS que operan en su ámbito geográfico.

Desde otro aspecto, es importante señalar la figura que las asociaciones público privadas (APPs) representan como solución al problema de la ineficiencia, Bonifaz e Itakura (2014) encontraron que la ineficiencia de empresas privadas (algunas de ellas bajo concesión) presentaban niveles significativamente bajos comparados a los de los operadores públicos; asimismo, las asociaciones público privadas han probado ser una herramienta muy 
importante para el desempeño de la empresas de agua potable y saneamiento a nivel internacional, mejorando la calidad del servicio y la eficiencia operativa (Marin, P., 2009), siempre que estén bien diseñadas y se adapten a las particularidades del ambiente geográfico, social y político que enfrentan. Mucho se ha criticado el modelo de gestión de las APPs en el África; sin embargo, existen claros ejemplos exitosos (con indicadores de desempeño crecientes) que demuestran que las APPs son una opción viable para una reforma positiva del sector en países en desarrollo, sobre todo en aquellos esquemas basados en inversiones públicas combinadas con una eficiente operación privada como son el caso de Colombia (Cartagena), Ecuador (Guayaquil), Cuba (La Habana), Senegal, entre otros (Marin, P., 2009).

El ente regulador tiene, entonces, una tarea pendiente para una mejor definición y regulación de las asociaciones público privadas, que podrían reducir la brecha de infraestructura que tenemos en el Perú. Al respecto, se debe señalar que, en los últimos años, el sector saneamiento y agua potable internacional ha sido materia de análisis para la implementación de contratos basados en el desempeño, iniciando así una transición de los métodos tradicionales de contrato basados en los insumos (Janssens, P. y Carron, D, 2018) a los basados en el desempeño, cuando de asociaciones público privadas se trata. En ese sentido, es necesario que SUNASS pueda identificar las potencialidades de este tipo de contratos, definiendo principalmente: 1) objetivos ambiciosos pero realistas, 2) distribución clara de los procesos empresariales entre las municipalidades y los concesionarios y 3) una línea de base; así como también es necesario que se identifique las características necesarias para que este tipo de contrato funcione, de acuerdo a Janssens y Carron (2018), por ejemplo, esos contratos no debieran incluir mucha inversión, y el concesionario debiera poder identificar el riesgo de rentabilidad, y sobre ellos tener espacio suficiente para definir sus tarifas.

Por otro lado, la presente investigación, logra identificar la relación de la ineficiencia con variables de gestión socio - ambientales, por ejemplo, el porcentaje de cobertura de agua cumple la significancia (al 5\%) para explicar la ineficiencia en costos de las EPS en el Perú urbano durante el periodo 2008-2016, cuya relación sería positiva, asimismo, se encontró correlación lineal negativa de la ineficiencia en costos con el porcentaje de pérdida de agua y el porcentaje de tratamiento de aguas residuales y la cobertura de alcantarillado. En ese sentido, resulta sumamente importante que estas variables sean incluidas como medidas de establecimiento de metas, para contribuir de esta manera en el cumplimiento del 
principio de "eficiencia" de la prestación de servicios de saneamiento al que la Ley № 30045 (2013), Ley de Modernización de los Servicios de Saneamiento ${ }^{38}$, hace referencia.

Cabe señalar que, dado el coeficiente positivo y significativo de la cobertura de agua para explicar la ineficiencia en costos, un incremento de esta cobertura incrementaría la ineficiencia en costos, según nuestros resultados, asimismo, la existencia de correlación positiva de la ineficiencia en costos con el porcentaje de medición de conexiones activas, nos alerta sobre la posibilidad que exista un problema de fondo relacionado a las economías de escala y al estado ineficiente de la industria de agua potable y saneamiento para el periodo estudiado, lo cual conllevaría a considerarse ciertos cambios estructurales como necesarios, los cuales debieran considerar variables netamente ambientales para la ubicación de las EPS, como las precipitaciones y la altitud así como medidas de regulación que promuevan la eficiencia.

Sobre las variables explicativas incluidas en el modelo de frontera estocástica de costos, y la no significancia de las variables relacionadas al trabajo y al capital, aun cuando esta investigación solo considera una proxy de cantidad relacionada a estos factores; podemos decir que, respecto al trabajo, se considera materia de análisis posterior, dado que el sector agua potable y saneamiento pese a no ser intensivo en mano de obra, cuenta con diversidad de sindicatos de trabajadores y normativas vigentes que hacen que este factor productivo sea rígido, desviando así a las empresas de la elección de producción óptima; sobre el capital, la relación no significativa, cobra sentido si es que observamos la dinámica de los agentes involucrados en la cual son los gobiernos locales y regionales, en la mayoría de casos, los cuales están a cargo financieramente de la expansión de redes de agua potable y saneamiento a gran escala, mientras que las EPS se encargan de la operatividad solamente, aquí las mayores inversiones de las EPS se concentrarían en las plantas de tratamiento de agua potable y de tratamiento de aguas residuales; sin embargo, no existe información clara sobre su costo o medios de financiamiento.

Sobre las variables ambientales, el consumo de agua potable ${ }^{39}$ y el porcentaje de agua extraída de la fuente subterránea, incluidas en el modelo de frontera estocástica de costos y su no significancia, podemos decir que estas características particulares de las EPS no impactan en su estructura de costos; sin embargo, eso no implica que no existan otras variables ambientales que afecten los costos de las EPS, sino que estás podrían no ser

\footnotetext{
${ }^{38}$ ARTÍCULO III. "Principios" de la Ley N 30045, Ley de Modernización de los Servicios de Saneamiento.

${ }^{39}$ Definida en esta investigación como el volumen diario facturado por habitante.
} 
observables en los sistemas de información actuales, como por ejemplo, características geográficas, cartográficas o meteorológicas.

Asimismo, uno de los grandes hallazgos de la investigación es que se encontraron deseconomías de escala en las prestadoras de servicios de agua potable y saneamiento, al respecto, se requerirá futuros análisis respecto a si una reducción del número de EPS podría incrementar la eficiencia en el sector, un análisis sobre el tamaño óptimo (jurisdicción de cobertura) de las EPS sería sugerido.

Por otro lado, existieron diversas limitaciones durante el desarrollo de esta investigación, principalmente aquellas vinculadas a la disponibilidad de información. Si bien el modelo de frontera estocástica desarrollado incluye los factores productivos clásicos de trabajo y capital. A partir de los cambios normativos y los nuevos sistemas de información a los cuales las EPS están migrando (SIAF) se podría, en lo posterior, incluir en el análisis una variable que capture el costo de capital y del trabajo.

Metodológicamente, se usa solamente el método paramétrico estocástico no determinístico, por ser la más adecuada según la base de datos trabajada y los hallazgos en los antecedentes; sin embargo, el análisis de la envolvente de datos quedaría como un tema pendiente, para medir la robustez del modelo. Cabe mencionar, que se han aplicado transformaciones para linealizar el modelo teórico, dichas transformaciones se realizaron sobre las variables explicativas mas no sobre las ambientales.

Asimismo, debido a la poca disponibilidad o baja consistencia de la data, la proxy del precio de la energía (costo de la energía) no fue normalizados, no se incluyó el costo de capital y del trabajo, y no todas la EPS municipales fueron cubiertas en este análisis. Cabe mencionar que, las empresas SEDAPAL y ATUSA fueron excluidas a propósito para limitar la investigación a proveedores públicos municipales.

El estudio analiza el periodo 2008-2016, de frecuencia anual para 44 EPS ${ }^{40}$, el alcance geográfico de estudio se limita al Perú y a la zona urbana, debido a la cantidad de variables analizadas a pesar que la base de datos de SUNASS provee información desde 1996, esta no es reportada continuamente por lo que el periodo de tiempo fue elegido en función a la disponibilidad de datos para las variables analizadas que tuvieran el mayor número de individuos (EPS) involucrados.

\footnotetext{
4048 EPS son el universo de las EPS de administración pública municipal (no incluye SEDAPAL ni la Empresa de Agua Potable y Alcantarillado de Tumbes-ATUSA); sin embargo, para el periodo de análisis solo se encontró información para 44 EPS, esta exclusión se detalla en la sección "Muestra".
} 


\section{Referencias}

Aigner, D., Lovell, C. A. K., y Schmidt, P. (1977). Formulation and estimation of stochastic frontier production function models. Journal of Econometrics, 6(1), 21-37. https://doi.org/10.1016/0304-4076(77)90052-5

Antonioli, B., y Filippini, M. (2001). The use of a variable cost function in the regulation of the Italian water industry. Utilities Policy, 10(3), 181-187. https://doi.org/10.1016/S0957-1787(02)00065-6

Apaéstegui, J. y Peña, F. (2017). Disponibilidad de Agua. En El Agua en el Perú: Situación y Perspectivas (Capítulo 2). Recuperado de http://ciga.pucp.edu.pe/publicaciones/elagua-en-el-peru-situacion-y-perspectivas/

Belotti, F., Daidone, S., Ilardi, G., y Atella, V. (2013). Stochastic Frontier Analysis using $\begin{array}{llll}\text { Stata. The Stata J19-758. } & \text { Journal, }\end{array}$ https://doi.org/10.1177/1536867X1301300404

Berg, S. (2010). Water Utility Benchmarking Measurement, Methodologies, and Performance Incentives. Water Intelligence Online, 9. https://doi.org/10.2166/9781780401690

Bonifaz, J., y Itakura, R. (2014). An Analysis of Inefficiency of Big Urban Water Utilities in Latin-America (p. 24). Presentado en Conferencia Anual del Consorcio de Universidades 2014. Recuperado de http://repositorio.up.edu.pe/handle/11354/970

Charnes, A., Cooper, W., y Rhodes, E. (1978). Measuring the efficiency of decision making units. European Journal of Operational Research, 2(6), 429-444. https://doi.org/10.1016/0377-2217(78)90138-8

Coelli, T., Perelman, S., y Romano, E. (1999). Accounting for Environmental Influences in Stochastic Frontier Models: With Application to International Airlines. Journal of Productivity Analysis, 11(3), 251-273. https://doi.org/10.1023/A:1007794121363

Coelli, T., Rao, D., O’Donnell, C., y Battese, G. (2005). An Introduction to Efficiency and Productivity Analysis (2. ${ }^{\mathrm{a}}$ ed.). Springer US. Recuperado de https://www.springer.com/gp/book/9780387242651

Comisión Económica para América Latina y el Caribe (CEPAL) - Naciones Unidas. (2011). Anuario estadístico de América Latina y el Caribe, 2010 = Statistical yearbook for Latin America and the Caribbean, 2010. Santiago, Chile: Publicación de las Naciones Unidas. Recuperado de https://repositorio.cepal.org/bitstream/handle/11362/925/S1000780 es.pdf?sequence $=1$ yis Allowed $=\mathrm{y}$

Corton, M. L. (2003). Benchmarking in the Latin American water sector: the case of Peru. Utilities Policy, 11(3), 133-142. https://doi.org/10.1016/S0957-1787(03)00035-3

Corton, M. L. (2011). Sector fragmentation and aggregation of service provision in the water industry. Journal of Productivity Analysis, 35(2), 159-169. https://doi.org/10.1007/s11123-010-0180-4 
Cueva, F. (2015). Proyectos de Agua y Saneamiento PAPT, § Ministerio de Vivienda, Construcción y Saneamiento. Recuperado de http://www3.vivienda.gob.pe/dnc/archivos/difusion/eventos/2011/huacho/Proyectos\% 20de\%20Agua\%20y\%20Saneamiento\%20PAPT.pdf

Dalhuisen, J., De Groot, H., y Nijkamp, P. (1999). The economics of water: a survey of issues (Serie Research Memoranda No. 0036). VU University Amsterdam, Faculty of Economics, Business Administration and Econometrics. Recuperado de https://ideas.repec.org/p/vua/wpaper/1999-36.html

Dammert, A., Molinelli, F., y Carbajal, M. (2013). Teoría de la Regulación Económica (1. ${ }^{a}$ ed.). Lima: Fondo Editorial USMP.

Daraio, C., y Simar, L. (2007). Advanced Robust and Nonparametric Methods in Efficiency Analysis: Methodology and Applications. Springer US. Recuperado de https://www.springer.com/us/book/9780387351551

Decreto Legislativo $\mathrm{N}^{\circ} 1240$, Decreto legislativo que modifica la Ley $\mathrm{N}^{\circ} 26338$ y la Ley $\mathrm{N}^{\circ}$ 30045. Diario Oficial "El Peruano", Lima, Perú, 26 de setiembre de 2015. Recuperado de https://elperuano.pe/NormasElperuano/2015/09/26/1292707-10.html

Decreto Legislativo № 1280, Decreto Legislativo que aprueba la Ley Marco de la Gestión y Prestación de los Servicios de Saneamiento. Diario Oficial "El Peruano", Lima, Perú, 29 de diciembre de 2016.2 Recuperado de https://busquedas.elperuano.pe/download/url/decreto-legislativo-que-aprueba-la-leymarco-de-la-gestion-y-decreto-legislativo-n-1280-1468461-1

Decreto Supremo N 086-2016-PCM, Declaran Estado de Emergencia ante déficit hídrico en el departamento de Moquegua. Diario Oficial "El Peruano", Lima, Perú, 25 de noviembre de 2016. Recuperado de https://busquedas.elperuano.pe/normaslegales/declaran-estado-de-emergencia-antedeficit-hidrico-en-el-dep-decreto-supremo-n-086-2016-pcm-1457484-2/

Decreto Supremo No 089-2016-PCM, Declaran el Estado de Emergencia por peligro inminente por déficit hídrico en los departamentos de Apurímac, Ancash, Ayacucho, Cajamarca, Cusco, Huancavelica, Ica, Junín, Lambayeque, La Libertad, Pasco, Piura, Puno, Tacna y Tumbes, así como en siete (07) provincias del departamento de Lima, y en cuatro (04) provincias del departamento de Arequipa. Diario Oficial "El Peruano", Lima, Perú, 07 de diciembre de 2016. Recuperado de https://busquedas.elperuano.pe/normaslegales/declaran-el-estado-de-emergenciapor-peligro-inminente-por-d-decreto-supremo-n-089-2016-pcm-1461423-2/

Decreto Supremo N013-2016-VIVIENDA, Decreto Supremo que aprueba el Reglamento de la Ley $N^{\circ} 30045$, Ley de Modernización de los Servicios de Saneamiento. Diario Oficial "El Peruano", Lima, Perú, 24 de julio de 2016. Recuperado de https://busquedas.elperuano.pe/normaslegales/aprueban-el-reglamento-de-la-ley-n30045-ley-de-modernizac-decreto-supremo-n-013-2016-vivienda-1408435-1/

Decreto Supremo $N^{\circ}$ 007-2017-VIVIENDA, Decreto Supremo que aprueba la Política Nacional de Saneamiento. Diario Oficial "El Peruano", Lima, Perú, 30 de marzo de 2017. Recuperado de https://busquedas.elperuano.pe/normaslegales/decretosupremo-que-aprueba-la-politica-nacional-de-saneamie-decreto-supremo-n-0072017-vivienda-1503314-7I 
Decreto Supremo N 031-2008-VIVIENDA, Decreto Supremo que modifica el Texto Único Ordenado del Reglamento de la Ley General de Servicios de Saneamiento, Lima, Perú, 29 de noviembre del 2008. Recuperado de http://spijlibre.minjus.gob.pe/normativa libre/main.asp.

Eid, U. (2015). The Importance of Water, Sanitation, and Hygiene as Keys to National Development. Recuperado de https://www.issuelab.org/resource/importance-of-watersanitation-and-hygiene-as-keys-to-national-development.html

Farrell, M. (1957). The Measurement of Productive Efficiency. Journal of the Royal Statistical Society. Series A (General), 120(3), 253-290. https://doi.org/10.2307/2343100

Faust, A., y Baranzini, A. (2014). The economic performance of Swiss drinking water utilities. Journal of Productivity Analysis, 41(3), 383-397. https://doi.org/10.1007/s11123-013-0344-0

Ferro, G., Lentini, E., y Romero, C. (2011). Eficiencia y su medición en prestadores de servicios de agua potable y alcantarillado. En CEPAL-Colección Documentos de proyectos (p. 58). Recuperado de https://archivo.cepal.org/pdfs/Waterguide/lcw0385s.PDF

Fuss, M., McFadden, D., y Mundlak, Y. (1978). A Survey of Functional Forms in the Economic Analysis of Production (History of Economic Thought Chapters Capítulo 4 en Production Economics: A Dual Approach to Theory and Applications). McMaster University Archive for the History of Economic Thought. Recuperado de https://eml.berkeley.edu/prodecon/theory/ch4.pdf

Greene, W. (2005). Reconsidering heterogeneity in panel data estimators of the stochastic frontier model. Journal of Econometrics, 126(2), 269-303. https://doi.org/10.1016/j.jeconom.2004.05.003

Instituto Nacional de Estadística e Informática (INEI). (2014). Anuario de Estadísticas Ambientales 2014. Recuperado 25 de marzo de 2019, de https://www.inei.gob.pe/media/MenuRecursivo/publicaciones digitales/Est/Lib1197/lib $\underline{\text { ro.pdf }}$

Instituto Nacional de Estadística e Informática (INEI). (2017). Series Nacionales: Abastecimiento de agua en los hogares [ENAHO y Encuesta Nacional de Programas Presupuestales]. Recuperado 25 de noviembre de 2017, de http://webapp.inei.gob.pe:8080/sirtod-series/

Janssens, J. G., y Carron, D. (2018). Performance-based contracts - setting the scene. En Performance-Based Contracts (PBC) for Improving Utilities Efficiency (pp. 001-006). International Water Association. https://doi.org/10.2166/9781780405964 0001

Jondrow, J., Knox Lovell, C. A., Materov, I. S., y Schmidt, P. (1982). On the estimation of technical inefficiency in the stochastic frontier production function model. Journal of Econometrics, 19(2-3), 233-238. https://doi.org/10.1016/0304-4076(82)90004-5

Keat, P., y Young, P. (2004). Economía de empresa. Pearson Education.

Laffont, J., y Tirole, J. (1986). Using Cost Observation to Regulate Firms. Journal of Political Economy, 94(3, Part 1), 614-641. https://doi.org/10.1086/261392 
Larios, J. F., González, C., y Álvarez, V. J. (2016). Investigación en economía y negocios: Metodología con aplicaciones en E-Views. Universidad San Ignacio de Loyola. Recuperado de http://repositorio.usil.edu.pe/handle/USIL/2527

Le Blanc, D. (2008). A Framework for Analyzing Tariffs and Subsidies in Water Provision to Urban Households in Developing Countries (UN Department of Economic and Social Affairs (DESA) Working Papers No. 63). https://doi.org/10.18356/bfc5bf00-en

Ley N²6338, Ley General de Servicios de Saneamiento. Diario Oficial “El Peruano”, Lima, Perú, 24 de julio de 1994. Recuperado de http://pnsr.vivienda.gob.pe/portal/wpcontent/uploads/2014/05/Ley-26338-Ley-General-de-Servicios-de-Saneamiento1.pdf

Ley N ${ }^{\circ} 30045$, Ley de Modernización de los Servicios de Saneamiento. Diario Oficial "EI Peruano", Lima, Perú, 18 de junio de 2013. Recuperado de https://busquedas.elperuano.pe/normaslegales/ley-de-modernizacion-de-losservicios-de-saneamiento-ley-n-30045-951518-1/

Lin, C. (2005). Service quality and prospects for benchmarking: Evidence from the Peru water sector. Utilities Policy, 13(3), 230-239. https://doi.org/10.1016/j.jup.2005.04.002

Marin, P. (2009). Public-private partnerships for urban water utilities: a review of experiences in developing countries. Washington, DC: World Bank: Public-Private Infrastructure Advisory Facility.

Ministerio de Economía y Finanzas. (2018a). RESULTA: Indicadores de Desempeño de los Programas Presupuestales. Recuperado 11 de enero de 2018, de https://apps4.mineco.gob.pe/resulta2

Ministerio de Economía y Finanzas. (2018b). Transparencia Económica: Consulta Amigable de Ejecución del Gasto Anual. Recuperado 11 de enero de 2018, de http://apps5.mineco.gob.pe/transparencia/Navegador/default.aspx

Ministerio de Economía y Finanzas. (2018c). Transparencia Económica: Consulta ETEs Presupuesto y Ejecución de Ingresos. Recuperado 11 de enero de 2018, de http://apps5.mineco.gob.pe/etesingreso/Navegador/Default.aspx

Ministerio de Vivienda, Construcción y Saneamiento. (2017a). Agua y Saneamiento. Recuperado 18 de octubre de 2017, de http://www3.vivienda.gob.pe/ejes/agua saneamiento/agua y saneamiento.html

Ministerio de Vivienda, Construcción y Saneamiento. (2017b). Agua y Saneamiento Inversión. Recuperado 18 de octubre de 2017, de http://www3.vivienda.gob.pe/ejes/agua saneamiento/inversion.html

Nicholson, W., y Snyder, C. (2012). Microeconomic Theory: Basic Principles and Extensions. Cengage Learning.

Oblitas, L. (2010). Servicios de agua potable y saneamiento en el Perú: beneficios potenciales y determinantes de éxito. En CEPAL-Colección Documentos de proyectos (p. 73). Recuperado de https://repositorio.cepal.org/bitstream/handle/11362/3819/lcw355.pdf;jsessionid=B3B 0786928DEE7479C722536737DBBCE? sequence $=1$ 
OTASS. (2017). Informe Final de Resultados de Evaluación de EPS-Periodo 2013-2015. Organismo Técnico de la Administración de los Servicios de Saneamiento (OTASS). Recuperado http://www.otass.gob.pe/images/documentos/Publicaciones/Direccion\%20Evaluacion/ InformeEPS 2013-2015/Informe Ejecutivo Resultados Evaluacion EPS 20132015.pdf

Romero, C., y Ferro, G. (2007). Estimaciones de frontera para el sector de agua y saneamiento en América Latina (UADE Textos de Discusión No. 61_2007). Instituto de Economía, Universidad Argentina de la Empresa. Recuperado de https://ideas.repec.org/p/ris/uadetd/2007 061.html

Salinas, S. (2012). La concesión de agua en Tumbes. Recuperado el 02.03.2019 de http://revistas.pucp.edu.pe/index.php/derechoadministrativo/article/view/13537

SUNASS. (2016). Las EPS y su desarrollo (Indicadores de Gestión). Recuperado 20 de julio de 2017, de https://www.sunass.gob.pe/websunass/index.php/eps/indicadoresgestion-benchmarking-regulatorio-eps?layout=edityid=92

SUNASS (2017). Solicitud de Transparencia: Indicadores de Gestión de las EPS.

SUNASS (2018). Solicitud de Transparencia: Indicadores de Gestión de las EPS.

SENAMHI, P. (2019). Sistema Nacional de Información de Recursos Hídricos [Biblioteca de Datos Climáticos]. Recuperado de http://ons.snirh.gob.pe/SOURCES/.Peru/.SENAMHI/.PISCO/.SPI/.SPI1/

Urrunaga, R., y Jara, O. (2013). Fronteras de eficiencia y cambio tecnológico en las empresas proveedoras de agua en Perú. Atlantic Review of Economics: Revista Atlántica de Economía, 2(1), 8-38.

Varian, H. (2010). Un enfoque actual de Microeconomía Intermedia (8. ${ }^{\mathrm{a}}$ ed.). España: Antoni Bosch S.A.

WHO (2015). Water, sanitation and higiene in Health care facilities: The roles of the WASH sector. Water Aid-The World Health Organization. March. 


\section{Anexos}

\section{Anexo 1: Matriz de consistencia}

\begin{tabular}{|c|c|c|c|c|}
\hline \multicolumn{5}{|c|}{ MATRIZ DE CONSISTENCIA } \\
\hline Tipo & Problemas & Objetivos & Hipótesis & Variables 1/ \\
\hline General & $\begin{array}{l}\text { ¿Cuáles son los } \\
\text { determinantes de la } \\
\text { ineficiencia técnica de las } \\
\text { Entidades Prestadoras de } \\
\text { Servicios de Saneamiento } \\
\text { (EPS) en el Perú urbano } \\
\text { entre } 2008 \text { y } 2016 ?\end{array}$ & $\begin{array}{l}\text { Analizar las variables } \\
\text { que influyen en la } \\
\text { ineficiencia de técnica } \\
\text { de la EPS en el Perú } \\
\text { urbano durante el } \\
\text { periodo } 2008 \text { - } 2016\end{array}$ & $\begin{array}{l}\text { La ineficiencia en costos de las } \\
\text { Entidades Prestadoras de } \\
\text { Servicios de Saneamiento } \\
\text { (EPS) es explicada } \\
\text { significativamente, por el } \\
\text { porcentaje de medición de } \\
\text { conexiones activas, la pérdida } \\
\text { de agua, el porcentaje de } \\
\text { tratamiento de aguas } \\
\text { residuales, el porcentaje de } \\
\text { cobertura de agua, el } \\
\text { porcentaje de cobertura de } \\
\text { alcantarillado, el índice de } \\
\text { precipitación estandarizado y la } \\
\text { altitud geográfica en el Perú } \\
\text { urbano de manera significativa, } \\
\text { durante el periodo 2008-2016. }\end{array}$ & $\begin{array}{l}\text { + Ineficiencia en costos* } \\
\text { - Porcentaje de Medición } \\
\text { de conexiones activas* } \\
\text { - Pérdida de agua* } \\
\text { - Porcentaje de tratamiento } \\
\text { de aguas residuales* } \\
\text { - Porcentaje de cobertura } \\
\text { de agua* } \\
\text { - Porcentaje de cobertura } \\
\text { de alcantarillado* } \\
\text { - Índice de precipitación } \\
\text { estandarizado* } \\
\text {-Altitud geográfica* } \\
\text { *de las EPS en el Perú } \\
\text { urbano periodo 2008-2016 }\end{array}$ \\
\hline $\begin{array}{c}\text { Específico } \\
1\end{array}$ & $\begin{array}{l}\text { ¿Cuáles son los } \\
\text { determinantes de la } \\
\text { frontera de costos de la } \\
\text { provisión de agua potable } \\
\text { y saneamiento para las } \\
\text { Entidades Prestadoras de } \\
\text { Servicios de Saneamiento } \\
\text { (EPS) en el Perú entre } \\
2008 \text { y } 2016 ?\end{array}$ & $\begin{array}{l}\text { Identificar las } \\
\text { variables de } \\
\text { producción y de } \\
\text { factores productivos } \\
\text { que influyen en la } \\
\text { frontera de costos de } \\
\text { las Entidades } \\
\text { Prestadoras de } \\
\text { Servicios de } \\
\text { Saneamiento en el } \\
\text { Perú entre 2008-2016 }\end{array}$ & $\begin{array}{l}\text { 1. Los costos operativos de } \\
\text { las Entidades Prestadoras de } \\
\text { Servicios de Saneamiento se } \\
\text { encuentran explicados por el } \\
\text { volumen producido de agua } \\
\text { potable, el número de } \\
\text { trabajadores, el número de } \\
\text { conexiones de agua y el costo } \\
\text { de la energía, en el Perú } \\
\text { urbano entre } 2008 \text { y } 2016\end{array}$ & $\begin{array}{l}\text { + Costos operativos* } \\
\text { - Volumen producido de } \\
\text { agua potable* } \\
\text { - Número de trabajadores* } \\
\text { - Número de conexiones } \\
\text { de agua* } \\
\text { - Costo de la energía* } \\
\text { *de las EPS en el Perú } \\
\text { urbano periodo 2008-2016 }\end{array}$ \\
\hline $\begin{array}{c}\text { Específico } \\
2\end{array}$ & $\begin{array}{l}\text { ¿Cuáles son las variables } \\
\text { ambientales que afectan } \\
\text { la función de costos de las } \\
\text { Entidades Prestadoras de } \\
\text { Servicios de Saneamiento } \\
\text { (EPS) en el Perú entre } \\
2008 \text { y } 2016 ?\end{array}$ & $\begin{array}{l}\text { Identificar las } \\
\text { variables ambientales } \\
\text { que influyen en la } \\
\text { función de costos de } \\
\text { las Entidades } \\
\text { Prestadoras de } \\
\text { Servicios de } \\
\text { Saneamiento en el } \\
\text { Perú entre 2008-2016 }\end{array}$ & $\begin{array}{l}\text { 2. Los costos operativos de } \\
\text { las Entidades Prestadoras de } \\
\text { Servicios de Saneamiento se } \\
\text { encuentran controlados por el } \\
\text { consumo de agua potable, y el } \\
\text { porcentaje de agua extraída de } \\
\text { la fuente subterránea, en el } \\
\text { Perú urbano entre } 2008 \text { y } 2016\end{array}$ & $\begin{array}{l}\text { + Costos operativos* } \\
\text { - Consumo de agua } \\
\text { potable* } \\
\text { - Porcentaje de agua } \\
\text { extraída de fuente } \\
\text { subterránea* } \\
\text { *de las EPS en el Perú } \\
\text { urbano periodo 2008-2016 }\end{array}$ \\
\hline $\begin{array}{c}\text { Específico } \\
3\end{array}$ & $\begin{array}{l}\text { ¿La ineficiencia en costos } \\
\text { está relacionada a } \\
\text { variables ambientales } \\
\text { observables de las } \\
\text { Entidades Prestadoras de } \\
\text { Servicios de Saneamiento } \\
\text { (EPS) en el Perú entre } \\
2008 \text { y } 2016 ?\end{array}$ & $\begin{array}{l}\text { Identificar las } \\
\text { variables ambientales } \\
\text { observables que se } \\
\text { relacionan con la } \\
\text { ineficiencia de costos } \\
\text { de las Entidades } \\
\text { Prestadoras de } \\
\text { Servicios de } \\
\text { Saneamiento en el } \\
\text { Perú entre 2008-2016 }\end{array}$ & $\begin{array}{l}\text { 3. La ineficiencia en costos se } \\
\text { encuentra correlacionado con el } \\
\text { porcentaje de medición de } \\
\text { conexiones activas, el } \\
\text { porcentaje de pérdida de agua, } \\
\text { el porcentaje de tratamiento de } \\
\text { aguas residuales, el porcentaje } \\
\text { de cobertura de agua y y, el } \\
\text { porcentaje de cobertura de } \\
\text { alcantarillado, el índice de } \\
\text { precipitación estandarizado y la } \\
\text { altitud geográfica de las } \\
\text { Entidades Prestadoras de } \\
\text { Servicios de Saneamiento en el } \\
\text { Perú entre } 2008 \text { y } 2016 \text {. }\end{array}$ & $\begin{array}{l}\text { + Ineficiencia en costos* } \\
\text { - Porcentaje de Medición } \\
\text { de conexiones activas* } \\
\text { - Pérdida de agua* } \\
\text { - Porcentaje de tratamiento } \\
\text { de aguas residuales* } \\
\text { - Porcentaje de cobertura } \\
\text { de agua } \\
\text { - Porcentaje de cobertura } \\
\text { de alcantarillado } \\
\text { - Índice de precipitación } \\
\text { estandarizado* } \\
\text {-Altitud geográfica* } \\
\text { *de las EPS en el Perú } \\
\text { urbano periodo 2008-2016 }\end{array}$ \\
\hline $\begin{array}{c}\text { Específico } \\
4\end{array}$ & $\begin{array}{l}\text { ¿En qué etapa de las } \\
\text { economías de escala se } \\
\text { encuentra la curva de } \\
\text { costos de las Entidades } \\
\text { Prestadoras de Servicios } \\
\text { de Saneamiento (EPS) en } \\
\text { el Perú entre } 2008 \text { y } \\
2016 ?\end{array}$ & $\begin{array}{l}\text { Determinar en qué } \\
\text { etapa de las } \\
\text { economías de escala } \\
\text { se encuentra la curva } \\
\text { de costos de las } \\
\text { Entidades } \\
\text { Prestadoras de } \\
\text { Servicios de } \\
\text { Saneamiento en el } \\
\text { Perú entre } 2008 \text { y } \\
2016\end{array}$ & $\begin{array}{l}\text { 4. La curva de costos de las } \\
\text { Entidades Prestadoras de } \\
\text { Servicios de Saneamiento en el } \\
\text { Perú entre } 2008 \text { y } 2016 \text {, se } \\
\text { encuentra en una etapa de } \\
\text { deseconomías de escala. }\end{array}$ & $\begin{array}{l}\text { +Costo operativo medio } \\
\text { (m3/s/)* } \\
\text { - Volumen producido de } \\
\text { agua potable }(\mathrm{S} /)^{\star} \\
\text { *de las EPS en el Perú } \\
\text { urbano periodo } 2008-2016\end{array}$ \\
\hline
\end{tabular}

Nota: Elaboración Propia 
Anexo 2: Listado de Siglas

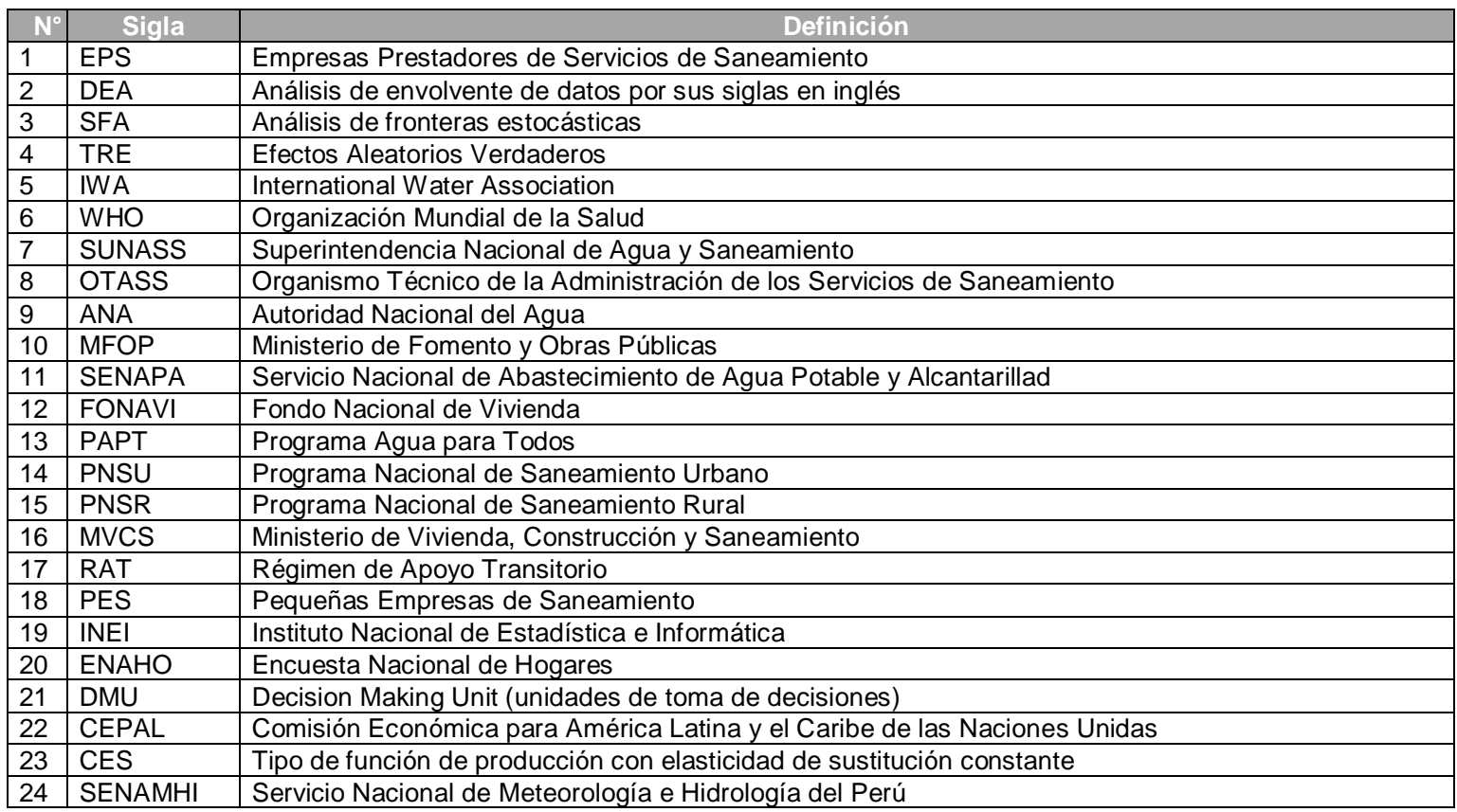

Nota: Elaboración Propia

Anexo 3: Ejecución de Ingresos por Fuente de Financiamiento - EPS

EMPRESAS MUNICIPALES DE AGUA POTABLE Y ALCANTARILLADO: EJECUCIÓN DE INGRESOS 2016

\begin{tabular}{|lrrrr|}
\hline Fuentes de Financiamiento (FF) & PIA 2016 & PIM 2016 & \multicolumn{1}{c}{$\begin{array}{c}\text { Ejecución anual } \\
2016\end{array}$} & $\begin{array}{c}\text { Participación } \\
\text { de la FF }\end{array}$ \\
\hline $\begin{array}{l}\text { 2. RECURSOS DIRECTAMENTE } \\
\text { RECAUDADOS }\end{array}$ & $\mathbf{8 9 0 , 1 8 2 , 1 1 5}$ & $\mathbf{1 , 0 5 5 , 7 0 1 , 8 5 9}$ & $\mathbf{1 , 0 3 6 , 6 9 7 , 6 5 7}$ & $\mathbf{7 8 . 7 \%}$ \\
\hline $\begin{array}{l}\text { 3. RECURSOS POR OPERACIONES } \\
\text { OFICIALES DE CREDITO }\end{array}$ & $\mathbf{7 2 6 , 0 0 0}$ & $\mathbf{8 , 3 0 1 , 8 6 1}$ & $\mathbf{5 , 9 1 7 , 6 4 9}$ & $\mathbf{0 . 5 \%}$ \\
\hline 4. DONACIONES Y TRANSFERENCIAS & - & $\mathbf{3 1 2 , 8 2 4 , 5 0 4}$ & $\mathbf{2 7 4 , 2 3 9 , 6 0 9}$ & $\mathbf{2 0 . 8 \%}$ \\
\hline $\begin{array}{l}\text { 5. RECURSOS DETERMINADOS } \\
\text { Total general }\end{array}$ & - & $\mathbf{5 8 0 , 3 1 4}$ & $\mathbf{3 7 4 , 1 2 1}$ & $\mathbf{0 . 0 \%}$ \\
\hline
\end{tabular}

Fuente: Ministerio de Economía y Finanzas (2018c)

EMPRESAS MUNICIPALES DE AGUA POTABLE Y ALCANTARILLADO: EJECUCIÓN DE INGRESOS 2016

\begin{tabular}{|c|c|c|c|c|}
\hline Fuentes de Financiamiento (FF) & PIA 2016 & PIM 2016 & $\begin{array}{r}\text { Ejecución } \\
\text { anual } 2016\end{array}$ & $\begin{array}{l}\text { Participación } \\
\text { de la FF }\end{array}$ \\
\hline 2. RECURSOS DIRECTAMENTE RECAUDADOS & $890,182,115$ & $1,055,701,859$ & $1,036,697,657$ & $78.7 \%$ \\
\hline $\begin{array}{l}\text { 1. IMPUESTOS Y CONTRIBUCIONES } \\
\text { OBLIGATORIAS }\end{array}$ & - & - & $1,039,647$ & $0.1 \%$ \\
\hline $\begin{array}{l}\text { 3. VENTA DE BIENES Y SERVICIOS Y } \\
\text { DERECHOS ADMINISTRATIVOS }\end{array}$ & $865,667,156$ & $890,839,748$ & $867,789,291$ & $65.9 \%$ \\
\hline 5. OTROS INGRESOS & $24,464,959$ & $52,667,909$ & $50,970,585$ & $3.9 \%$ \\
\hline 6. VENTA DE ACTIVOS NO FINANCIEROS & 50,000 & 50,000 & - & $0.0 \%$ \\
\hline 8. ENDEUDAMIENTO & - & 490,898 & 409,101 & $0.0 \%$ \\
\hline 9. SALDOS DE BALANCE & - & $111,653,304$ & $116,489,033$ & $8.8 \%$ \\
\hline $\begin{array}{l}\text { 3. RECURSOS POR OPERACIONES OFICIALES } \\
\text { DE CREDITO }\end{array}$ & 726,000 & $8,301,861$ & $5,917,649$ & $0.4 \%$ \\
\hline 4. DONACIONES Y TRANSFERENCIAS & - & $312,824,504$ & $274,239,609$ & $20.8 \%$ \\
\hline 5. RECURSOS DETERMINADOS & - & 580,314 & 374,121 & $0.0 \%$ \\
\hline Total general & $890,908,115$ & $1,377,408,538$ & $1,317,229,036$ & $100.0 \%$ \\
\hline
\end{tabular}

Fuente: Ministerio de Economía y Finanzas (2018c) 


\section{Anexo 4: Programa Agua Para Todos (PAPT)}

El Programa Agua para Todos (PAPT) creado mediante Decreto Supremo Nº 006-2007VIVIENDA como Unidad Ejecutora del Ministerio de Vivienda Construcción y Saneamiento, tuvo como objetivo estratégico el dotar a la población de escasos recursos de servicios de Saneamiento, el cual brindaría soporte técnico - financiero a los proyectos de inversión pública de Gobiernos Regionales, Locales y Empresas Prestadoras de Servicios (EPS), priorizando la atención a poblaciones en situación de Pobreza y Pobreza Extrema a nivel Nacional.

Solamente entre el periodo agosto 2006 - marzo 2011, el PAPT invirtió cerca de S/ 3,445,523,574 ${ }^{41}$ en proyectos relacionados al sector (Cueva, 2015), para ello englobó varias estrategias y/o subprogramas, entre ellos se encontraban el Programa de Medidas de Rápido Impacto (PMRI), el Programa Nacional de Agua y Saneamiento Rural (PRONASAR), entre otros especialmente instaurados para promover un shock de inversiones, en particular aquel brindado a través del FORSUR para proyectos de agua y saneamiento en el Sur del Perú, la Figura A4.1 resume esta inversión realizada por el PAPT en sus "subprogramas" más relevantes. A fin de tener una óptica descentralizada, la Figura A4.2 muestra la inversión realizada por el PAPT a nivel departamental, la línea naranja representa el monto ejecución en soles, y las barras azules el número de proyectos en los cuales se invirtió, particularmente las inversiones Lima y Ayacucho merecen tener un análisis profundo dado que tomando como referencia esta Figura, relativamente a otros departamentos, estos tuvieron menor inversión (monto ejecutado) pero se habrían "atendido" más proyectos.

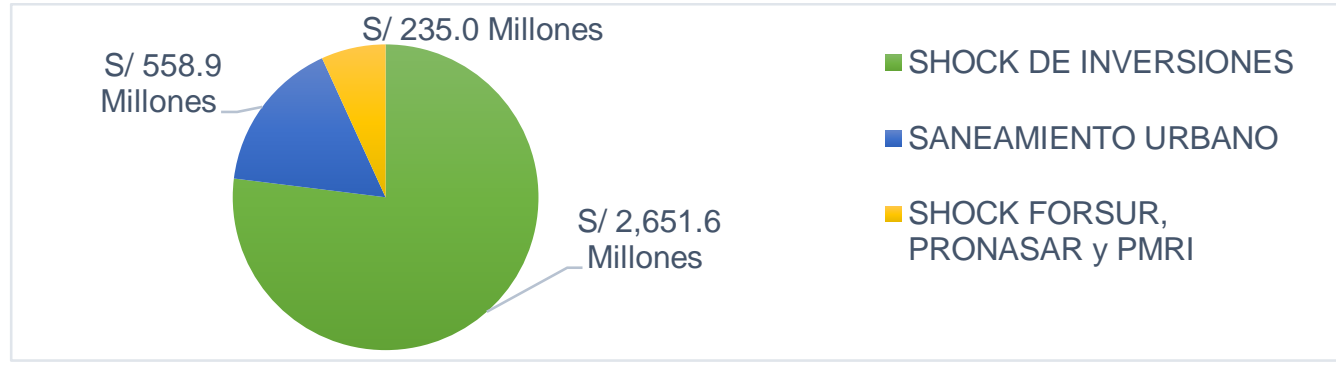

Figura A4.1. PAPT, Inversión realizada por "sub-programa" desde agosto 2006 hasta marzo 2011 (soles). Adaptado de OGEI - Ministerio de Vivienda Construcción y Saneamiento (Cueva, 2015)

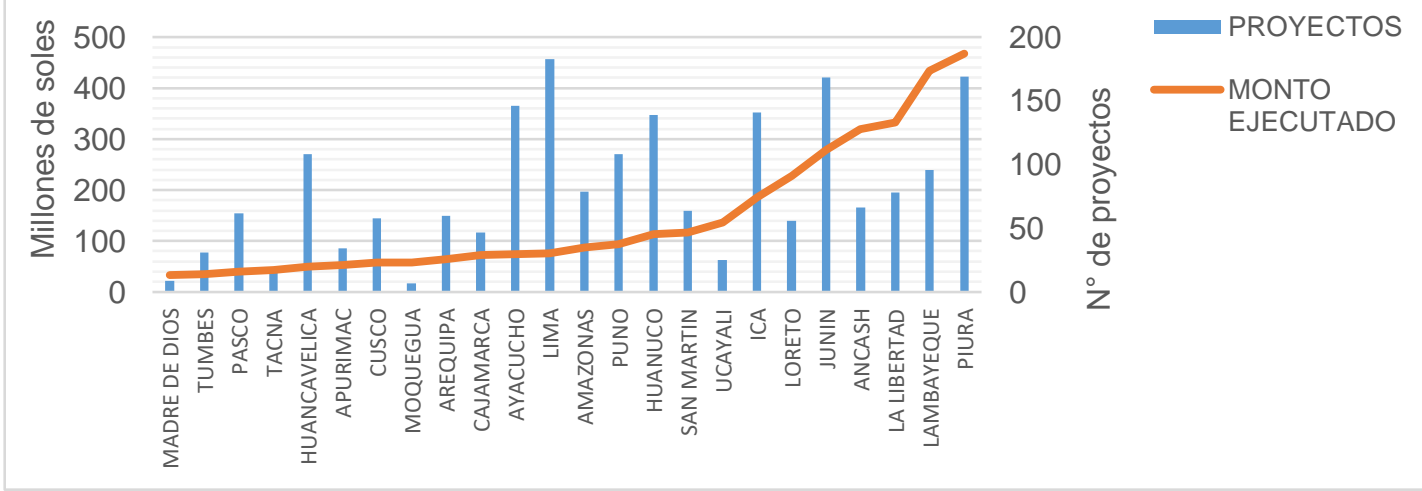

\footnotetext{
${ }^{41}$ Resumen general de inversión del programa agua para todos realizado en el periodo agosto 2006 - marzo del 2011.
} 
Figura A4.2. PAPT, Inversión por departamento desde agosto 2006 hasta marzo 2011 (soles). Adaptado de OGEI - Ministerio de Vivienda Construcción y Saneamiento (Cueva, 2015)

\section{Anexo 5: Indicadores históricos de los Programa Presupuestales del Sector}

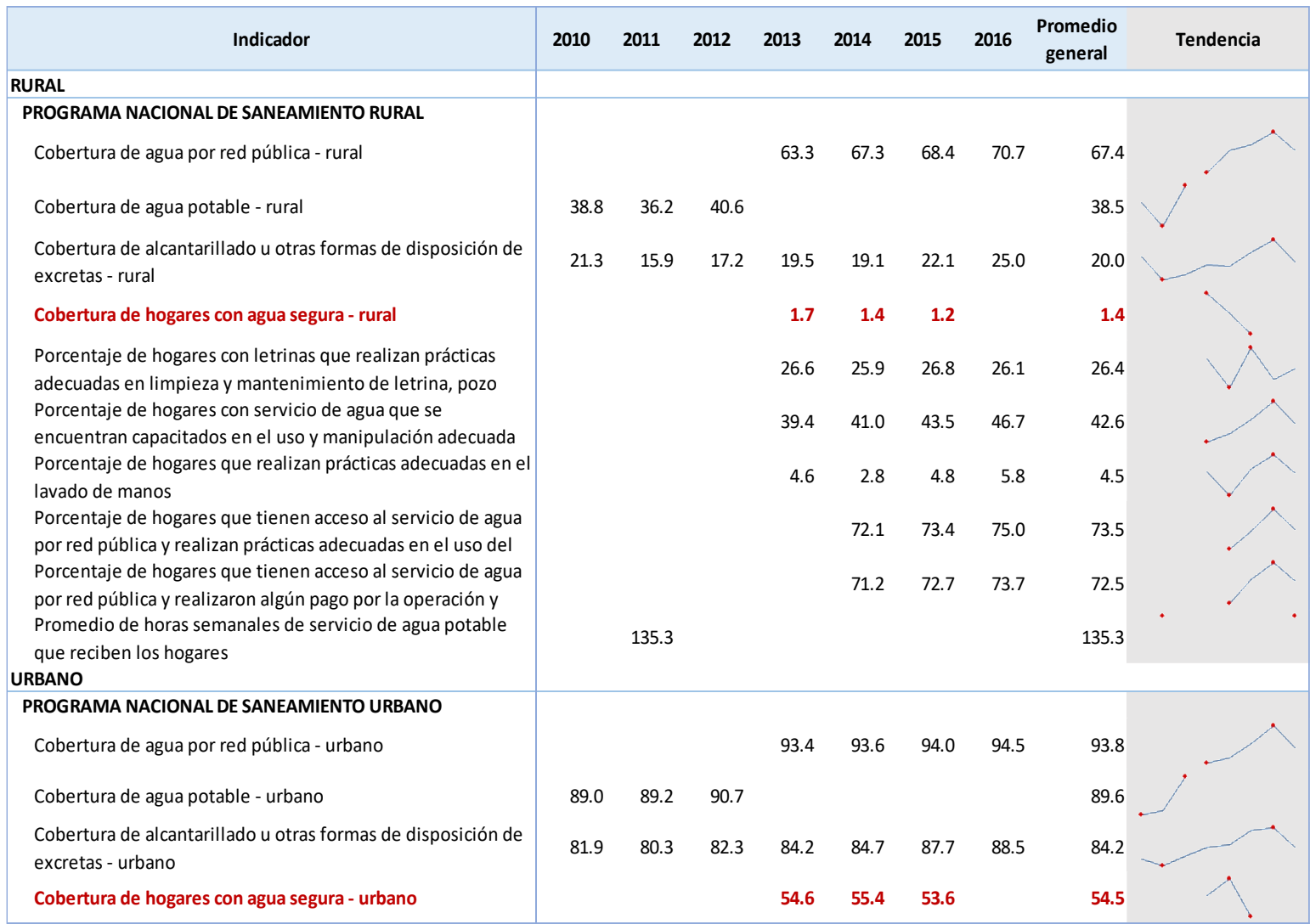

Fuente: Ministerio de Economía y Finanzas (2018a) Elaboración propia

\section{Anexo 6: Ejecución de inversiones de los gobiernos locales en PPR ${ }^{42} 2015$}

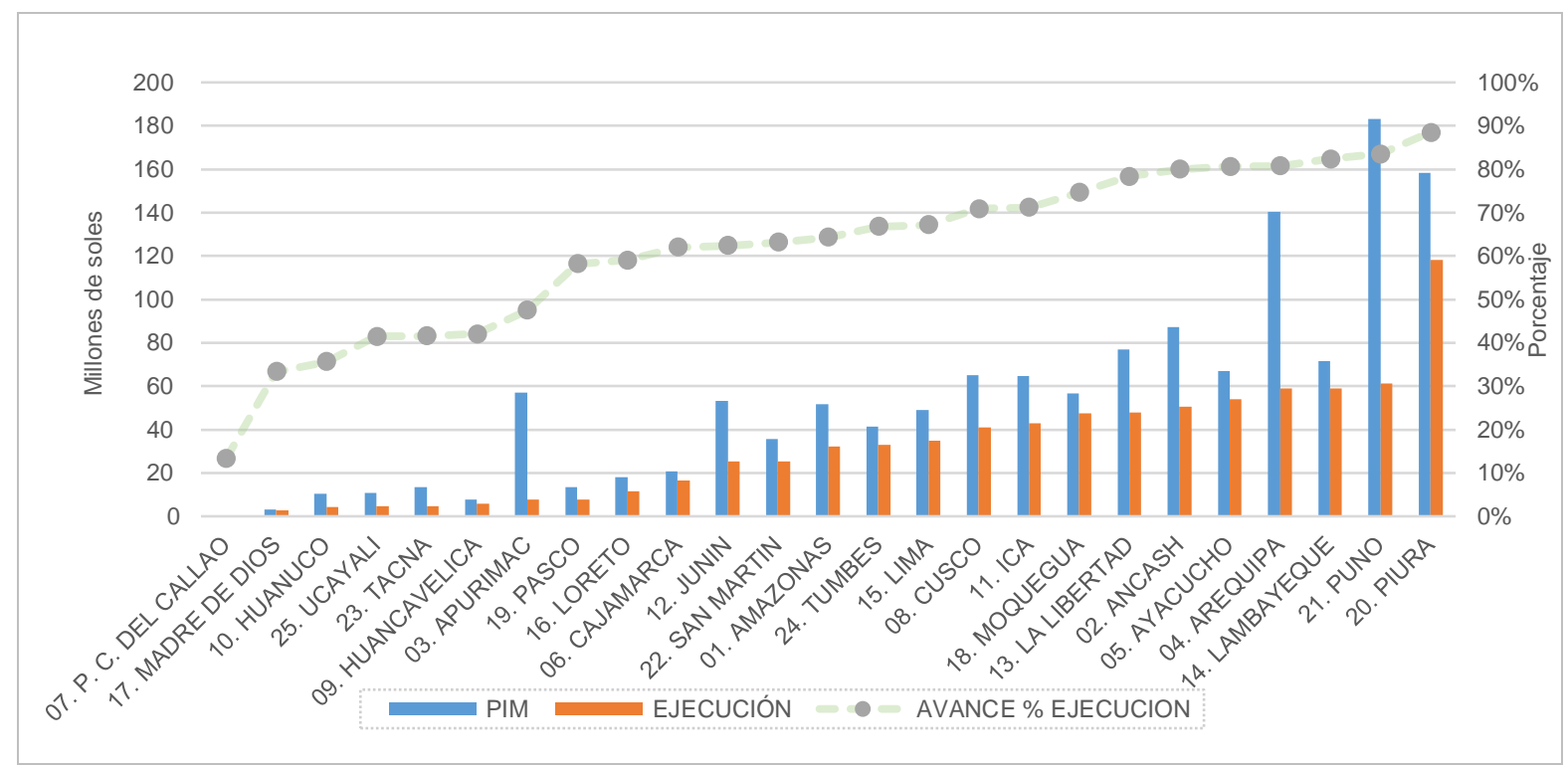

\footnotetext{
${ }^{42}$ Programas Presupuestales de Saneamiento Urbano y Rural en el año 2015
} 
Figura A6.1. Programa Nacional de Saneamiento Urbano (PNSU). Fuente: Ministerio de Economía y Finanzas (2018b) Elaboración Propia

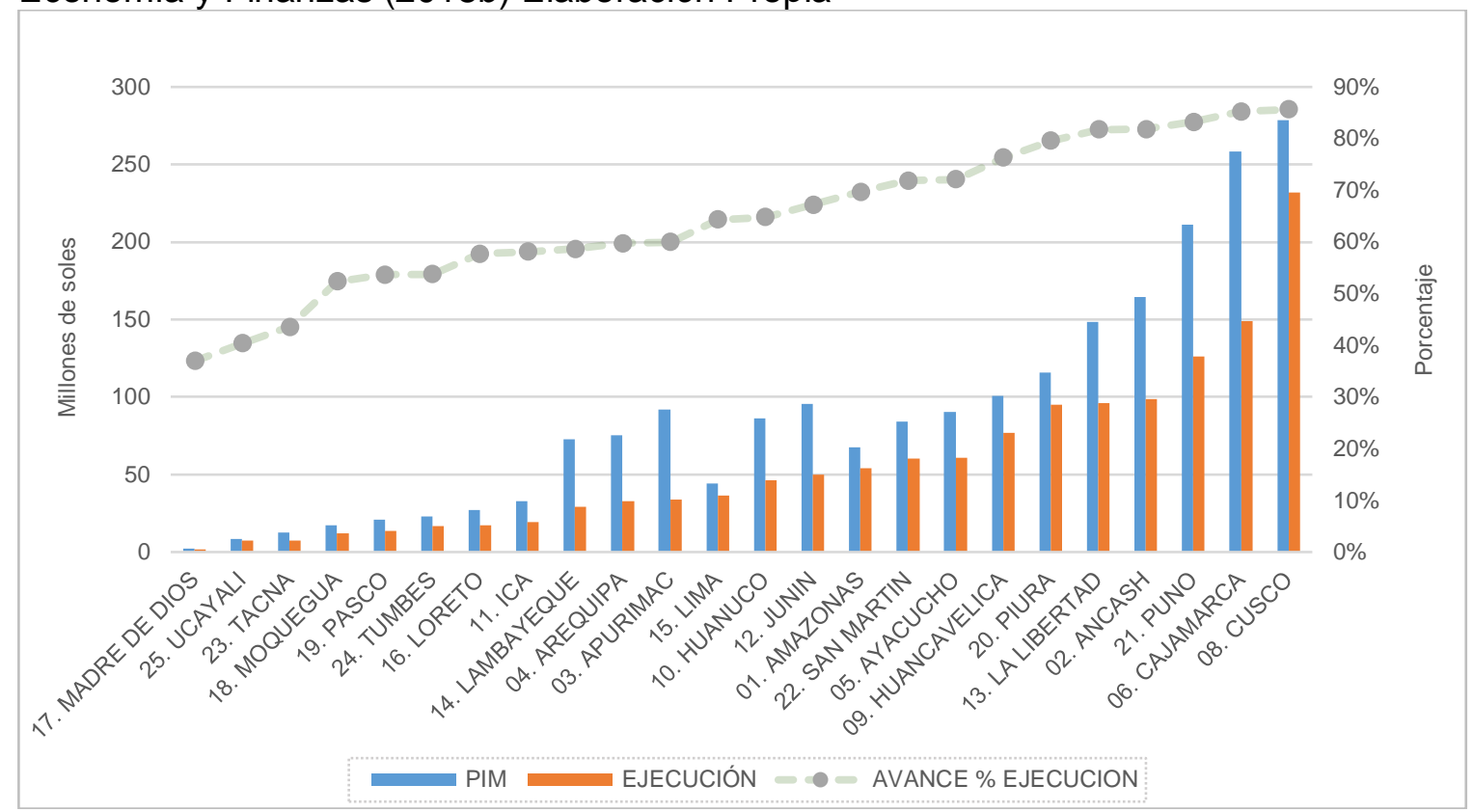

Figura A6.2. Programa Nacional de Saneamiento Rural (PNSR). Fuente: Ministerio de Economía y Finanzas (2018b) Elaboración Propia

\section{Anexo 7: Apuntes sobre la economía del agua}

Desde el punto de vista económico una característica crucial del agua es que la asignación de propiedad es difícil. El agua no es un bien excluyente pero sí rival por lo que no puede ser categorizado como bien público (Dalhuisen et al., 1999), por lo que es normalmente clasificado como un recurso "común" que tiene un límite de consumo y que a su vez debe ser compartido para diversos usos y zonas; sin embargo, los diferentes usuarios no son capaces de percibir el perjuicio generado por su consumo (o acciones) en el recurso limitado, y solo van en busca de sus propios intereses ${ }^{43}$.

Este recurso es renovable estocástica y estacionalmente, lo que genera incertidumbre en su provisión, para asegurar una provisión regular de la misma a la población, asimismo, al poseer diversas fuentes de extracción, que van desde la superficial (ríos, lagunas, etc.) hasta la subterránea, la calidad de la misma varía, por tanto, el agua en sí misma no es un bien homogéneo. Acerca de la irregularidad en la provisión y la diversidad de "calidades" de agua, Dalhuisen et al. (1999) precisan que se requiere de gran inversión a fin de enfrentar estas características; invertir en tecnologías para el almacenamiento en época de sequías o en última instancia de inversión en nuevas tecnologías (como la desalinizadora) para generar fuentes del recurso, resultará necesario, asimismo, la inversión para garantizar la mínima calidad necesaria de agua potable, puesto que esta debería estar regulada por el estado también se requería de recursos para la supervisión y regulación.

Desde el punto de vista del mercado, se puede separar la demanda en dos grandes grupos de usuarios: 1) para fines productivos y 2) para consumo, Dalhuisen et al. (1999) además hace una separación según la calidad de agua necesitada: alta calidad (alimentación, aseo, etc.) y baja calidad (sanitario, jardinería, etc.), considera así, que ciertas actividades del ser

\footnotetext{
${ }^{43}$ Situación conocida como "tragedia de los comunes" o "tragedia de los bienes comunales".
} 
humano no requieren agua potable; sin embargo, esta clasificación (por nivel de "calidad") ha sido escasamente aceptada, toda vez que la provisión de agua potable en la mayor parte del mundo se da como un bien homogéneo, el Perú no es la excepción.

Para determinar el efecto precio e ingreso sobre la demanda de agua frecuentemente se ha estudiado el agua como un bien homogéneo. La mayoría de estudios de las elasticidades de la demanda (elasticidad precio e ingreso) indican que estás serían menor a 1 (en valor absoluto) y significativamente diferente de cero. Por otra parte, la elasticidad dependería de la estación del año en que se encuentren y del uso que se le dé al agua. Por su parte, la evidencia de aplicación de ciertas políticas de cobro y medición, pueden ayudar en el estudio de elasticidades antes descrito, existe evidencia sobre los ahorros de agua generados por medición y cobro de la tarifa por volumen consumido (Dalhuisen et al., 1999), en síntesis, la medición es efectiva para reducir la demandada para consumo, y los consumidores reducen su pico de demanda en respuesta a la introducción de tasas estacionales y de bloques crecientes.

Desde el lado de la oferta, la industria del agua consiste en recolectar, tratar, transportar, almacenar y distribuir el agua, además de, recolectar y tratar las aguas residuales. Esto la conlleva a ser una industria intensiva en capital, puesto que su cadena "productiva" requiere infraestructura costosa y de largo plazo (Dalhuisen et al., 1999) que muchas veces termina convirtiéndose en costos hundidos para el inversionista.

Existen dos fuentes principales de agua dulce, agua superficial, que es renovable (mediante lluvias, tratamiento de aguas residuales, etc.) pero su provisión es irregular, y agua subterránea, que no es renovable a pesar de que tiene una recuperación está se da una tasa baja, por otro lado, la calidad de agua también varía, el agua subterránea es de mayor calidad permite ahorrar costos en la potabilización; sin embargo, su extracción es costosa.

La provisión de suficiente agua de alta calidad presenta graves problemas a pesar de su "abundancia" (Dalhuisen et al., 1999), entre estos se encuentran: la variable provisión de agua según el tiempo y la zona geográfica, el crecimiento de la población que incrementa la demanda global, la concentración de población en lugares lejanos de fuentes hídricas poderosas y la reducción de agua de alta calidad (glaciares y nevados descongelándose).

Debido a las características expuestas es necesaria la intervención del gobierno, el cual debería asegurar que todos los usuarios tengan el mínimo de calidad de agua requerido, así como garantizar la provisión en sí misma. Dentro de las más comunes intervenciones del estado se encuentran los subsidios, la regulación o intervención técnica, la solicitud de información, la privatización, entre otros (Dalhuisen et al., 1999).

\section{Anexo 8: Escala Mínima Eficiente del Monopolio}

Para estudiar las causas de la existencia de los monopolios, Varian (2010) precisa que sería necesario conocer el volumen de la producción que minimiza el coste medio en relación a la demanda, a esto se le conoce como Escala Mínima Eficiente (EME). Asimismo, la curva de coste medio que depende de la tecnología asociada, determina el carácter competitivo o monopolístico de la industria, si el nivel de producción que minimiza el costo medio (escala mínima eficiente de producción) de producir un bien o servicio es insignificante respecto a la demanda, entonces es probable que el mercado pueda tener muchos oferentes para cubrir dicha demanda, por el contrario si se presenta una escala mínima eficiente de producción grande en relación con las dimensiones del mercado entonces solamente una empresa podrá asegurar la oferta. 
El sector de agua potable y saneamiento, presenta una escala mínima eficiente de producción grande en relación a la demanda, sobre todo en aquellas provincias con un nivel de población reducida. Varian (2010) señala que tomar en cuenta la escala en relación con las dimensiones del mercado, puede ayudar en el acercamiento de la industria al bienestar, si no es posible alterar la escala mínima eficiente, ya que esta depende de la tecnología, es posible alterar las dimensiones del mercado mediante la política económica. La política económica; sin embargo, en el caso del sector agua potable y saneamiento necesita de inversión para la expansión de redes, es por ello que al menos para esta industria esta vía no sería la más factible; sin embargo, aun cuando no es posible modificar la escala mínima eficiente de producción en sí misma, una renovación de la tecnología de la EPS se encuentra en proceso de desarrollo como objetivo fundamental del desarrollo del país.

\section{Anexo 9: Indicadores de Gestión EPS ${ }^{44}$}

\begin{tabular}{|c|c|c|c|}
\hline $\mathrm{N}^{\circ}$ & Nombre de indicador & Unidad de medida & $\begin{array}{l}\text { Operativización de } \\
\text { variables }\end{array}$ \\
\hline 1.1 & Presencia de cloro residual & Porcentaje (\%) & Cloro \\
\hline 1.2 & Presencia de coliformes termotolerantes & Porcentaje (\%) & Coliformes \\
\hline 1.3 & Turbiedad & Porcentaje (\%) & Turbiedad \\
\hline 1.4 & Continuidad & Horas (h) & Continuidad \\
\hline 1.5 & Presión & Metros de columna de agua (mca) & Presión \\
\hline 1.6 & Densidad de reclamos totales & $\begin{array}{l}\text { Reclamos al mes por cada } 1000 \\
\text { conexiones de agua potable } \\
\text { (Recl./mes/1000 conex.) }\end{array}$ & Dens_Recl \\
\hline 1.7 & Tratamiento de aguas residuales & Porcentaje (\%) & Trat A R \\
\hline 2.1 & Tarifa media & Soles por metro cúbico $\left(\mathrm{S} / . / \mathrm{m}^{3}\right)$ & Tarif_Media \\
\hline 2.3 & Consumo unitario medido & Litros por habitante al día (Iphd) & Cons_Med_Unit \\
\hline 2.4 & Volumen facturado unitario & Litros por habitante al día (Iphd) & Vol_Fact_Unit \\
\hline 3.1 & Cobertura de agua potable & Porcentaje (\%) & Cobert_Agua \\
\hline 3.2 & Cobertura de alcantarillado & Porcentaje (\%) & Cobert_Alcan \\
\hline 4.1 & Relación de trabajo & Sin unidad de medida & Rel_Trab \\
\hline 4.2 & Reposición de activos fijos & Porcentaje (\%) & Rep_Act_Fijos \\
\hline 4.3 & $\begin{array}{l}\text { Costos de mantenimiento de la } \\
\text { infraestructura }\end{array}$ & Porcentaje (\%) & Cost_Mant_Infraestr \\
\hline 4.4 & Liquidez corriente & Sin unidad de medida & Liquidez \\
\hline 4.5 & Endeudamiento & Sin unidad de medida & Endeudam \\
\hline 4.6 & Cobertura de intereses & Porcentaje (\%) & Cobert_Intereses \\
\hline 4.7 & Margen operativo & Porcentaje (\%) & Margen_Ope \\
\hline 4.8 & Rendimiento sobre los activos & Porcentaje (\%) & ROA \\
\hline 4.9 & Rendimiento sobre el capital propio & Porcentaje (\%) & ROE \\
\hline 5.1 & Agua no facturada & Porcentaje (\%) & Agua no fact \\
\hline 5.2 & Micromedición & Porcentaje (\%) & Micromed \\
\hline 5.3 & $\begin{array}{l}\text { Conexiones activas facturadas por } \\
\text { medición }\end{array}$ & Porcentaje (\%) & Conex_Act_Micro \\
\hline 5.4 & Morosidad & Meses (m) & Morosidad \\
\hline 5.5 & $\begin{array}{l}\text { Costo operativo por unidad de volumen } \\
\text { producido }\end{array}$ & Soles por metro cúbico $\left(\mathrm{S} / . / \mathrm{m}^{3}\right)$ & Costo_Op_x_Vol_Prod \\
\hline 5.6 & $\begin{array}{l}\text { Costo operativo por unidad de volumen } \\
\text { facturado }\end{array}$ & Soles por metro cúbico $\left(\mathrm{S} / . / \mathrm{m}^{3}\right)$ & Costo_Op_x_Vol_Fact \\
\hline 5.7 & $\begin{array}{l}\text { Agua producida obtenida mediante } \\
\text { fuentes subterráneas }\end{array}$ & Porcentaje (\%) & Agua_Sub \\
\hline 5.8 & Volumen producido unitario & Litros por habitante al día (Iphd) & Vol_Prod_Unit \\
\hline 5.9 & $\begin{array}{l}\text { Gastos de personal por unidad de } \\
\text { volumen facturada }\end{array}$ & Soles por metro cúbico $\left(\mathrm{S} / . / \mathrm{m}^{3}\right)$ & Gast_Pers_Vol_Fact \\
\hline 5.10 & $\begin{array}{l}\text { Gastos de servicios de terceros por } \\
\text { unidad de volumen facturada }\end{array}$ & Soles por metro cúbico $\left(\mathrm{S} / . / \mathrm{m}^{3}\right)$ & $\begin{array}{l}\text { Gast_Serv_Terc_Vol_ } \\
\text { Fact }\end{array}$ \\
\hline 5.11 & $\begin{array}{l}\text { Gastos de administración y ventas por } \\
\text { unidad de volumen facturada }\end{array}$ & Soles por metro cúbico $\left(\mathrm{S} / . / \mathrm{m}^{3}\right)$ & $\begin{array}{l}\text { Gast_Adm_Ven_Vol_F } \\
\text { act }\end{array}$ \\
\hline
\end{tabular}

44 Para algunos indicadores, sólo se encuentra información disponible para los periodos 2000-2017; 2004-2017; 2005-2017; o sólo para el año 2017. Para las variables incluidas en la investigación se encuentra información disponible para el periodo 2008-2016. 


\begin{tabular}{|c|l|l|l|}
\hline $\mathbb{N}^{\circ}$ & Nombre de indicador & Unidad de medida & $\begin{array}{l}\text { Operativización de } \\
\text { variables }\end{array}$ \\
\hline 5.12 & $\begin{array}{l}\text { Densidad de roturas en las redes de } \\
\text { distribución de agua potable }\end{array}$ & $\begin{array}{l}\text { Roturas mensuales por } \mathrm{km} \text { de red de } \\
\text { distribución (Rot./mes/km) }\end{array}$ & $\begin{array}{l}\text { Densidad_Roturas_Ag } \\
\text { ua }\end{array}$ \\
\hline 5.13 & $\begin{array}{l}\text { Densidad de atoros en las redes de } \\
\text { alcantarillado }\end{array}$ & $\begin{array}{l}\text { Atoros mensuales por } \mathrm{km} \text { de red de } \\
\text { distribución (Ator./mes/km) }\end{array}$ & $\begin{array}{l}\text { Densidad_Atoros_Alca } \\
\mathrm{nt}\end{array}$ \\
\hline 5.14 & Conexiones activas & Porcentaje (\%) & Conex_Activas \\
\hline
\end{tabular}

Fuente: SUNASS (2018). Elaboración propia

\section{Anexo 10: Pruebas estadísticas}

Multicolinealidad, heteroscedasticidad y comparación de modelos

Tabla A10.1

Test para determinar forma funcional

\begin{tabular}{|c|c|c|c|}
\hline \multicolumn{4}{|c|}{ Measures of Fit for regress of logCosto_X_Vol_T } \\
\hline Model: & $\begin{array}{l}\text { Modelo Cobb- } \\
\text { Douglas }\end{array}$ & $\begin{array}{l}\text { Modelo Trans } \\
\text { Logarítmico }\end{array}$ & Diferencia \\
\hline $\begin{array}{l}\text { N: } \\
\text { Log-Lik Intercept } \\
\text { Only: } \\
\text { Log-Lik Full Model: } \\
\text { D: } \\
\text { LR: } \\
\text { Prob > LR: } \\
\text { R2: } \\
\text { Adjusted R2: } \\
\text { AIC: } \\
\text { AIC*n: } \\
\text { BIC: } \\
\text { BIC': }\end{array}$ & $\begin{array}{c}266 \\
-458.592 \\
-79.921 \\
159.842(259) \\
757.341(6) \\
0 \\
0.942 \\
0.941 \\
0.654 \\
173.842 \\
-1286.283 \\
-723.84\end{array}$ & $\begin{array}{c}294 \\
-507.947 \\
-34.256 \\
68.512(275) \\
947.382(18) \\
0 \\
0.96 \\
0.958 \\
0.362 \\
106.512 \\
-1494.472 \\
-845.077\end{array}$ & $\begin{array}{c}-28 \\
49.355 \\
-45.665 \\
91.330(-16) \\
-190.041(-12) \\
0 \\
-0.018 \\
-0.017 \\
0.291 \\
67.33 \\
208.189 \\
121.237\end{array}$ \\
\hline
\end{tabular}

Nota: Prueba para comparar los modelos de trans-logaritmica y Cobb-Douglas para modelar la función de costos de las EPS. Elaboración propia.

\section{Tabla A10.2}

Test de Multicolinealidad

\begin{tabular}{lcc}
\hline \multicolumn{1}{c}{ Variable } & VIF & 1/VIF \\
\hline Cobertura de Alcantarillado & 2.47 & 0.405233 \\
Cobertura de Agua & 2.22 & 0.450441 \\
Altitud de la provincia & 1.43 & 0.698592 \\
Tratamiento de Aguas Residuales & 1.4 & 0.715491 \\
Conex. Activas con micromedición & 1.39 & 0.719505 \\
Agua No Facturada & 1.33 & 0.752023 \\
SPI (índice de precipitación) & 1.06 & 0.940792 \\
\hline \multicolumn{1}{c}{ VIF Promedio } & 1.61 &
\end{tabular}

Nota: Prueba de VIF para la Multicolinealidad para modelar la ineficiencia en la segunda etapa y en la tercera etapa, dado que es solamente una regresora el VIF promedio es $1^{*}$. Elaboración propia

Tabla A10.3

Test de Heterocedasticidad (i)

\section{White's test for Ho:}

homoskedasticity

against $\mathrm{Ha}$ : unrestricted

heteroscedasticity

$\operatorname{chi}^{2}(20)=47.92$

Prob $>\mathrm{chi}^{2}=0.0716$

Cameron \& Trivedi's decomposition of IM-test

\begin{tabular}{lrrl}
\hline Source & chi $^{2}$ & df & p \\
\hline Heteroskedasticity & 47.92 & 35 & 0.0716 \\
Skewness & 8.74 & 7 & 0.2717 \\
Kurtosis & 1.8 & 1 & 0.1795 \\
\hline Total & 58.46 & 43 & 0.0581 \\
\hline Nota: Prueba de White para la Heteroscedasticidad \\
para modelar la ineficiencia en la segunda etapa.
\end{tabular}

Elaboración propia

\section{Tabla A10.4}

Test de Heterocedasticidad (ii)

White's test for Ho:

homoskedasticity

against $\mathrm{Ha}$ : unrestricted heteroskedasticity

$$
\operatorname{chi}^{2}(20)=1.97
$$

Prob $>\mathrm{chi}^{2}=0.3743$

Cameron \& Trivedi's decomposition of IM-test

\begin{tabular}{lccc}
\hline \multicolumn{1}{c}{ Source } & $\mathbf{c h i}^{\mathbf{2}}$ & $\mathbf{d f}$ & $\mathbf{p}$ \\
\hline Heteroskedasticity & 1.97 & 2 & 0.3743 \\
Skewness & 3.78 & 1 & 0.0517 \\
Kurtosis & 1.15 & 1 & 0.2829 \\
\hline \multicolumn{1}{c}{ Total } & 6.9 & 4 & 0.1411 \\
\hline
\end{tabular}


Nota: Prueba de White para la Heteroscedasticidad de la regresión lineal de los costos operativos por volumen

\section{Anexo 11: Economías de escala}

producido, para determinar la etapa de las economías de escalas. Elaboración propia

Según Dammert et al. (2013), la representación matemática de economías de escala se expresa de la siguiente manera: $\boldsymbol{C}(\boldsymbol{t} . \boldsymbol{y})<\boldsymbol{t} . \boldsymbol{C}(\boldsymbol{y})$

Según esto $t$ es un valor no negativo, donde un aumento proporcional de la producción en el valor t incrementa los costos de producción según la expresión $\boldsymbol{C}(\boldsymbol{t} . \boldsymbol{y})$, y cuyo incremento es menor que aumentar en dicha proporción los costos.

Dividiendo la expresión anterior respecto al vector de producto respectivo tenemos lo siguiente: $\boldsymbol{C M e}(\boldsymbol{t} . \boldsymbol{y})<\boldsymbol{C M e}(\boldsymbol{y})$

Donde se verifica que los costos medios de una producción t.y son menor a una producción $\boldsymbol{y}$.

Derivando los costos medio respecto la producción tenemos lo siguiente.

$$
\frac{\partial C M e}{\partial y}=\frac{C M g \cdot y-C(y)}{y^{2}}=\frac{1}{y}(C M g-C M e)<0
$$

Donde si $\frac{\partial C M e}{\partial y}$ es menor a cero podemos decir que los costos medios son decrecientes y se cumple las economías de escala. En caso que sea mayor a cero, podemos decir que se cumple las deseconomías de escala. Gráficamente podemos observar el concepto de economías de escala.

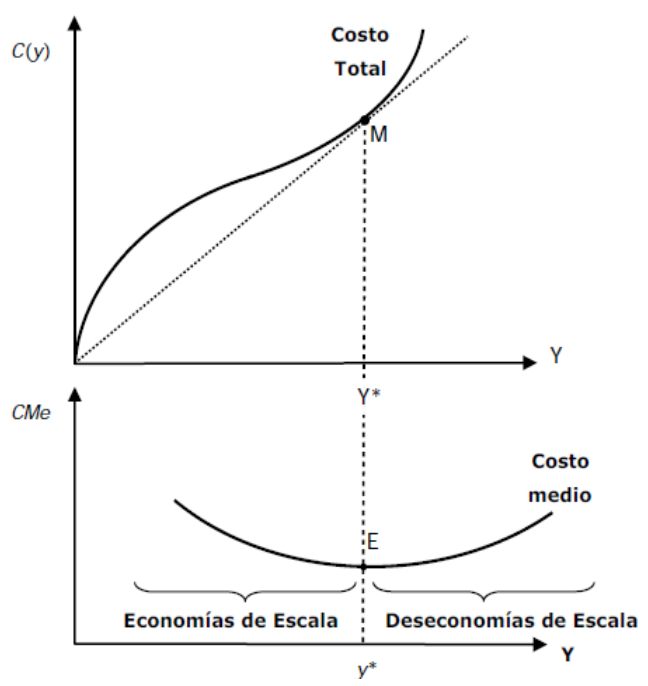

Figura A11. Economías de Escala.

Fuente: Dammert, Molinelli y Carbajal (2013) 